\title{
A STUDY OF ELEVATED CONVECTION AND ITS IMPACTS ON SURFACE WEATHER CONDITIONS
}

\author{
A Dissertation \\ presented to \\ the Faculty of the Graduate School \\ at the University of Missouri-Columbia \\ In Partial Fulfillment \\ of the Requirements for the Degree \\ Doctor of Philosophy \\ by \\ Joshua Kastman \\ Dr. Patrick Market, Dissertation Supervisor \\ December 2017
}


(C) copyright by Joshua S. Kastman 2017

All Rights Reserved 
The undersigned, appointed by the dean of the Graduate School, have examined the dissertation entitled

\section{A Study of Elevated Convection and its Impacts on Surface Weather Conditions}

presented by Joshua Kastman,

a candidate for the degree of doctor of philosophy, Soil, Environmental, and Atmospheric Sciences

and hereby certify that, in their opinion, it is worthy of acceptance.

Professor Patrick Market

Associate Professor Neil Fox

Professor Anthony Lupo

Associate Professor Sonja Wilhelm Stannis 


\section{ACKNOWLEDGMENTS}

I would like to begin by thanking Dr. Patrick Market for all of his guidance and encouragement throughout my time at the University of Missouri. His advice has been invaluable during my graduate studies. His mentorship has meant so much to me and I look forward his advice and friendship in the years to come. I would also like to thank Anthony Lupo, Neil Fox and Sonja Wilhelm-Stannis for serving as committee members and for their advice and guidance. I would like to thank the National Science Foundation for funding the project. I would 1 also like to thank my wife Anna for her, support, patience and understanding while I pursued this degree. Her love and partnerships means everything to me. I would like to thank my Parents Scott and Lisa for all of their encouragement and support and providing a household I which the pursuit of knowledge was encouraged. A family saying growing up was "Work Hard, Learn Hard." This became my motto while pursuing my $\mathrm{PhD}$.

I would also like to thank the many graduate and undergraduate students who helped along the way; Mike Simpson, Chelsy Simpson, Adam Hirsch, Chasity Henson, Kevin Grempler and Brad Workman (and others). The friendships that I have developed with them as a result of graduate school will be cherished. A special thank you to Katie Vigil. She was always there to answer any questions that arose and provided an excellent counsel on how to navigate life as a graduate student.

In conclusion I would like to thank all the professors I've had along my way for challenging me and encouraging me to grow as a student, the University of Missouri and the good Lord above. 


\section{TABLE OF CONTENTS}

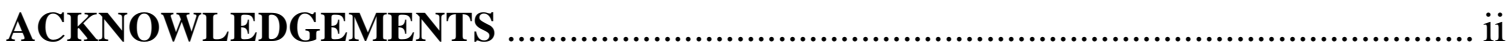

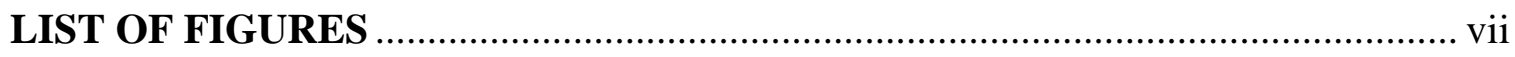

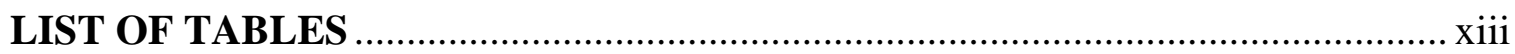

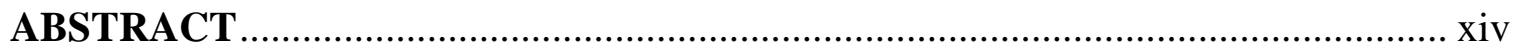

\section{Chapter}

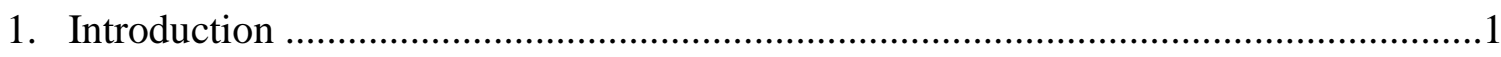

1.1. Dissertation Themes and Layout ..............................................................

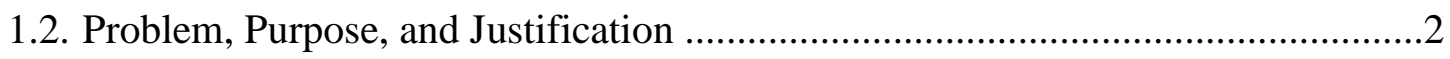

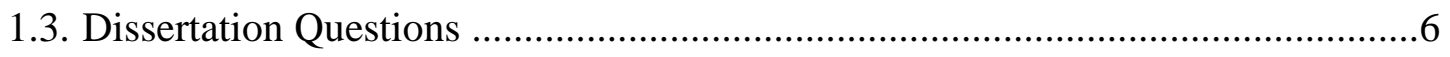

1.4. Basic Assumptions and Limitations .........................................................

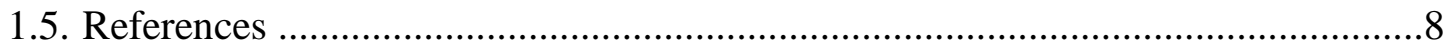

2. Lightning and Rainfall Characteristics in Elevated vs. Surface Based Convection in the Midwest that Produce Heavy Rainfall .......................................................... 10

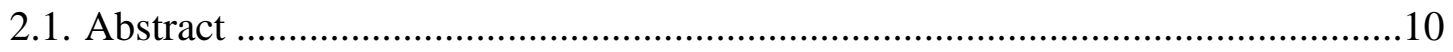

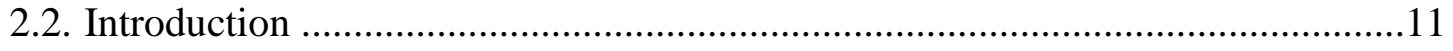

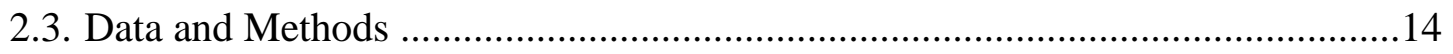

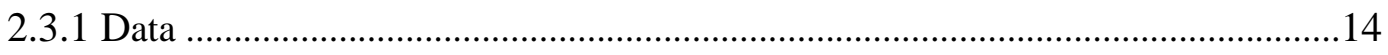

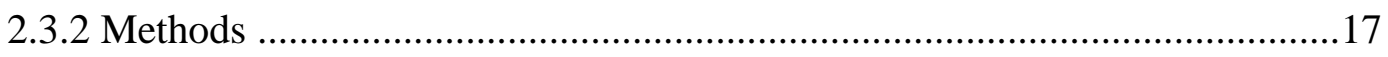

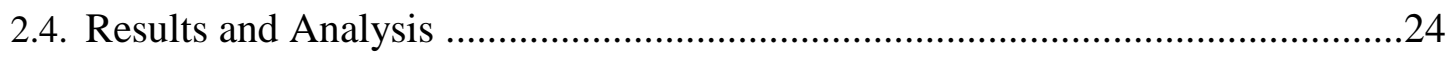

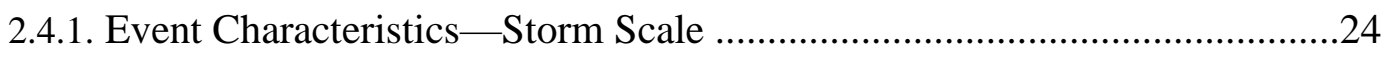

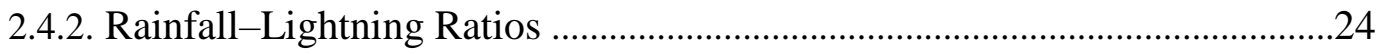

2.4.3. Extent of the Heavy Rainfall Area ....................................................25

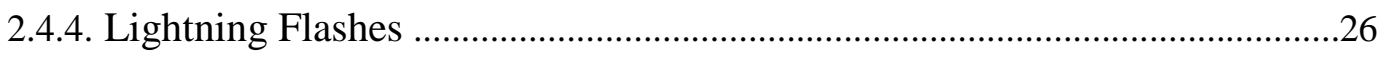


2.4.5. Maximum and Mean Rainfall Amounts .........................................................28

2.4.6. Event Characteristics - Mesoscale Environment ..................................29

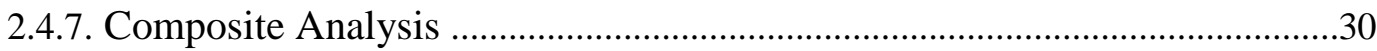

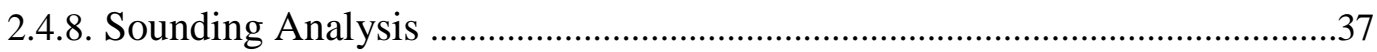

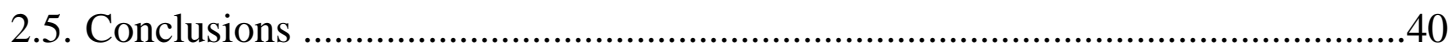

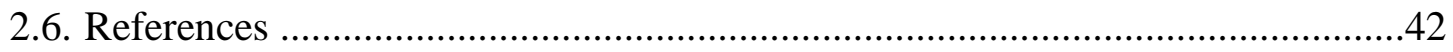

3. An Example of Synergistic Coupling of Upper and Lower-Level Jets Associated with Flash Flooding

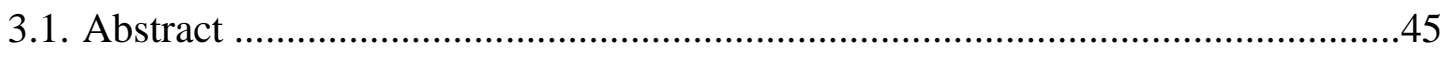

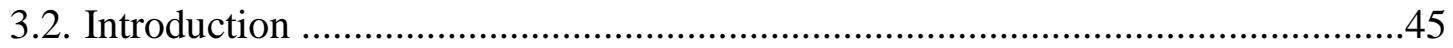

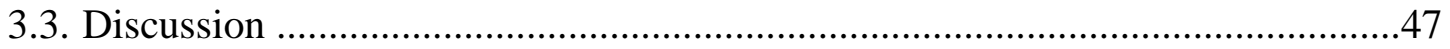

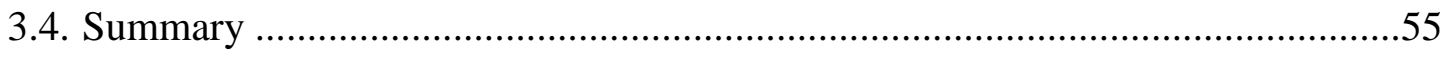

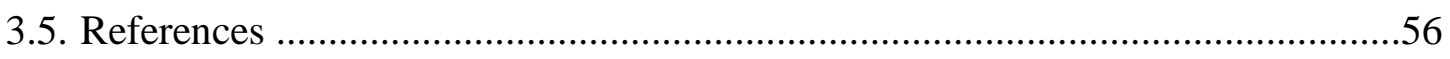

4. Evaluating Elevated Convection with the Downdraft Convective Inhibition ............58

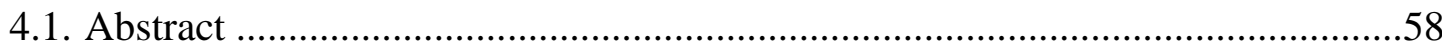

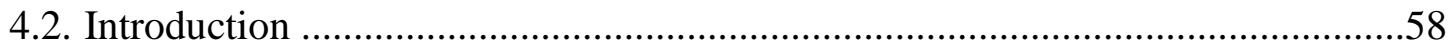

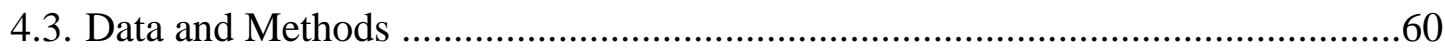

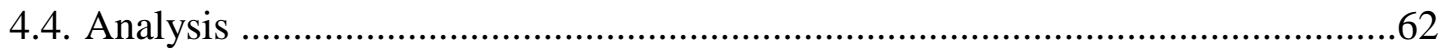

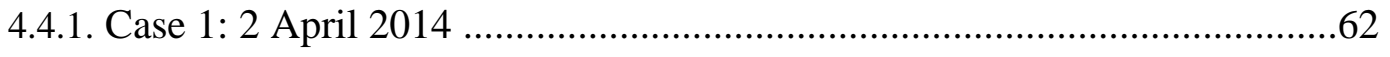

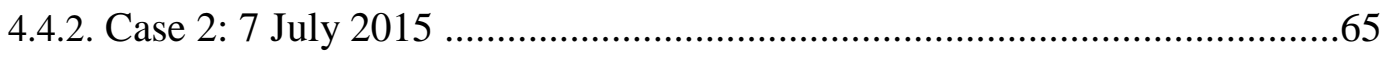

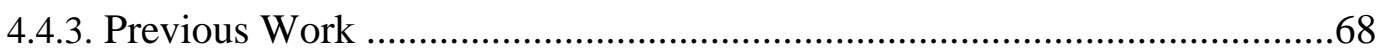

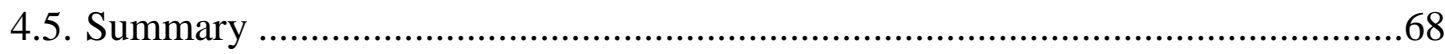

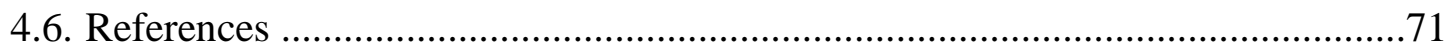

5. Dynamic Ensemble Reanalysis of Frontal Placement Impacts in the Presence of Elevated Thunderstorm during PRECIP Events ...............................................73 


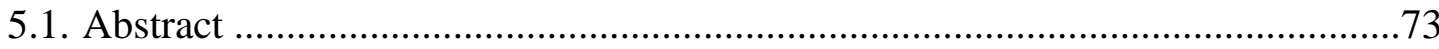

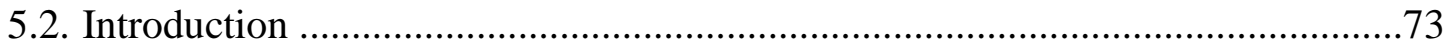

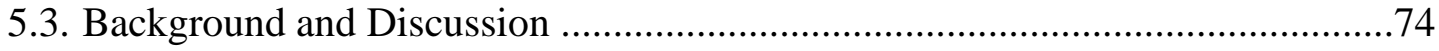

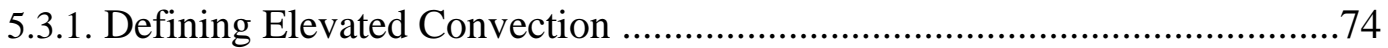

5.3.2. Forecasting Elevated Convection and Cold Pools ..................................76

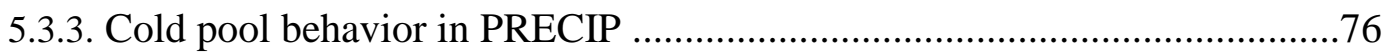

5.3.4. High Resolution Ensemble Modeling of Heavy Rainfall ...........................77

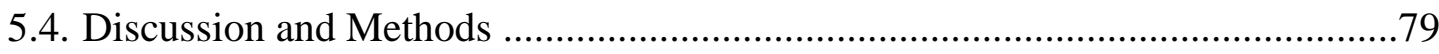

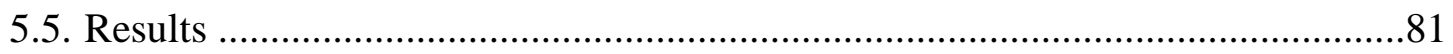

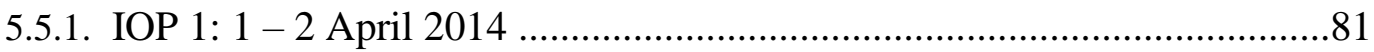

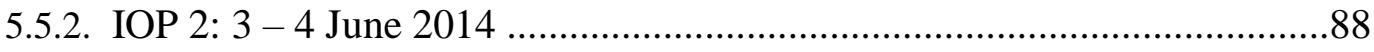

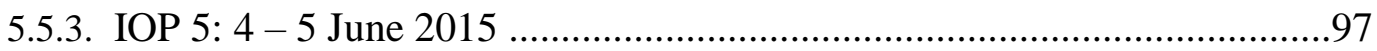

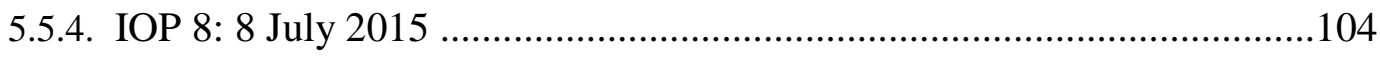

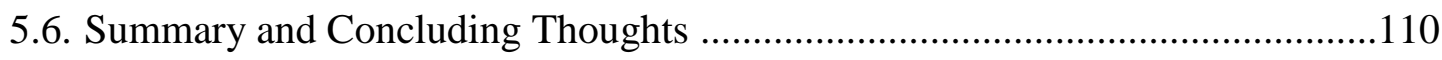

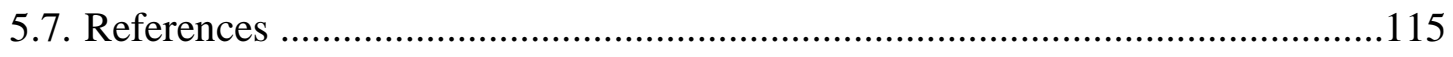

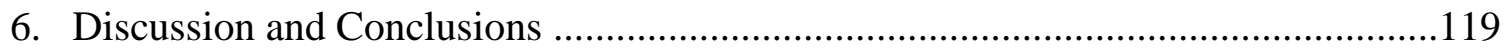

6.1. Discussion of Questions and Key Findings ...............................................119

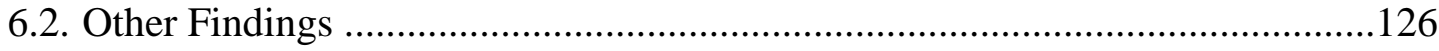

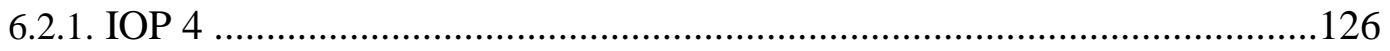

6.2.2. Elevated Convection Environments .................................................. 128

6.2.3. Surface Based Convection Compared to Elevated Convection ............................129

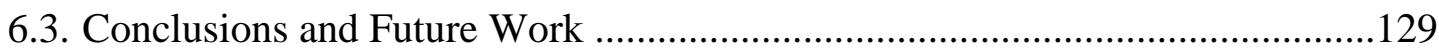




\section{APPENDIX}

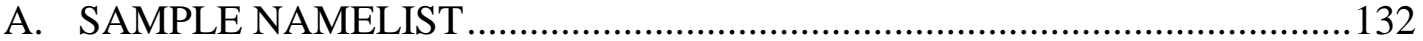

B. AMERICAN METEROLOGICAL SOCIETY CONFERENCE POSTER ....136

C. NATIONAL WEATHER ASSOCIATION CONFERENCE POSTER ........ 137

VITA 


\section{LIST OF FIGURES}

Figure

page

2.1. Map showing the study area for this project ........................................ 12

2.2. An example of kriging interpolation method for 24-h precipitation ( $\mathrm{mm})$ that ended at 12:00 UTC 12 May 2010

2.3. Example of the heavy rainfall area for an elevated thunderstorm case (left); and surface based thunderstorm case (right). The elevated thunderstorm case occurred 11 September 2010. The surface based thunderstorm case occurred 16 September 2010

2.4. The 500-hPa geopotential heights ( $\mathrm{dkm})$ every $30 \mathrm{dkm}$ from 5500 to 6000 : (a) composites for elevated convection; and (b) composites for surface based convection

2.5. The 700-hPa vertical motion $(\omega)\left(\mathrm{Pa} \cdot \mathrm{s}^{-1}\right)$ ( shaded; every $\left.0.02 \mathrm{~Pa} \cdot \mathrm{s}^{-1}\right)$ from -0.2 to 0.2: (a) composites for elevated convection; and (b) composites for surface based convection.

2.6. The $850-\mathrm{hPa}$ isotach wind (shaded; every $\mathrm{m} \cdot \mathrm{s}^{-1}$ ) from 0 to 12 : (a) composites for elevated convection; and (b) composites for surface based convection

2.7. Precipitable water (shaded; every $2 \mathrm{~kg} \cdot \mathrm{m}^{-2}$ from) 20 to 50: (a) composites for elevated convection; and (b) composites for surface based convectio. 35

2.8. The 2-m temperature (K) every $3 \mathrm{~K}$ from 270 to 320: (a) composites for elevated convection; and (b) composites for surface based convection....36

2.9. Pressure reduced to mean sea level; every $200 \mathrm{~Pa}$ from 100,000 to 10,300 : (a) composites for elevated convection; and (b) composites for surface based convection.

2.10. Composite sounding profiles for surface-based convection (red) and elevated convection (blue) on a standard skew-T log p diagram.

Temperature traces $\left({ }^{\circ} \mathrm{C}\right.$; solid) and dew point traces $\left({ }^{\circ} \mathrm{C}\right.$; dashed) are accompanied by standard wind plots (right) with speeds in represented in knots.

3.1. a) $250-\mathrm{hPa}$ geopotential heights (every 120 gpm; solid, brown lines), wind speed (every $5 \mathrm{~ms}^{-1}$, starting at $20 \mathrm{~ms}^{-1}$; shaded) and divergence (every $2 \mathrm{x}$ $10-5 \mathrm{~s}^{-1}$; pink dashes) at 0000 UTC 11 July 2006. b) As in a) but at 0300 
UTC 11 July 2006. Black star (located in Missouri) in Figures 1a-b represent location of heaviest rainfall.

3.2. a) 850-hPa geopotential heights, (every 15 gpm; solid, black lines), wind barbs (ms-1, blue barbs) and isotachs wind speed (every $2.5 \mathrm{~ms}^{-1}$, starting at $10 \mathrm{~ms}-1$; shaded) at 0000 UTC 11 July 2006. b) As in a) but at 0300 UTC 11 July 2006. Black stars (located within Missouri) in Figures 1a-b represent location of heaviest rainfall.

3.3. a) Mean sea-level pressure (every $2 \mathrm{hPa}$; solid, brown), 1000-500-hPa thickness (every $30 \mathrm{gpm}$, dashed), and precipitable water (every $5 \mathrm{~mm}$, starting at $25 \mathrm{~mm}$, shaded). b) As in a) but at 0300 UTC 11 July 2006. Black stars (located within Missouri) in Figures 1a-b represent location of heaviest rainfall

3.4. Cross sections from Shreveport, Louisiana (SHV), to Boscobel, Wisconsin (OVS), taken through the event on 11 July 2006 at a) 0000 UTC and b) 0300 UTC. Cross section path (red line), and end points, are visible in the map in the upper right hand corner of a). Each figure features $\theta_{e}$ (every $5 \mathrm{~K}$; solid lines) with $338 \mathrm{~K}$ highlighted in red, scaled ageosotrophic circulation vectors (arrows), isotachs (every $10 \mathrm{~ms}^{-1}$; heavy dashes), divergence (every $4 \times 10^{-5} \mathrm{~s}^{-1}$; dotted), upward vertical velocity (every 5

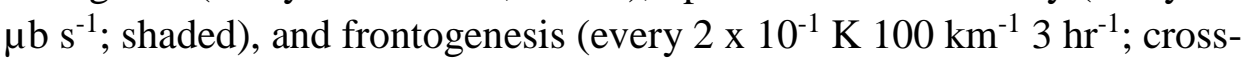
hatched)

3.5. Cross sections from Shreveport, Louisiana (SHV), to Boscobel, Wisconsin (OVS), taken through the event on 11 July 2006 at a) 0000 UTC and b) 0300 UTC. Each figure features $\theta_{e}$ (every $3 \mathrm{~K}$; dashed lines) and potential vorticity (every $0.25 \times 10^{-6} \mathrm{~m} \mathrm{~Pa} \mathrm{~K}^{-1} \mathrm{~s}^{-3}$; solid lines)..............................56

4.1. Standard surface analysis for the central United States valid at 0600 UTC 2 April 2014 from the United States Weather Service Weather Prediction Center. Bold ' $\mathrm{X}$ ' marks the location of Clinton, MO. .65

4.2. Sounding analyses from Clinton, MO, flown on 2 April 2014, and launched at (a) 0534 UTC, (b) 0753 UTC and (c) 0937 UTC. The right and left red traces represent the temperature and dew point temperatures, respectively; the purple trace to the right of the temperature trace is the virtual temperature. The convective available potential energy (CAPE) for the most unstable parcel is shaded in red, convective inhibition (CIN), if any, for that same parcel is shaded in light blue, DCAPE for the coldest wet bulb temperature in the lowest $6 \mathrm{~km}$ is shaded in dark purple, and the 
DCIN for that same parcel is shaded in a lighter purple; each of these values is calculated with the virtual temperature correction applied.

4.3. Plots of time (abscissa) versus wind speed (knots; ordinate) and reflectivity (dBz; ordinate) for (a) the location of the Clinton, MO, airport (KGLY) on 2 April 2014 and (b) the location of the Jefferson City, MO, airport (KJEF) on 8 July 2015. Wind speeds are represented by black filled circles (joined by a line of long dashes), wind gusts by blue filled squares (joined by a solid line), and reflectivity values (from a) Pleasant Hill, MO, National Weather Service radar; and (b) the University of Missouri radar) by red filled triangles (joined by a line of short dashes)..67

4.4. Standard surface analysis for the central United States valid at 1800 UTC 8 July 2015 from the United States Weather Service Weather Prediction Center. Bold ' $\mathrm{X}$ ' marks the location of Columbia, MO.

4.5. As in Figure 1, except for sounding analyses from Columbia, MO, flown on 8 July 2015, and valid at (a) 1448 UTC, (b) 1737 UTC and (c) 2035 UTC.

5.1. Roebber performance diagram showing each member (labeled blue dots) of the WRF-HRHPEFS for IOP 1. X-Axis shows the Success Ratio (SR), Y-Axis shows the Probability of Detection, curved lines represent Critical Success Index (CSI) values and the dashed diagonal lines represent Frequency Bias (FBIAS). A full description of each member can be found in Table 5.2

5.2. MODE output showing observed (red color filled area) QPE and forecast QPF (blue outline) from the WDME model configuration for IOP 1. The Table at the bottom of the image describes comparison of the forecasted (blue outline) to observed object (red color filled); these values are discussed in the text

5.3. WDME model configuration 2-meter temperature (every $2{ }^{\circ} \mathrm{C}$; color filled) and 975-mb $\theta_{e}$ (every $3 \mathrm{~K}$; white contours) during IOP 1 . The approximate location of the warm front is denoted $\mathrm{b}$ the solid red line, Valid at a) 0000 UTC 2 April 2014, and b) 1800 UTC 2 April 2014

5.4. Showing DCIN values (every $-50 \mathrm{Jkg}^{-1}$; solid black contours) and simulated reflectivity (over $40 \mathrm{dBZ}$ gray color fill) from the WDME model configuration. Valid 1200 UTC 02 April 2014. 
5.5. Soundings from IOP 1 valid 0900 UTC 2 April 2014 for a location near Clinton, MO. (a) observed from PRECIP balloon launch, (b) model sounding from the WDME model configuration.

5.6. Roebber performance diagram showing each member (labeled blue dots) of the WRF-HRHPEFS for IOP 2. X-Axis shows the Success Ratio (SR), $\mathrm{Y}$-Axis shows the Probability of Detection, curved lines represent Critical Success Index (CSI) values and the dashed diagonal lines represent Frequency Bias (FBIAS). A full description of each member can be found in Table 5.2

5.7. MODE output showing observed (red color filled area) QPE and forecast QPF (blue outline) from the TNG model configuration for IOP 2. The Table at the bottom of the image describes comparison of the forecasted (blue outline) to observed object (red color filled); as in Fig. 5.2, these values are discussed in the text

5.8. TNG model configuration 2-meter temperature ((every $2{ }^{\circ} \mathrm{C}$; color filled) and $975-\mathrm{mb} \theta_{e}$ (every $3 \mathrm{~K}$; white contours) during IOP 2 . The dark ted line indicates the approximate location of the boundary, Valid at a) 2100 UTC 03 June 2014, at b) 0600 UTC 04 June 2014, and at (c 1200 UTC 04 June 2014

5.9. Contours of DCIN $<0$ from the TNG model configuration for IOP 2. (a) Valid 0600 UTC 04 June 2014, (b) DCIN 1200 UTC 04 June 2014

5.10. 0400 UTC 04 June 2014 sounding launched by PRECIP near Bethany, Missouri. This sounding sampled an environment just north of the surface warm front, and about 15 miles south of ongoing convection.

5.11. Roebber performance diagram showing each member (labeled blue dots) of the WRF-HRHPEFS for IOP 5. X-Axis shows the Success Ratio (SR), Y-Axis shows the Probability of Detection, curved lines represent Critical Success Index (CSI) values and the dashed diagonal lines represent Frequency Bias (FBIAS). A full description of each member can be found in Table 5.2. 102

5.12. MODE output showing observed (red color filled area) QPE and forecast QPF (blue outline) from the WDYG model configuration for IOP 5. The Table at the bottom of the image describes comparison of the forecasted 
(blue outline) to observed object (red, blue and green color filled); these values are described in the test.

5.13. WDYG model configuration 2-meter temperature (every $2{ }^{\circ} \mathrm{C}$; color filled) and $975-\mathrm{mb} \theta_{e}$ (every $3 \mathrm{~K}$; white contours) during IOP 5 . The red line indicates the approximate location of the boundary; Valid at a) 2100 UTC 04 June 2015, at b) 0600 UTC 05 June 2015, and at c) 1200 UTC 05 June 2015.

5.14. Sounding from observed from PRECIP balloon launch during IOP 5 valid 0000 UTC 05 June 2015. Launched near Nebraska City, NE. 105

5.15. (a) DCAPE (black contours) and simulated reflectivity (gray color fill) from the WDYG model configuration. Valid 0600 UTC 05 June 2015. (b) DCIN (black contours) and simulated reflectivity (gray color fill) from the WDYG model configuration. Valid 0600 UTC 05 June 2015. 105

5.16. Roebber performance diagram showing each member (labeled blue dots) of the WRF-HRHPEFS for IOP 8. X -Axis shows the Success Ratio (SR), Y-Axis shows the Probability of Detection, curved lines represent Critical Success Index (CSI) values and the dashed diagonal lines represent Frequency Bias (FBIAS). A full description of each member can be found in Table 5.2

5.17. MODE output showing observed (red color filled area) QPE and forecast QPF (blue outline) from the MNGW model configuration for IOP 8. The Table at the bottom of the image describes comparison of the forecasted (blue outline) to observed object (red color filled); these values are described in the text.

5.18. MNGW model configuration 2-meter temperature (every $2{ }^{\circ} \mathrm{C}$; color filled) and 975-mb $\theta_{e}$ (every $3 \mathrm{~K}$; white contours) during IOP 8; at a) 2100 UTC 07 June 2015, at b) 0600 UTC 08 June 2015, at c) 1200 UTC 08 June 2015

5.19. Observed sounding valid at 1200 UTC 08 June 2015, launched by PRECIP near Columbia, MO during IOP 8

5.20. Showing DCIN values (black contours) and simulated reflectivity (gray color fill) from the MNGW model configuration.(a) Valid 1200 UTC 08 July 2015 and (b) valid 1500 UTC 08 July 2015 
5.21. $13 \mathrm{~km}$ RAP model initial fields. 950-mb $\theta_{e}$ Every $3 \mathrm{~K}$ (brown contours). Reflectivity Every $5 \mathrm{dBZ}$ (filled colors). 950-mb Petterssen Frontogenesis every $10^{-1} \mathrm{~K} / 100 \mathrm{~km} / 3 \mathrm{hr}$ (white dashes) at a) 1800 UTC 03 June 2014, at c) 0000 UTC 04 June 2014, and at e) 0600 UTC 04 June 2014. Corfidi Vectors. 2-meter Temperature every $2{ }^{\circ} \mathrm{C}$ (filled colors). $\theta_{e}$ Every $3 \mathrm{~K}$ (red contours). 950-mb Petterssen Frontogenesis every $10^{-1} \mathrm{~K} / 100 \mathrm{~km} / 3 \mathrm{hr}$ (brown dashes) at b) 1800 UTC 03 June 2014, at d) 0000 UTC 04 June 2014, and at f) 0600 UTC 04 June 2014.

6.1. 1 km Radar Composite Valid 06002 April 2014 (IOP 1). Showing reflectivity colorfill) every $5 \mathrm{dBZ}$ from $10-75 \mathrm{dBZ}$.

6.2. 1 km Radar Composite Valid 02004 June 2014 (IOP 2). Showing reflectivity colorfill) every $5 \mathrm{dBZ}$ from $10-80 \mathrm{dBZ}$.

6.3. 6.3. 24 Hour Observed Rainfall (inches, color fill from 0.01 in to 1.25 in) Valid 1200 UTC 2 April 2014. Black dot indictes data collection point for northern PRECIP deployed team. Black triangle indicates data collection point for southern PRECIP team

6.4. 24 Hour Observed Rainfall (inches, color fill from 0.01 in to 3.50 in) Valid 1200 UTC 7 June 2014. Black dot indicates data collection point for northern PRECIP deployed team. Black triangle indicates data collection point for southern PRECIP team 125

6.5 24 Hour Observed Rainfall (inches, color fill from 0.01in to 5.00 in) Valid 1200 UTC 4 June 2014. Black dot indicates data collection point for northern PRECIP deployed team. Black triangle indicates data collection point for southern PRECIP team

6.6. 24 Hour Observed Rainfall (inches, color fill from 0.01in to 3.50 in) Valid 1200 UTC 5 June 2015 128

6.7. 24-Hour observed rainfall (inches, color fill from 0.10in to 10.00 in) Valid 1200 UTC 17 July 2014. Black star indicates data collection point for northern PRECIP deployed team.

6.8. $1 \mathrm{~km}$ radar composite valid 060017 July 2014 (IOP 4), showing reflectivity (colorfill) every $5 \mathrm{dBZ}$ from $10-75 \mathrm{dBZ}$ 


\section{LIST OF TABLES}

Tables

page

2.1. p-Values determined by nonparametric Mann-Whitney test for elevated thunderstorms vs. surface based thunderstorms

2.2. RLR values for elevated convection events (left) and surface based convection events (right) within the heavy rain area.............................26

2.3. Extent of the heavy rainfall areas $\left(\mathrm{km}^{2}\right)$ for elevated convection events (left) and surface based convection events (right).

2.4. Lightning flash characteristics within the heavy rainfall area for surface based convection events.

2.5. Lightning flash characteristics within the heavy rainfall area for elevated convection events.

2.6. Maximum and mean rainfall amounts for elevated convection events (left) and surface based convection events (right). .30

2.7. Warm cloud depth $(\mathrm{m})$ for all convection cases. An asterisk (*) indicates that atmospheric blocking was present in the Pacific Region $\left(140^{\circ} \mathrm{E}-100^{\circ}\right.$ W)........

2.8. Classification of thunderstorm complexes for all cases. TS indicates trailing stratiform; PS indicates parallel stratiform; LS indicates leading stratiform; and NL indicates the system was non-linear and was not classified.....

4.1. Dates, Times (UTC), DCAPE and DCIN values (units of J kg-1) for Case 1 (Clinton, MO) and Case 2 (Columbia, MO) collected by the authors for this work as well as the individual values from the five severe cases from the Horgan et al. (2007) study....

5.1. A listing of the cases discussed throughout this paper. This table provides details on the case that include date, location and brief synoptic description

5.2. WRF-HRHPEFS model member configurations names and components of each configuration. Working from left to right will describe each member's Name, initial condition (IC), microphysics scheme used, Planetary Boundary Layer (PBL) scheme used, cumulus physics scheme used and the advection scheme used. 


\begin{abstract}
Elevated convection is a vexing phenomenon that causes forecasting problems for both numerical weather prediction systems and human forecasters alike. It is frequently associated with heavy rain and can produce flash flooding. The conducive environment for elevated convection will be explored, with case studies presented, and will be compared to surface based convection. Comparisons of surface impacts (including lightning frequency, rainfall amounts and coverage) will be shown. It was observed during the Program for Research on Elevated Convection with Intense Precipitation (PRECIP) that synoptic warm fronts stalled out when elevated convection formed in an environment rich in downdraft convective available potential energy (DCAPE). Specific examples of this will be shown. It will also be shown that when DCIN was present boundary stalling did not occur. High resolution $(3 \mathrm{~km})$ simulations of observed elevated convection cases will be explored and differences in the solutions in which elevated convection caused a boundary to stall, or not stall will be highlighted.
\end{abstract}




\section{Introduction}

The forecasting of elevated convective complexes, and the heavy rainfall frequently associated with them (Moore et. al 2003), have long vexed numerical weather prediction (NWP) models and forecasters alike (Corfidi et. al 2008; Cofidi 2003). During the Program for Research on Elevated Convection with Intense Precipitation (PRECIP) the displacement of Quantified Precipitation Estimates (QPE) compared to the quantified precipitation forecast (QPF) generated by operational NWP models was observed This displacement was observed when elevated mesoscale convective systems (MCSs), containing intense convective complexes, form on the cold side of a lower tropospheric synoptic/mesoscale thermal boundary. Yet in other elevated convection episodes, this displacement was not observed. Understanding the environmental conditions in which a displacement is observed compared to an environment in which a displacement is not observed will be of chief concern to this dissertation.

\subsection{Dissertation Themes and Layout}

Throughout this dissertation the impacts of convection generated on the thermally cool side of a lower-tropospheric boundary will be investigated. The motion of that boundary and the surface weather impacts will be explored and discussed. In addition, the connection between elevated thunderstorms and enhanced Cloud-to-Ground (CG) lightning flashes and the environmental conditions in which elevated thunderstorms form will be explored. Composite synoptic conditions will be shown that highlight the different synoptic environments in which surface based and elevated Mesoscale Convective Systems (MCS) that produced at least two inches $(50.8 \mathrm{~mm})$ from (Kastman 
et. al, 2015b). Investigation into a specific case study of elevated convection producing heavy rainfall adhering to an environment discussed in Moore et. al 2003, will be presented ( Kastman et al., 2017; McCoy et. al 2017). This example shows the evolution of the environment of an elevated convection event that will have been discussed in the previous chapter. Critical to this dissertation was the derivation of downdraft convective inhabitation (DCIN), which was observed during the PRECIP field campaigns of 20142015 (Market et al. 2017). DCIN will be explored in Chapter 4 and it will be shown in context of boundary displacement in later Chapter 5 .

\subsection{Problem, Purpose, and Justification}

During PRECIP it was noted in instances in which intense elevated convection generated north of a poleward advancing synoptic/mesoscale thermal boundary produces heavy precipitation ( $>2$ inches), the boundary becomes stationary (locked into place) or retrogrades to the south. During PRECIP, forecasters observed that operational deterministic and ensemble forecast models did not handle the the stalling of boundaries well. When boundary stalling occurred it was observed that flash flooding frequently occurred as well. Flash floods are the second most deadly weather-related hazard in the United States behind extreme heat (Ashley and Ashley 2008).

Forecasters have observed that operational NWP models often under forecasted maximum precipitation amounts, created too broad of a precipitation extent, and over forecasted (by way of displacement) precipitation amounts north of the boundary. These errors were due to the anticipated northward track of the boundary by NWP models. This is a major problem that needs to be addressed as it leads to very poor forecasts of rainfall, flash flood warnings in areas that are not anticipating heavy rainfall (no flash flood 
watches) and flash flood watches where rainfall does not occur (false alarms, desensitization) as the system is blocked from reaching forecasted locations.

In order to help understand what causes NWP models to have poor forecasts of the boundary stalling phenomena, the Weather Research and Forecasting (WRF) model will be used to create a dynamic (multi-physics) high resolution (3-km) ensemble. This ensemble will be used to create reanalysis simulations that will allow for a high resolution exploration of the environmental conditions throughout the atmosphere. Microphysics schemes (MS), cumulus parameterization schemes (CPS), planetary boundary layer schemes (PBLS) and moisture advection schemes (MAS) will be varied. The results of the best deterministic outcome for each case investigated will be further explored using the best performing model (best performance will be determined by the results of a Roebber performance diagram, Roebber, 2009).

The phenomenon of boundary stalling was noted by Smull and Augustine (1993), who observed the northward advance of a warm front arrested across OK - AR, and speculated this was due to an MCS that affected the area 6 hours earlier. However, these authors never explored why the MCS stalled the warm front. Numerous examples of studies on boundary - thunderstorm interaction exist (e.g., Mahoney 1988, Blanchard 2008; Droegemeier and Wilhemson, 1987; Maddox, Hoxit and Chappell, 1980) to name a few. However, none of these studies directly deal with the impacts elevated convection have on warm fronts/stationary boundaries, nor attempt to connect this issue with model forecasting errors. Bryan and Fritsch (2000) came the closest, studying the impacts of a cold front and associated frontogenesis when introducing warm air ahead of a the front. 
A recent example of frontal motions stalling occurred 9-10 September 2014. A cold front was in place across the Northern Plains while a developing warm front was located over Iowa. Convection formed between the fronts and was not handled well by operational deterministic nor probabilistic numerical weather prediction (NWP) solutions. A large MCS was expected to form over Iowa and move into Wisconsin, where flash flood watches had been issued by the National Weather Service. Instead convection remained locked onto the developing warming front. Eventually this convection, and the boundary, moved into northern Missouri where it produced over $200 \mathrm{~mm}$ of rainfall, never reaching Wisconsin. This event resulted in flash flooding in unwarned areas (Missouri) and an unverified flash flood watch by the NWS (Wisconsin). While the above example was not sampled by PRECIP balloon observation, it is representative of the aforementioned problem and was encountered during many of the PRECIP events.

This dissertation will explore the primary questions: Why do certain instances of elevated convection cause boundary displacement? How do the environments look for displacement cases vs undisturbed cases? What environmental conditions stand out as potential predictors?

In answering the previous questions many other topics must be explored. This dissertation will attempt to determine what role the cold pool, gust front, and local sea level pressure changes have in shifting the position of the existing synoptic/mesoscale boundary. Bryan and Fritsch (2000) note, since fronts are zones of transition rather than surface discontinuities, their effects can be felt well ahead of the surface frontal location. Thus it should be possible for an approaching front to interact with a frontogenetic feature well in advance of the front. MCS movement appears to be key in understanding 
why frontal location changes. Corfidi (2003) notes that forecasting movement of MCS that develop on the cool side of surface boundaries is difficult. Suggesting that whether the system will remain elevated or will at some point become "rooted"' in the boundary layer is key. It is clear that neither the original nor downwind versions of the Corfidi Vector can be applied to a purely elevated MCS to determine motion even though they are dependent on the existence of surface based convection along a gust front.. Jankov and Gallus. (2004) showed that the lowest equitable threat scores (ETS, which measure forecast accuracy values) of their modeled sample were elevated convection north of a stationary or warm front. These studies attest to the difficulty of predicting elevated MCSs.

This dissertation will model four instances of elevated convective complexes, generated north of a poleward advancing synoptic/mesoscale boundary with heavy precipitation (>2 inches) observed during an Intense Observation Periods (IOPs) in association with PRECIP. A 48 member, high resolution $(3 \mathrm{~km}) \mathrm{WRF}$ ensemble model will be used. It is not the purpose of this dissertation to create new schemes of microphysics or cumulus or planetary boundary parameterizations, as there are already a wealth of those in existence, but rather explore the environment produced by top performing combinations of these parameterizations in a high resolution environment. The current operation ensembles (Short Range Ensemble (SREF) Forecast, Global Ensemble Forecast System (GEFS), North American Ensemble Forecast System (NAEFS)) primarily rely on perturbation methods to develop spread. With the notable exception being the Storm Scale Ensemble Forecast (SSEF), which generates spread using mixed physics. While the perturbation method may be effective for generating 
spread in the medium and long range forecasts, they fail in developing spread in the short term (hours 0-12) as seen in Clark (2010); Schwartz (2010); Schumacher et. al (2013) among others. Iyer (2016) notes that the SSEF (dynamic ensemble) outperforms the SREF (perturbation ensemble) in terms of ETS even out through hour 60. This dissertation will explore the solutions of a high resolution dynamic ensemble, the WRFHigh Resolution Heavy Precipitation Ensemble Forecasting System (WRF-HRHPEFS), that generates spread by altering microphysics, cumulus parameterization, planetary boundary layer parameterization and moisture advection schemes to determine if this type of ensemble model can better forecast elevated convection and its resultant heavy rainfall. It should be noted that while some WRF-HRHPEFS ensemble members are similar to the SSEF, the IC/LBC conditions are different as are almost all of the parameterization combinations.

\subsection{Dissertation Questions}

1. The presence of convective complexes north of a synoptic/mesoscale boundary alters poleward progression and/or causes an equatorward retreat of the synoptic/mesoscale boundary as a result of convectively generated cold pools (and associated gust fronts). When unified cold pools form they impact tropospheric advections, prevent precipitation from advancing poleward, and result in more intense rainfall (often in the shape of a narrow horizontal band) than instances when convective cold pools are not present at the surface (relatively more equally distributed area of rainfall).

2. DCIN can be used as an indicator if there is a potential for elevated parcels to reach the surface unabated or if they will be impacted by a DCIN layer. A further 
objective of this dissertation is to model elevated convection using a reanalysis ensemble to determine best practices for a potential operation ensemble and provide a templated on reanalysis ensemble construction.

\subsection{Basic Assumptions and Limitations}

The modeling portion of this experiment is using RAP initial fields for its initial and lateral boundary conditions. Therefore error in initial conditions provided by the RAP will be introduced the WRF-HRHPEFS simulations. This will, at times, limit accuracy of modeled atmospheric conditions compared to observed conditions. However, any errors introduced will be done so in all simulations. Model solution differences will be a result of the varied parameterizations and not because the initial fields contained errors.

Some of the observed soundings flown during PRECIP IOPs that will be shown were contaminated by rainfall/thunderstorms during the launch. As a result, some of these observed soundings were terminated prematurely by natural causes (rain, hail, ice) and only the lowest $200-500$ hectopascals of the troposphere were sampled. 


\subsection{References}

Ashley, S.; Ashley, W. Flood fatalities in the United States. J. Appl. Meteorol. Climatol. 2008, 47, 806-818.

Blanchard, D. O., 2008: Interactions between a Supercell and a Quasi-Stationary Frontal Boundary. Monthly Weather Review, 136, 5199-5210.

Bryan, G. H., and J. M. Fritsch, 2000: Discrete Propagation of Surface Fronts in a Convective Environment: Observations and Theory. Journal of the Atmospheric Sciences, 57, 2041-2060.

Clark, A. J., W. A. Gallus, M. Xue, and F. Kong, 2010: Convection-Allowing and Convection-Parameterizing Ensemble Forecasts of a Mesoscale Convective Vortex and Associated Severe Weather Environment. Weather and Forecasting, 25, 1052-1081.

Corfidi, S. F., S. J. Corfidi, and D. M. Schultz, 2008: Elevated Convection and Castellanus: Ambiguities, Significance, and Questions. Weather and Forecasting, 23, 1280-1303Corfidi, S. F., 2003: Cold Pools and MCS Propagation: Forecasting the Motion of Downwind-Developing MCSs. Weather and Forecasting, 18, 997-1017.

Droegemeier, K. K., and R. B. Wilhelmson, 1987: Numerical Simulation of Thunderstorm Outflow Dynamics. Part I: Outflow Sensitivity Experiments and Turbulence Dynamics. Journal of the Atmospheric Sciences, 44, 1180-121

Iyer, E.R., A.J. Clark, M. Xue, and F. Kong, 2016: A Comparison of 36-60-h Precipitation Forecasts from Convection-Allowing and Convection-Parameterizing Ensembles.Wea. Forecasting, 31, 647-661, https://doi.org/10.1175/WAF-D-15-0143.1

Jankov, I., and W. A. G. Jr., 2004: MCS Rainfall

Forecast Accuracy as a Function of Large-Scale Forcing. Weather and Forecasting, 19, 428-439

Kastman JS, Market PS, Foscato A. 2015b. Rainfall-Lightning Ratio Calculations for Elevated Thunderstorms With Heavy Rainfall. Seventh Conference on the Meteorological Applications of Lightning Data. American Meteorological Society: Phoenix, AZ.

Kastman, Joshua S., Laurel D. Mccoy, Patrick S. Market, and Neil I. Fox. "An example of synergistic coupling of upper-and lower-level jets associated with flash flooding." Meteorological Applications 24, no. 2 (2017): 206-210

Maddox, R.A., L.R. Hoxit, and C.F. Chappell, 1980: A Study of Tornadic Thunderstorm Interactions with Thermal Boundaries. Mon. Wea. Rev., 108, 322336,https://doi.org/10.1175/1520-0493(1980)108<0322:ASOTTI>2.0.CO;2 
Mahoney, W. P.., 1988: Gust Front Characteristics and the Kinematics Associated with Interacting Thunderstorm Outflows. Monthly Weather Review, 116, 1474-1492.

Market, P. S., Scott M. Rochette, J. Shewchuk, R. Difani, Joshua S. Kastman, C. B. Henson, and N. I. Fox. "Evaluating elevated convection with the downdraft convective inhibition." Atmospheric Science Letters 18, no. 2 (2017): 76-81.

McCoy, Laurel P., Patrick S. Market, Chad M. Gravelle, Charles E. Graves, Neil I. Fox, Scott M. Rochette, Joshua Kastman, and Bohumil Svoma. "Composites of Heavy Rain Producing Elevated Thunderstorms in the Central United States." Advances in Meteorology 2017 (2017).

Moore, J. T., F. H. Glass, C. E. Graves, S. M. Rochette, and M. J. Singer, 2003: The Environment of Warm-Season Elevated Thunderstorms Associated with Heavy Rainfall over the Central United States. Weather and Forecasting, 18, 861-878.

Roebber, P. J., 2009: Visualizing multiple measures of forecast quality. Wea.

Forecasting, 24, 601-608, doi:10.1175/2008WAF2222159.1

Schumacher, R. S., A. J. Clark, M. Xue, and F. Kong, 2013: Factors Influencing the Development and Maintenance of Nocturnal Heavy-Rain-Producing Convective Systems in a Storm-Scale Ensemble. Monthly Weather Review, 141, 2778-2801

Schwartz, C. S., and Coauthors, 2010: Toward Improved Convection-Allowing Ensembles: Model Physics Sensitivities and Optimizing Probabilistic Guidance with Small Ensemble Membership. Weather and Forecasting, 25, 263-280.

Smull, B. F., and J. A. Augustine, 1993: Multiscale Analysis of a Mature Mesoscale Convective Complex. Monthly Weather Review, 121, 103-132. 


\title{
Chapter 2. Lightning and Rainfall Characteristics in Elevated vs. Surface Based Convection in the Midwest that Produce Heavy Rainfall
}

\author{
Joshua S. Kastman, Patrick S. Market, Neil I. Fox, Alzina L. Foscato and Anthony \\ R. Lupo * \\ Department of Atmospheric Science, School of Natural Resources, University of \\ Missouri, Columbia, MO 65
}

Kastman, Joshua S., Patrick S. Market, Neil I. Fox, Alzina L. Foscato, and Anthony R. Lupo. "Lightning and Rainfall Characteristics in Elevated vs. Surface Based Convection in the Midwest that Produce Heavy Rainfall." Atmosphere 8, no. 2 (2017): 36.

\subsection{Abstract}

There are differences in the character of surface-based and elevated convection, and one type may pose a greater threat to life or property. The lightning and rainfall characteristics of eight elevated and eight surface-based thunderstorm cases that occurred between 2007 and 2010 over the central Continental United States were tested for statistical differences. Only events that produced heavy rain $\left(>50.8 \mathrm{~mm} \cdot \mathrm{day}^{-1}\right)$ were investigated. The nonparametric Mann-Whitney test was used to determine if the characteristics of elevated thunderstorm events were significantly different than the surface based events. Observations taken from these cases include: rainfall-lightning ratios (RLR) within the heavy rain area, the extent of the heavy rainfall area, cloud-toground (CG) lightning flashes, $\mathrm{CG}$ flashes $\cdot \mathrm{h}^{-1}$, positive $\mathrm{CG}$ flashes, positive CG flashes $\cdot \mathrm{h}^{-1}$, percentage of positive CG flashes within the heavy rainfall area, and maximum and mean rainfall amounts within the heavy rain area. Results show that elevated convection cases produced more rainfall, total CG lightning flashes, and positive CG lightning flashes than surface based thunderstorms. More available moisture and storm morphology explain these differences, suggesting elevated convection is a greater lightning and heavy rainfall threat than surface based convection. 


\subsection{Introduction}

Research into elevated convection has been ongoing for many years. A climatology of elevated thunderstorms (Colman 1990a, Colman 1990b) showed that the central United States is the focus for occurrences of elevated convection. Elevated thunderstorm complexes are often associated with heavy rain and can lead to flash flooding (Rochette et al. 1996; Moore et. al 1996; McCoy 2014). However, surface based thunderstorms also produce heavy rain and flash flooding.

This study aims to investigate the observed differences in the mesoscale environment between elevated thunderstorms and surface based thunderstorms that produced heavy rain. The environmental differences will be explored using both planview and sounding composites of elevated and surface based convection. Observational differences will be examined in rainfall-lightning ratios (RLR) within the heavy rain area, the extent of the heavy rainfall area, cloud-to-ground (CG) lightning flashes, CG flashes per hour, positive CG flashes, positive CG flashes per hour, percentage of positive CG flashes within the heavy rainfall area, and maximum and mean rainfall amounts within the heavy rain area. The heavy rainfall area is defined as the continuous area in which $>50.8 \mathrm{~mm} \cdot \mathrm{day}^{-1}$ (two inches) of rain fell in association with elevated thunderstorms or surface based thunderstorms. This threshold was selected due to previous work with elevated convection (McCoy 2014). All of the cases investigated during this study occurred over Missouri, Kansas and Iowa in the central USA (Figure 2.1) during the months of May to September 2007-2010. 


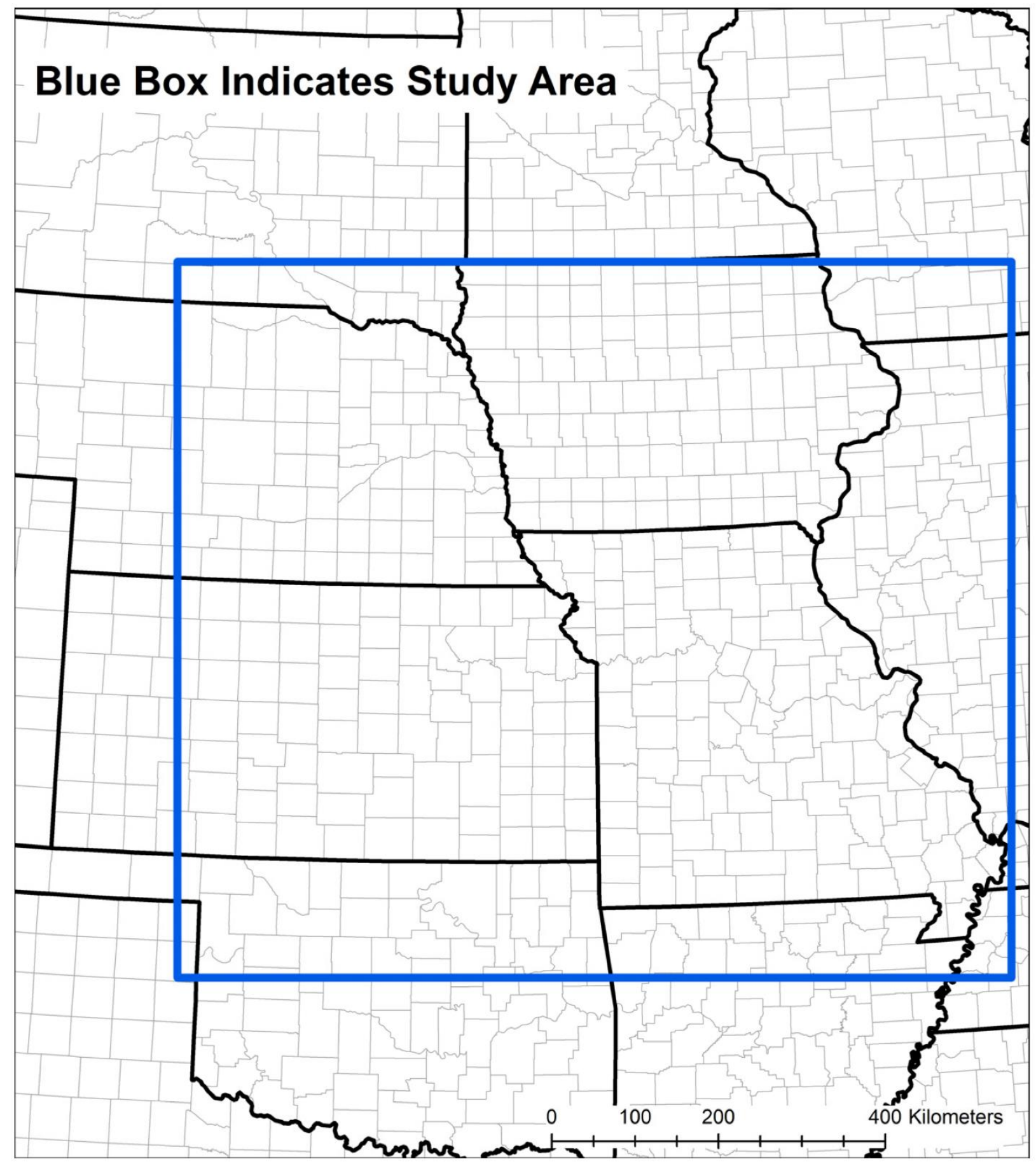

Figure 2.1. Map showing the study area for this project.

The results of this study are important as they show that there is a clear difference in mesoscale environmental conditions between elevated and surface based cases. These differences directly point to higher observations in rainfall and lightning amounts and 
coverage. Furthermore, these differences are not subtle, but rather predictable and therefore should be able to be forecasted.

Heavy rainfall is commonly caused by deep moist convection, and can lead to flash flooding. Flash flooding is responsible for the second greatest number of weatherrelated fatalities in the United States, behind only extreme heat (Ashley and Ashley 2008). Convective rainfall is very well correlated with cloud-to-ground (CG) lightning flashes (Gungle and Krider 2006; Rutledge and MacGorman 1988; Holle et al. 1994). It is now understood that the common processes necessary for heavy rainfall are similar to those which cause lightning, and were discussed as early as 1965 (e.g., (Battan 1965; Peterson and Rutledge 1998)). While flash flooding is more dangerous, lightning also poses a threat to life and property. The most recent weather related fatalities assessment covering the last 30 years (1984-2013) by the National Weather Service (NWS) (National Weather Service 2017) found lightning to be the third highest cause of fatalities. CG lightning is a serious, well documented, threat from any thunderstorm (Cooper et al. 2007; Holle et al. 2005). This study shows that CG lightning (total and positive CG flash counts) remains a threat from elevated thunderstorms as well. Positive CG flashes are arguably the more dangerous type of flashes (Uman 1987), given their ability to produce stronger peak currents (Rakov 2003) and can cause serious harm to people and their property. These facts motivated the current work.

Section 1 discusses the background of previously conducted studies and provide reasons as to why these cases were selected. Section 2 discusses the methods used and their rationale. In Section 3, the results and analyses are presented. Section 4 consists of discussion and the conclusions of the study. 


\subsection{Data and Methods}

\subsubsection{Data}

A direct comparison of surface-based and elevated convection in the context of lightning and heavy rain characteristics has yet to appear in the literature. We look first to the research on RLRs, which began in earnest with (Battan 1965). A relationship had been established between lightning flashes and rainfall before (Battan 1965), but this work was the foundation for many studies to follow. The work of (Tapia et al. 1998) conducted a RLR study on the storm scale, analyzing 22 thunderstorms over Florida. The median RLR, which expressed the convective rainfall volume per CG lightning flash, for the 22 storms was $4.3 \times 107 \mathrm{~kg} \cdot \mathrm{fl}^{-1}$. An important conclusion of the study was that the RLR varies with convective regime. They (Tapia et al. 1998) also concluded that high lightning frequencies led to lower RLR values. If RLR values remain high, along with elevated lightning flashes, then the corresponding rainfall would need to increase as well. This could be used as a tool in the short-term prediction of flash floods and in the hydrological analyses of the spatial distribution of rainfall in regions where radar coverage is poor.

In addition, Peterson (Peterson and Rutledge 1998) took a different approach to analyzing the RLRs. They completed a climatology of RLRs for the Continental United States (CONUS). They broke the USA into various regions of similar geography. They also computed the RLR values using a time period of one month. They found an average RLR value for the country to be $1 \times 108 \mathrm{~kg} \cdot \mathrm{fl}^{-1}$. They (Peterson and Rutledge 1998) also stated that results seemed to be highly dependent on weather regime and geographic regime. This suggestion was taken into consideration when cases were selected for the 
current study. However, rather than focus on weather regime, differences in mesoscale environment were of particular interest here. Only cases that had a surface based thunderstorm and elevated thunderstorm events occurring over a similar geographic area (central United States), during a similar temporal timeframe (within 30 days), were used for this study. This study would fall into the "Mid-Continent" geographic region used by (Peterson and Rutledge 1998), which both include Missouri. Both (Peterson and Rutledge 1998) and (Tapia et al. 1998) concluded that convective regimes played a large role in the distribution of RLRs. The idea of differing convective regimes is an important one, and impacts maximum and mean rainfall amounts between elevated and surface-based thunderstorms. It should be noted that this study focuses on the mesoscale convective environment and not the regime.

Looking more closely at lightning characteristics, Fuquay (Fuquay 1982) conducted research describing positive CG lightning of 48 thunderstorm days over three consecutive summers. He found by averaging CG lightning over three years that $3 \%$ of the ground flashes were positive flashes. The data (Fuquay 1982) compiled were ambient electric field and electric field change. The study conducted for this paper found differences between elevated and surface based thunderstorms in positive CG lightning flash percentages using data from the National Lightning Detection Network (NLDN). Elevated convection is also a known flash flood threat as stated by (Moore et al. 2003), and was defined by (Colman 1990a) as a storm that is isolated from surface diabatic effects and found above a frontal inversion. The studies of (Colman 1990a, Colman 1990b) defined an elevated thunderstorm via the following selection criteria based on observations from stations reporting a thunderstorm: (1) the observation must lie on the 
cold side of an analyzed front that shows a clear contrast in temperature, dew point, and wind; (2) the station's wind, temperature, and dew point must be qualitatively similar to the immediately surrounding values; and (3) the surface air on the warm side of the analyzed front must have a higher equivalent potential temperature $(\theta \mathrm{e})$ than the air on the cold side of the front. Similar criteria were also used by (Rochette and Moore 1996; Moore et al. 2003; McCoy 2014; Grant 1995; Moore et al. 1998) for studies involving elevated thunderstorms and will be used for this study as well.

The work of (Rochette and Moore 1996) focused on elevated mesoscale convective systems (MCS), highlighting the synoptic regimes favorable for elevated MCS and episodes of heavy rain and elevated thunderstorms. This was also the theme of (Moore et al. 2003). The elevated thunderstorm cases occurred in synoptically favored conditions, i.e., synoptic regimes with a well-defined thermal inversion, though most occurred with boundaries (cold fronts, warm fronts and stationary fronts), which led to a wide area of heavy rainfall. The surface based thunderstorms that produces a widespread area of heavy rainfall occurred in broad synoptic conditions, similar to what is presented in (Rochette and Moore 1996; Moore et al. 2003) (ample moisture, lift, and instability, minus the frontal boundary). However, the surface based cases that had smaller areas of heavy rainfall did not occur over a frontal zone, or in synoptically favorable conditions. These storms often were slow moving and that was a significant cause for the heavy rainfall, not simply an atmosphere primed for heavy rainfall through moisture and instability. Then (Moore et al. 1998) also touched on the idea of favorable synoptic conditions leading to widespread heavy precipitation, however that study also included cold-season precipitation. None of the studies above make any comparison to surface 
based thunderstorms, but do highlight regimes that are favorable for elevated thunderstorms. Simply put, elevated convection tends to occur in environments with greater large scale organization for moisture and lift, with a thermal boundary (often a front with an inversion): surface based convection can thrive in synoptically more marginal conditions, without an inversion.

Additionally, McCoy (McCoy 2014) investigated over 250 cases of elevated thunderstorms over the central CONUS, which produced composites of conditions that were found just prior to elevated convection. This work proved useful as they provided a list of elevated cases in the time frame of this study. These cases were confirmed using similar methods in Colman 1990a, Colman 1990b). The main difference between the two regimes was the presence or absence of an inversion often below the 850-hPa level.

\subsubsection{Methods}

For comparison, statistics were calculated separately for each thunderstorm type (both within the heavy rain area): RLR within the heavy rain area, the extent of the heavy rainfall area, cloud-to-ground (CG) lightning flashes, CG lightning per hour, positive CG flashes, positive CG flashed per hour, percentage of positive CG flashes within the heavy rainfall area, and maximum and mean rainfall amounts within the heavy rain area were calculated for each category of thunderstorm. The locations of the cases were confined to the central CONUS, specifically areas in or near Missouri.

Cases were selected for investigation with the intention of minimizing bias. Elevated thunderstorm cases were selected for dates between May and September during the years 2007 to 2010. Cases identified in (McCoy 2014) were used. Surface based thunderstorms were only selected if they occurred during the same months and year as 
the elevated thunderstorm case. This does not guarantee the sets of thunderstorms occurred in a similar weather regime (as in (Peterson and Rutledge)), but rather shows that both elevated and surface based thunderstorms with heavy rainfall are possible within the warm season near a given date. If more than one surface based thunderstorm case occurred in a month, the case closest to the elevated case date was used. This allowed for a balanced dataset with each thunderstorm type represented equally. This also ensured that elevated and surface based thunderstorms occurred during a similar timeframe. However, this limited the number of each type of case to eight for a total of 16 cases. Again, mesoscale environment was examined, not regime. Composites of 18 elevated and 18 surface based convective reanalysis environments are discussed further in Section 3.

The goal of this study is to compare the two populations of convective storms based on the extent of the heavy rainfall areas $(>50.8 \mathrm{~mm}$ per $24 \mathrm{~h})$ for surface based and elevated convection. The heavy rainfall area is being used as the investigation area for a few reasons: (1) it provides a common threshold for both sets of thunderstorms; (2) it focuses on the most dangerous portion of the storm (from a flooding and lightning perspective); (3) the size of the area itself is telling about the thunderstorm complexes; and (4) numerous studies (Peterson and Rutledge 1998; Tapia et al. 1998; Soriano et al. 2001) link heavy convective rainfall and CG lightning flashes.

The data used for this project came from a variety of sources. The lightning data were obtained from the National Lightning Detection Network (NLDN) via Vaisala, for the period 2007-2011. As noted by (Tapia et al. 1998), the NLDN has a detection efficiency of $85 \%$. This is much better than satellite sources, which vary greatly between 
day and night and, according to (Xu et al. 2013), can have detection efficiency of $\sim 70 \%$. The lightning data supply a latitude and longitude and whether the flash was CG or cloud-to-cloud (or cloud-to-air). Lightning flash rates of flashes per hour over the heavy rainfall area were used. This was calculated by dividing the total number of CG strikes within the heavy rainfall area and dividing by lightning start time and end time within the same area. Hourly flashes rates were selected as these cases are focused on the heavy rain footprint, which falls into the mesoscale temporal and spatial scale. Hourly observations are appropriate for investigating mesoscale phenomena per (Orlanski 1975). In addition, Reap (Reap and MacGorman 1989) showed CG lightning flashes broken into hour bins. Radar data in Level II format was acquired through the National Climate Data Center (NCDC). The precipitation data were acquired through the National Weather Service's (NWS) Advanced Hydrologic Prediction Service. These data are radar-estimated daily (24 h) liquid precipitation accumulation and comes as a point dataset. This dataset is rain gauge augmented as well as satellite augmented, and it treats the rain gauge values as absolute (ground) truth-values. Because the rain gauge network is neither uniform nor complete in coverage, gaps are filled in with radar-estimated precipitation accumulations. If radar data are not available, then satellite data are used to fill in the gaps. The daily data begin at 12:00 UTC and end at 11:59 UTC the day of recording. For example, the daily rainfall amounts recorded for 4 April are data from 12:00 UTC 3 April to 11:59 UTC 4 April.

In order to be selected, elevated convection events had to meet the following criteria: (1) Each event day (12:00-11:59 UTC) had to have an area of an average convective rainfall accumulation depth $\left(>50.8 \mathrm{~mm} \cdot \mathrm{day}^{-1}\right) ;(2)$ the majority of precipitation had to 
occur as convective rainfall (radar reflectivity $\geq 40 \mathrm{dBZ}$ ); (3) CG lightning flashes had to occur over the heavy rain area; (4) each thunderstorm type had to occur during a similar timeframe and over a similar geographical location; and(5) had to meet the selection criteria of (Colman 1990a), and/or exist above a significant thermal inversion (McCoy 2014).

The radar reflectivity threshold of $\geq 40 \mathrm{dBZ}$ was selected because Xu (Xu et al. 2013) showed that convective rainfall was associated with values of $\geq 40 \mathrm{dBZ}$. Radar data were inspected for each potential case to ensure convective rainfall occurred.

Precipitation data were then plotted for the central CONUS. Because the precipitation is a point dataset, interpolation using the Aeronautical Reconnaissance Coverage Geographical Information System (ArcGIS) ArcMAP software package (Version 10.1, ESRI, New York, NY, USA) licensed to the University of Missouri, via kriging, was conducted to highlight areas that had an average precipitation accumulation depth $\geq 50.8$ $\mathrm{mm} \cdot \mathrm{day}^{-1}$.

Figure 2.2 shows the results of the kriging interpolation of the point file acquired from the NWS Advanced Hydrologic Prediction Service. Kriging was shown to be the best interpolation method when using radar-derived precipitation accumulation (Earls and Dixon 2007). Through a series of tests on the data, it was found that ordinary kriging, using a spherical semivariogram model, with a variable search radius of 10 would yield the best results. This conserved both maxima and minima of accumulated precipitation. The kriging process revealed areas of $>50.8 \mathrm{~mm} \cdot \mathrm{day}^{-1}$ (referred to as the heavy rain areas), as seen in Figure 2.3. These areas of heavy rain were traced from the precipitation interpolation and a new layer was created. Lightning and point rainfall data were then 
clipped to these heavy rain area layers. This clipping revealed total CG lightning flashes within the heavy rain area as well the maximum and average rainfall within the heavy rain area. CG flashes were then sorted to determine positive and negative flash counts. This allowed percentages of positive flashes to be calculated.

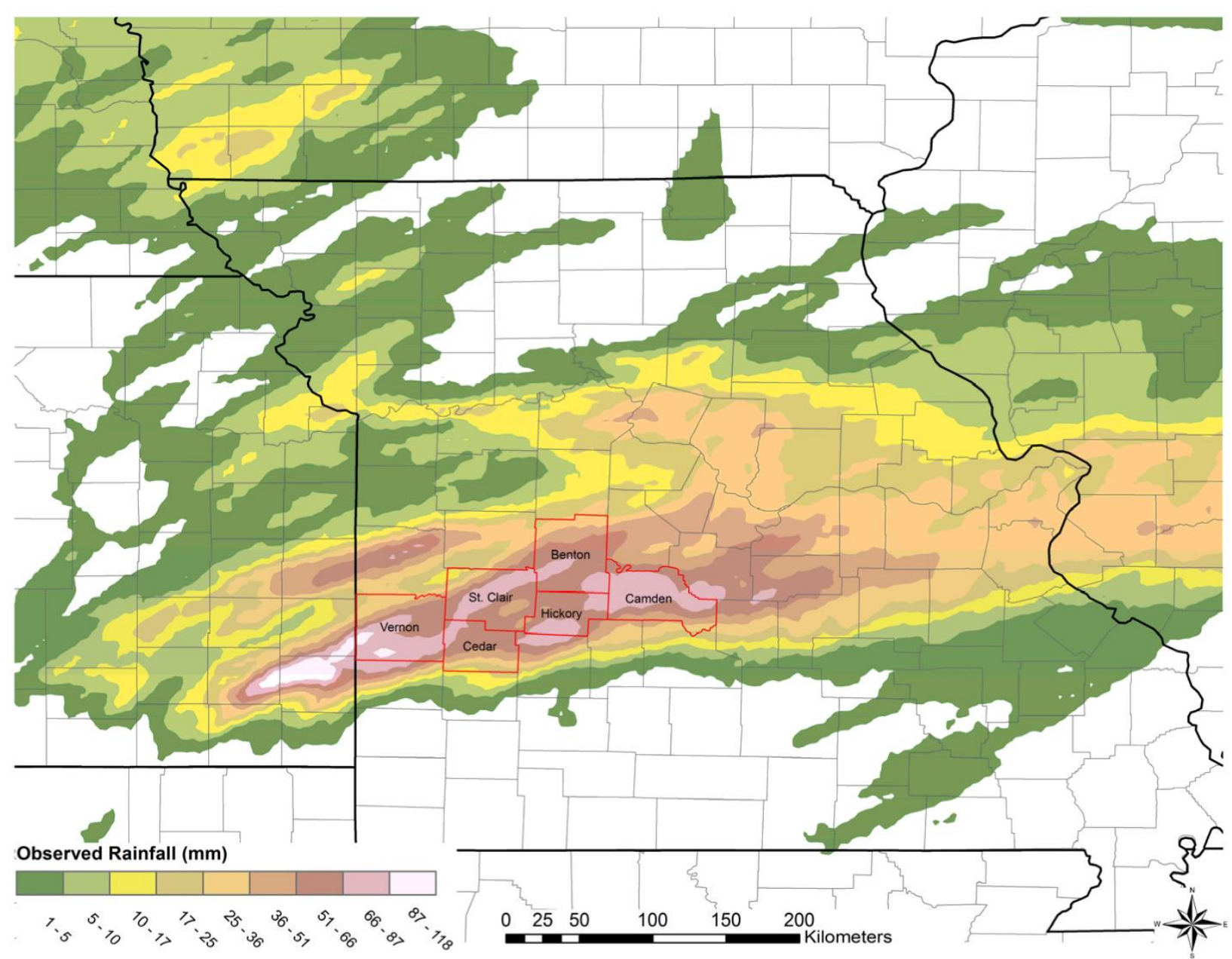

Figure 2.2. An example of kriging interpolation method for 24-h precipitation (mm) that ended at 12:00 UTC 12 May 2010. 


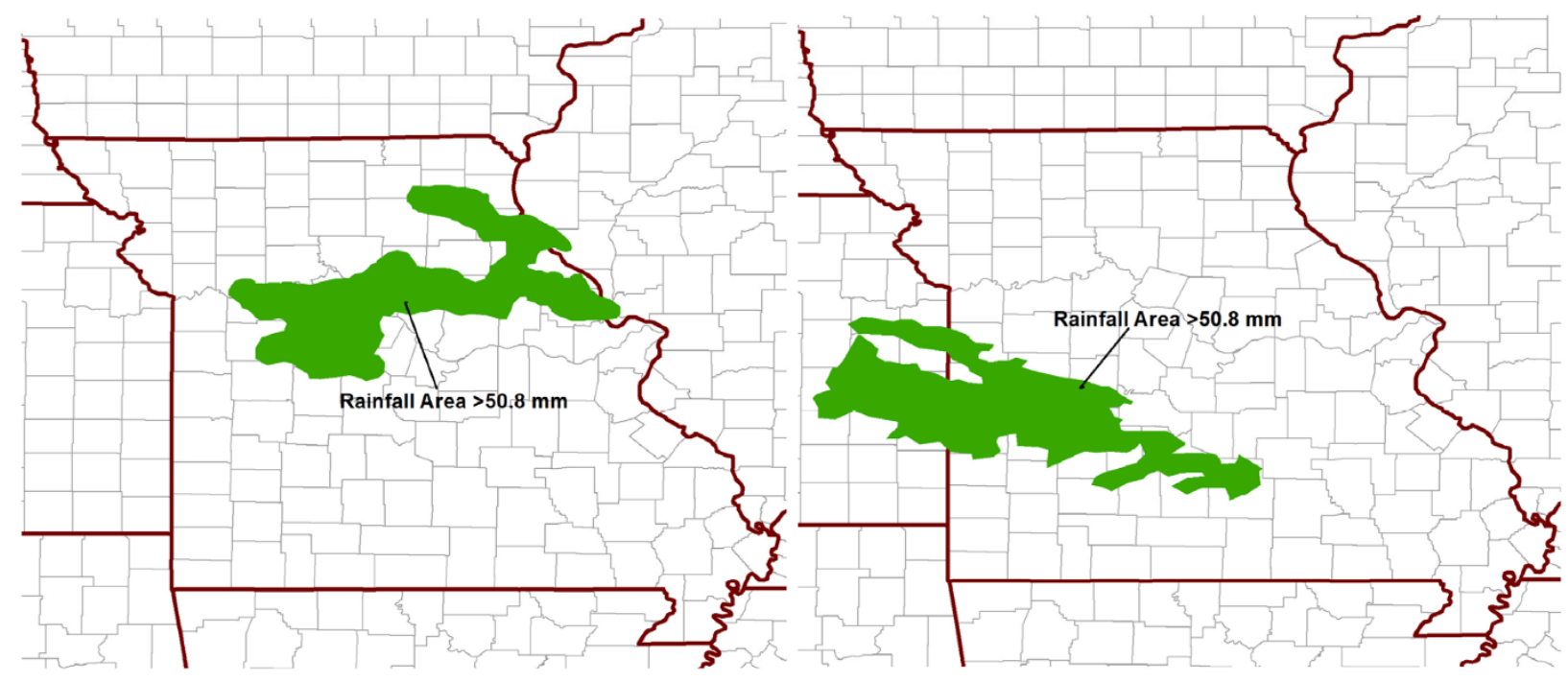

Figure 2.3. Example of the heavy rainfall area for an elevated thunderstorm case (left); and surface based thunderstorm case (right). The elevated thunderstorm case occurred 11 September 2010. The surface based thunderstorm case occurred 16 September 2010.

Vertical profiles from the North American Regional Reanalysis (NARR) were inspected to confirm whether storms were elevated or surface based, which used by (McCoy 2014) for initial case identification. The latitude and longitude of the heaviest rainfall location was used to determine sounding location. The nearest time step (to the hour) prior to precipitation occurring at that location was used for the soundings. In a further effort to minimize bias between the two groups of thunderstorms, sounding parameters were calculated, including the depth of the warm cloud layer, for both elevated and surface based convection. This was done for both individual soundings, as well as their composites as suggested by (Brown 1993) and employed by (Market et al. 2006). In addition, the two sets were examined for the dominant mode of convection. Here, the NARR profiles and Level II radar data were employed, respectively, to help establish commonality between the two groups. 
RLRs for both sets of thunderstorms were also calculated, using the heavy rain area $\left(\mathrm{km}^{2}\right)$, total event period (12:00 UTC to 12:00 UTC) CG lightning flashes within the heavy rainfall area, and average accumulated rainfall within the heavy rainfall area. Next, the precipitation accumulation average depth was established. While the kriging highlighted areas of interest, it did not provide a mean precipitation depth. The mean rainfall within the heavy rain area point precipitation file was used to find the mean depth.

Finally, the Mann-Whitney nonparametric statistical approach was used to test for differences between surface based thunderstorms and elevated thunderstorms in the following categories; RLR within the heavy rain area, the extent of the heavy rainfall area, CG lightning flashes, positive CG flashes, and percentage of positive strikes in the heavy rainfall area, maximum and mean rainfall amounts within the heavy rain area. The Mann-Whitney test was used as opposed to a two-sample t-test because the variables tested are not normally distributed. This was done in a similar manner by (Market et al. 2006) for proximity soundings of thundersnow and non-thundering snow events in the central United States. All surface based thunderstorm cases $(n=8)$ were considered one set of data and the elevated thunderstorm cases $(n=8)$ were considered the other set of data for the Mann-Whitney tests. Given the low number of cases, the null hypothesis was rejected if $\mathrm{p}>0.10$. A summary of all the $\mathrm{p}$-values can be found in Table 2.1. 
Table 2.1. $\mathrm{p}$-Values determined by nonparametric Mann-Whitney test for elevated thunderstorms vs. surface based thunderstorms.

\begin{tabular}{|l|c|}
\hline \multicolumn{1}{|c|}{ Parameter } & P-value \\
\hline RLR & 0.47 \\
\hline Heavy Rainfall Extent & 0.11 \\
\hline CG Lightning Flashes & 0.05 \\
\hline CG Positive Flashes & 0.06 \\
\hline CG Percent Positive Flashes & 0.04 \\
\hline Maximum Rainfall & 0.03 \\
\hline Mean Rainfall & 0.04 \\
\hline CG Flashes per Hour & 0.08 \\
\hline Positive CG Flashes per Hour & 0.06 \\
\hline
\end{tabular}

\subsection{Results and Analysis}

\subsubsection{Event Characteristics_-Storm Scale}

For each case, the first step was to establish the heavy rainfall area from the NWS Advanced Hydrologic Prediction Service data. Figure 2.3 shows an example of the heavy rainfall area for the 11 September 2010 and 16 September 2010 cases. The green area in each panel represents the area where $>50.8 \mathrm{~mm} \cdot \mathrm{day}^{-1}$ of rainfall was accumulated over a designated $24 \mathrm{~h}$ period which occurred as a result of convection. Once this was completed, all other analysis could proceed, as all other data was clipped to this heavy rainfall area.

\subsubsection{Rainfall-Lightning Ratios}

The RLR $\left(\mathrm{kg} \cdot \mathrm{fl}^{-1}\right)$ was the first parameter calculated for all 16 of the events, as it was the initial goal of this study. The medians of RLR were $3.916 \times 107$ and $3.997 \times 107$ for surface based and elevated thunderstorms, respectively, with a Mann-Whitney test result of $p=0.47$. Table 2.2 shows all RLR values for elevated and surface based convection events within the heavy rainfall area. It should be noted that the average RLR 
for all 16 cases was $5.79 \times 107 \mathrm{~kg} \cdot \mathrm{fl}^{-1}$. This result was similar to the findings of (Peterson and Rutledge 1998; Tapia et al. 1998; Soriano et al. 2001).

Table 2.2. RLR values for elevated convection events (left) and surface based convection events (right) within the heavy rain area.

RLR for Elevated Convection

RLR for Surface Based Convection

\begin{tabular}{|l|c|c|c|}
\hline Date & RLR $\left(\mathbf{x 1 0} \mathbf{~ k g ~ f l}^{-1}\right)$ & Date & RLR $\left(\mathbf{x 1 0} \mathbf{~ k g ~ f l}^{-1}\right)$ \\
\hline $5 / 6 / 2007$ & 3.24 & $5 / 24 / 2007$ & 34.162 \\
\hline $6 / 2 / 2007$ & 3.68 & $6 / 19 / 2007$ & 3.7588 \\
\hline $8 / 24 / 2007$ & 4.15 & $8 / 8 / 2007$ & 1.9963 \\
\hline $6 / 14 / 2008$ & 6.80 & $6 / 20 / 2008$ & 4.5091 \\
\hline $7 / 25 / 2008$ & 6.74 & $7 / 22 / 2008$ & 1.8558 \\
\hline $5 / 12 / 2010$ & 2.19 & $5 / 13 / 2010$ & 4.2325 \\
\hline $7 / 20 / 2010$ & 2.65 & $7 / 25 / 2010$ & 3.4422 \\
\hline $9 / 11 / 2010$ & 5.70 & $9 / 16 / 2010$ & 10.6170 \\
\hline Median & 3.92 & Median & 3.9956 \\
\hline
\end{tabular}

\subsubsection{Extent of the Heavy Rainfall Area}

Determination of the extent of the heavy rain areas for each storm type was necessary for calculation of other parameters. The medians for the heavy rainfall area were $15,381 \mathrm{~km}^{2}$ for elevated thunderstorms and $5209 \mathrm{~km}^{2}$ for surface based thunderstorms. While the differences in the averages seems substantial, the MannWhitney test returned a modest $\mathrm{p}=0.11$. The extent of the heavy rainfall area for all elevated convection events and surface based convection events can be found in Table 2.3. 
Table 2.3. Extent of the heavy rainfall areas $\left(\mathrm{km}^{2}\right)$ for elevated convection events (left) and surface based convection events (right).

Heavy Rain Area for Elevated Convection

\begin{tabular}{|l|c|l|c|}
\hline Date & $\begin{array}{c}\text { Heavy Rain Area } \\
\left(\mathbf{k m}^{\mathbf{2}}\right)\end{array}$ & Date & Heavy Rain Area $\left.\mathbf{( k m}^{\mathbf{2}}\right)$ \\
\hline $5 / 6 / 2007$ & 8,374 & $5 / 24 / 2007$ & 3,380 \\
\hline $6 / 2 / 2007$ & 12,256 & $6 / 19 / 2007$ & 5,312 \\
\hline $8 / 24 / 2007$ & 13,463 & $8 / 8 / 2007$ & 29,247 \\
\hline $6 / 14 / 2008$ & 9,341 & $6 / 20 / 2008$ & 3,700 \\
\hline $7 / 25 / 2008$ & 42,713 & $7 / 22 / 2008$ & 2,912 \\
\hline $5 / 12 / 2010$ & 17,299 & $5 / 13 / 2010$ & 49,532 \\
\hline $7 / 20 / 2010$ & 34,125 & $7 / 25 / 2010$ & 5,105 \\
\hline $9 / 11 / 2010$ & 28,191 & $9 / 16 / 2010$ & 30,831 \\
\hline Median & 15,381 & Median & 5,209 \\
\hline
\end{tabular}

\subsubsection{Lightning Flashes}

CG lightning flashes produced by surface based and elevated thunderstorms were the next dataset to be evaluated. Only CG lightning flashes that occurred within the heavy rain area were counted. The median CG lightning flash count for the eight elevated thunderstorm cases was 27,249 flashes and 9386 for surface based convection, producing a Mann-Whitney result of $\mathrm{p}$-value $=0.05$, showing that elevated thunderstorms produced more CG flashes than surface based thunderstorms. Table 2.4 shows the lightning flash activity for elevated convection events, including total CG lightning flashes, positive CG lightning flashes, and percentage of positive CG lightning flashes. Table 2.5 shows the same for surface based convection events. 
Table 2.4. Lightning flash characteristics within the heavy rainfall area for elevated based convection events.

\section{Lightning Flash Activity for Elevated Convection}

\begin{tabular}{|l|c|c|c|}
\hline Date & $\begin{array}{c}\text { CG Lightning } \\
\text { Total Flashes }\end{array}$ & $\begin{array}{c}\text { CG Lightning Positive } \\
\text { Flashes }\end{array}$ & $\begin{array}{c}\text { Positive CG Lightning } \\
\text { Flash Percentage }\end{array}$ \\
\hline $5 / 6 / 2007$ & 18,496 & 487 & $2.63 \%$ \\
\hline $6 / 2 / 2007$ & 22,324 & 503 & $2.25 \%$ \\
\hline $8 / 24 / 2007$ & 22,841 & 631 & $2.76 \%$ \\
\hline $6 / 14 / 2008$ & 10,152 & 427 & $4.21 \%$ \\
\hline $7 / 25 / 2008$ & 61,935 & 1,788 & $2.89 \%$ \\
\hline $5 / 12 / 2010$ & 50,063 & 2,432 & $4.86 \%$ \\
\hline $7 / 20 / 2010$ & 117,961 & 3,548 & $3.01 \%$ \\
\hline $9 / 11 / 2010$ & 31,657 & 1,207 & $3.81 \%$ \\
\hline Median & 27,249 & 919 & $2.95 \%$ \\
\hline
\end{tabular}

Table 2.5. Lightning flash characteristics within the heavy rainfall area for surface convection events.

\section{Lightning Flash Activity for Surface Based Convection}

\begin{tabular}{|l|c|c|c|}
\hline Date & $\begin{array}{c}\text { CG Lightning } \\
\text { Total Flashes }\end{array}$ & $\begin{array}{c}\text { CG Lightning } \\
\text { Positive Flashes }\end{array}$ & $\begin{array}{c}\text { Positive CG Lightning } \\
\text { Flash Percentage }\end{array}$ \\
\hline $5 / 24 / 2007$ & 653 & 15 & $2.30 \%$ \\
\hline $6 / 19 / 2007$ & 9,299 & 193 & $2.08 \%$ \\
\hline $8 / 8 / 2007$ & 99,332 & 2,359 & $2.37 \%$ \\
\hline $6 / 20 / 2008$ & 5,547 & 102 & $1.84 \%$ \\
\hline $7 / 22 / 2008$ & 9,399 & 201 & $2.14 \%$ \\
\hline $5 / 13 / 2010$ & 77,239 & 3,214 & $4.16 \%$ \\
\hline $7 / 25 / 201$ & 9,373 & 191 & $2.04 \%$ \\
\hline $9 / 16 / 2010$ & 20,356 & 925 & $4.54 \%$ \\
\hline Median & 9,386 & 197 & $2.22 \%$ \\
\hline
\end{tabular}

Positive CG flashes are the most dangerous types of lightning flashes (Uman 1987). Therefore, these types of flashes were also investigated within the heavy rainfall area. Median positive CG flashes were 919 for elevated thunderstorms and 197 for surface based thunderstorms. A p-value $=0.06$ was found with the Mann-Whitney test. 
This also indicated that the elevated thunderstorm cases produced more positive CG flashes than surface based thunderstorms did.

The percentage of the polarity in CG flashes within the heavy rain area was also of interest. The median percentage positive percentage of CG flashes was $2.95 \%$ for the elevated thunderstorms cases and $2.22 \%$ for surface based thunderstorms. A p-value $=$ 0.04 suggesting this is a significant result because thunderstorm complexes can produce thousands of CG flashes.

Peak current of positive flashes was also investigated. It was found that elevated convection had a higher average peak current at $172 \mathrm{kA}$ compared to $139.25 \mathrm{kA}$ in surface based storms. However, the results of the Mann-Whitney test revealed a p-vale of 0.13 .

Finally, lightning was broken down into CG flashes per hour and CG flashes per area within the heavy rainfall area per each set. The elevated thunderstorm set had a much higher value for the median flashes per hour at $2212.3 \mathrm{fl} \cdot \mathrm{h}^{-1}$ compared to only 1216.7 $\mathrm{fl} \cdot \mathrm{h}^{-1}$ for surface based set with a $\mathrm{p}$-value $=0.08 . \mathrm{CG}$ Flashes per area and the median values were close $\left(1.73 \mathrm{fl} \cdot \mathrm{km}^{-2}\right.$ for elevated sets and $1.65 \mathrm{fl} \cdot \mathrm{km}^{-2}$ for surface based sets). Positive CG lightning per hour between each thunderstorm set was also tested, with a p-value $=0.06$ found. The elevated thunderstorm set also had a higher mean positive CG hourly flash rate at $63.5 \mathrm{CG} \mathrm{fl} \cdot \mathrm{h}^{-1}$ compared to just $20.0 \mathrm{CG} \mathrm{fl} \cdot \mathrm{h}^{-1}$ for the surface based thunderstorm set.

\subsubsection{Maximum and Mean Rainfall Amounts}

Maximum and mean rainfall amounts within the heavy rain area are important to investigate as it reveals how serious of a flash flooding threat these storms pose. Table 
2.6 shows the maximum and mean rainfall amounts for elevated convection events and surface based convection events. The maximum amount of rainfall for all cases was $264.2 \mathrm{~mm}$ (10.4 in) which occurred 25 July 2008 with elevated convection. The highest maximum amount of rainfall from a surface based thunderstorm case was $136.4 \mathrm{~mm}$ (5.34 in). This was below the average of maximum rainfall amounts observed in the elevated thunderstorm cases, which was $166 \mathrm{~mm}$ (6.53 in). The median value of maximum rainfall was $128 \mathrm{~mm}$ for elevated thunderstorms and $105 \mathrm{~mm}$ for surface based thunderstorms. The Mann-Whitney test showed a p-value $=0.03$, indicating that elevated thunderstorms produced higher maximum amounts than surface based thunderstorms.

The mean rainfall within the heavy rainfall area showed a very similar pattern. The median for the mean rainfall within the heavy rain area was 71 for elevated thunderstorms and 66 for surface based thunderstorms with a p-value $=0.04$. Both tests clearly indicate that there were statistical differences between these data sets. Both point to the same conclusion that elevated thunderstorm cases produced more rainfall than surface based thunderstorm cases, and thus elevated convection cases posed a more serious threat for flash flooding.

\subsubsection{Event Characteristics - Mesoscale Environment}

Rainfall initiation to dissipation values indicate elevated convection lasted longer than surface based convection, on average by around one hour. Average rainfall time of $9.89 \mathrm{~h}$ for elevated storms compared to 8.94 for surface based storms. This assuredly contributes to the larger rainfall footprint and higher rainfall amounts. It also speaks to the larger lightning coverage: as persistent convection is able to sustain itself, there is more opportunity for lightning strikes and heavy rainfall. However, the difference is not 
so great to solely account for the higher amounts and areas seen in elevated convection.

Therefore, synoptic composites and soundings will be investigated to look at the environmental differences.

Table 2.6. Maximum and mean rainfall amounts for elevated convection events (left) and surface based convection events (right).

Maximum and Mean Rainfall Amounts Maximum and Mean Rainfall Amounts for for Elevated Convection Surface Based Convection

\begin{tabular}{|l|c|c|l|c|c|}
\hline Date & $\begin{array}{c}\text { Daily Mean } \\
\text { Rainfall }(\mathrm{mm})\end{array}$ & $\begin{array}{c}\text { Maximum } \\
\text { Observed } \\
\text { Rain }\end{array}$ & Date & $\begin{array}{c}\text { Maximum } \\
\text { Rainfall }(\mathrm{mm})\end{array}$ & $\begin{array}{c}\text { Mbserved } \\
\text { Rain }\end{array}$ \\
\hline $5 / 6 / 2007$ & 72 & 124 & $5 / 24 / 2007$ & 66 & 84 \\
\hline $6 / 2 / 2007$ & 67 & 128 & $6 / 19 / 2007$ & 66 & 104 \\
\hline $8 / 24 / 2007$ & 70 & 100 & $8 / 8 / 2007$ & 68 & 157 \\
\hline $6 / 14 / 2008$ & 74 & 213 & $6 / 20 / 2008$ & 68 & 105 \\
\hline $7 / 25 / 2008$ & 98 & 264 & $7 / 22 / 2008$ & 60 & 92 \\
\hline $5 / 12 / 2010$ & 63 & 128 & $5 / 13 / 2010$ & 66 & 102 \\
\hline $7 / 20 / 2010$ & 92 & 246 & $7 / 25 / 2010$ & 63 & 106 \\
\hline $9 / 11 / 2010$ & 64 & 125 & $9 / 16 / 2010$ & 70 & 136 \\
\hline Median & 71 & 128 & Median & 66 & 105 \\
\hline
\end{tabular}

\subsubsection{Composite Analysis}

Composites of elevated and surface based convection which occurred during the period of study and over the geographical area were created in order to establish that the cases presented in the study are representative of the respective phenomena. Composites were derived on a regional scale (southwest corner; $25^{\circ} \mathrm{N}, 108^{\circ} \mathrm{W}$; northeast corner; $50^{\circ}$ $\left.\mathrm{N}, 80^{\circ} \mathrm{W}\right)$ and the continental scale at the closest time (00:00 UTC, 06:00 UTC, 12:00 UTC or 18:00 UTC) prior to convective initiation. This was done to ensure convection had not altered the composited environment. Composites (18 elevated convection environments; 18 surface based convection environments) were created using the Earth Systems Research Laboratory's (ESRL) 20th Century Reanalysis tool (ESRL 2016). The following parameters were composited for both surface based and elevated cases at the 
times and locations previously described; $\operatorname{MSLP}(\mathrm{Pa}), 700-\mathrm{hPa}$ omega $\left(\mathrm{Pa}^{\mathrm{s}} \mathrm{s}^{-1}\right)$, precipitable water $\left(\mathrm{kg} \cdot \mathrm{m}^{-2}\right), 850-\mathrm{hPa}$ vector wind $\left(\mathrm{m} \cdot \mathrm{s}^{-1}\right), 500-\mathrm{hPa}$ geopotential heights $(\mathrm{dkm})$, and 2-m Surface Temperature (K). Noticeable differences are seen between the surface based cases and elevated cases, most of which revolve around intensity.

Figure 2.4 shows that the 500-hPa geopotential height pattern composites for elevated (Figure 2.4a) and surface based (Figure 2.4b) convection have some similarities and differences. Both generally show troughing west of Missouri and ridging to the east. However, the location and intensity of these features differ. Surface based composites show a very weak trough to the west and weak ridge near the Great Lakes. The pattern could be described as more zonal given the weak intensities of the ridges and troughs. The elevated convection composite, on the other hand, shows a distinct, deeper, shortwave across the Intermountain West and more substantial ridge over the Great Lakes region, similar to what (McCoy 2014) showed in their composite work on elevated convection.

Figure 5 depicts the 700-hPa vertical motion $(\omega)$ for elevated (Figure 2.5a) and surface based (Figure 2.5b) composites. The elevated composites reveal much stronger upward vertical velocities $\left(-0.12 \mathrm{~Pa} \cdot \mathrm{s}^{-1}\right.$ compared to $\left.-0.06 \mathrm{~Pa} \cdot \mathrm{s}^{-1}\right)$ and a larger coverage area. This figure is perhaps best viewed along with Figure 2.6, which is the 850-hPa isotachs (Figure 2.6a elevated, Figure 2.6b surface based). Together, these figures show that the Low level jet (LLJ) was stronger, more southerly and exhibited a much sharper wind gradient in the elevated convection composites. Additionally, the bulk of the omega (including maximum value) occurred along and to the left of the leading edge of the LLJ gradient. This pattern is a known influencer of elevated convection (Rochette and Moore 
1996; Moore et al. 2003; Corfidi 2003) and speaks to increased coverages and longevity of elevated convection.

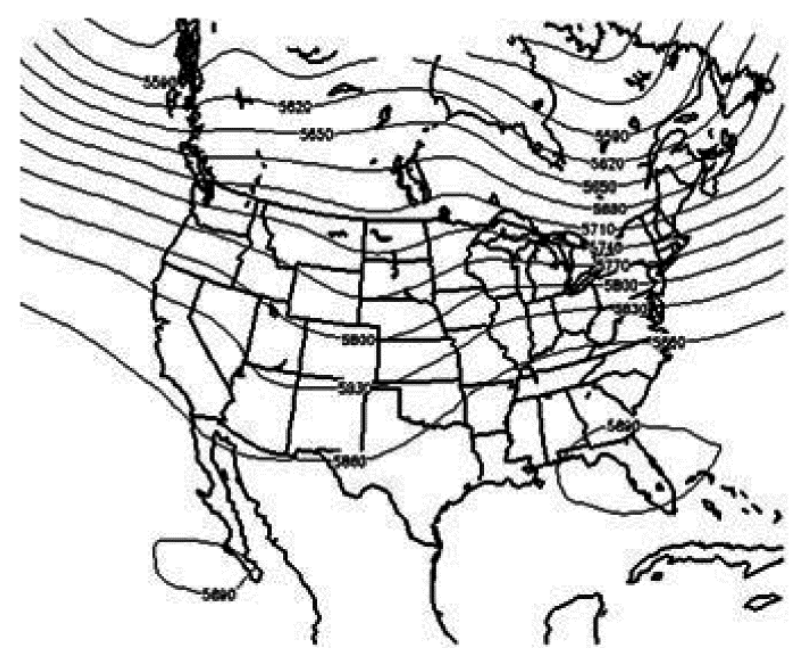

(a)

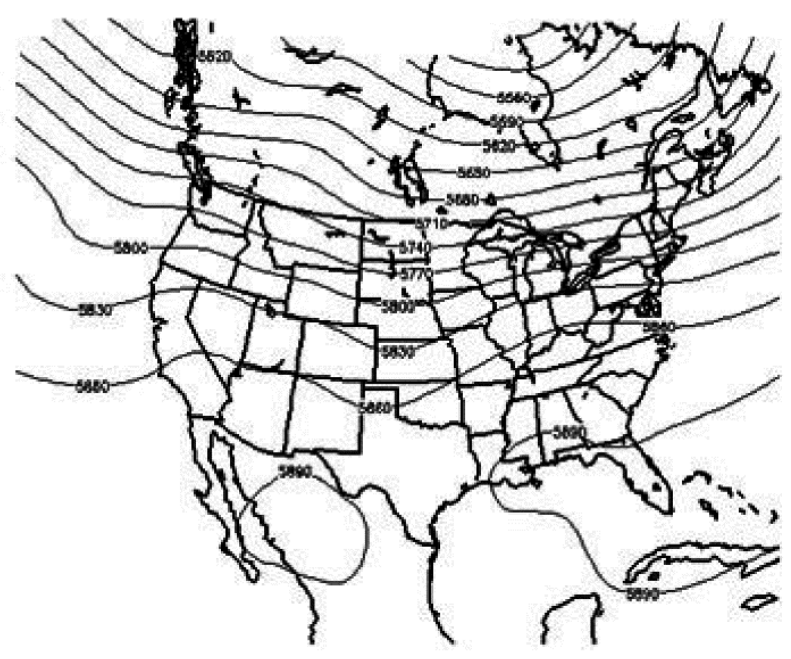

(b)

Figure 2.4. The 500-hPa geopotential heights (dkm) every $30 \mathrm{dkm}$ from 5500 to 6000 : (a) composites for elevated convection; and (b) composites for surface based convection.

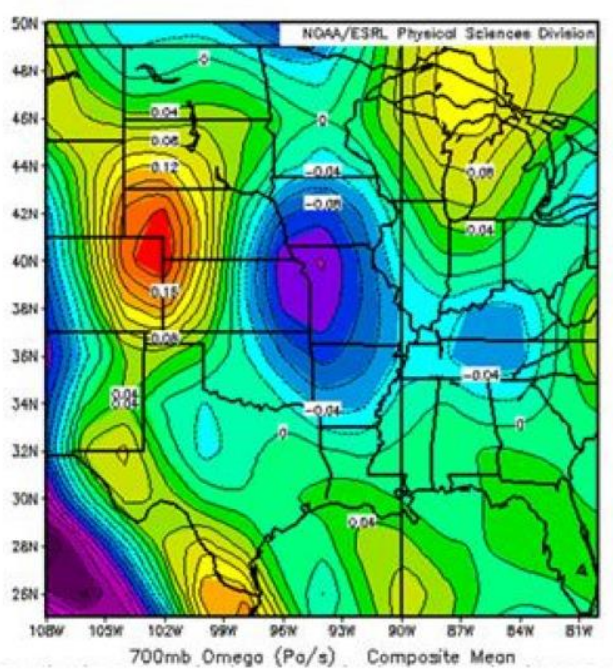

(a)

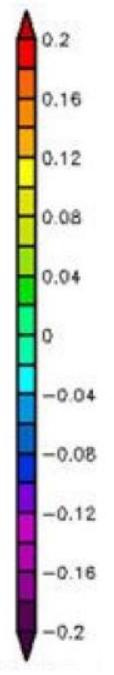

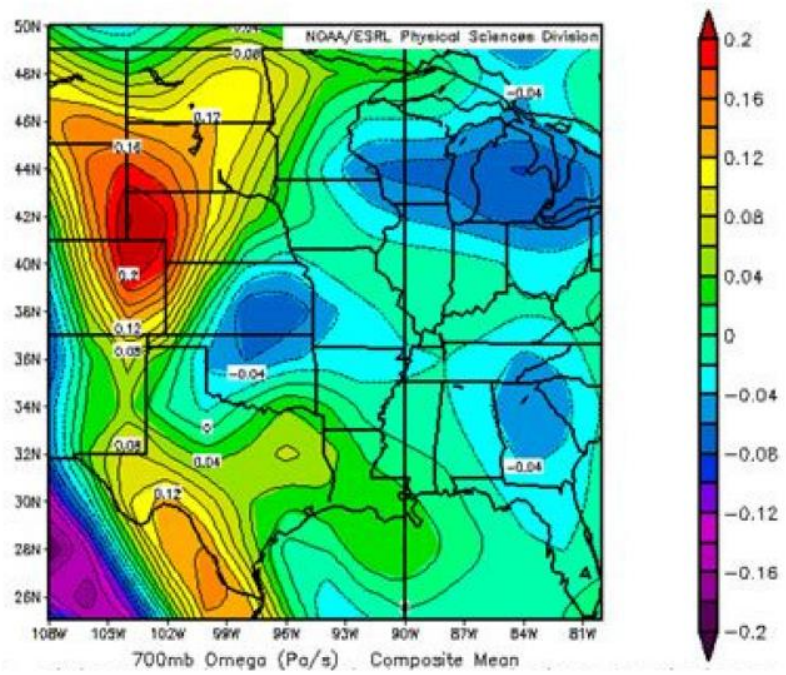

(b)

Figure 2.5. The 700-hPa vertical motion $(\omega)\left(\mathrm{Pa} \cdot \mathrm{s}^{-1}\right)$ (shaded; every $0.02 \mathrm{~Pa} \cdot \mathrm{s}^{-1}$ ) from -0.2 to 0.2 : (a) composites for elevated convection; and (b) composites for surface based convection. 


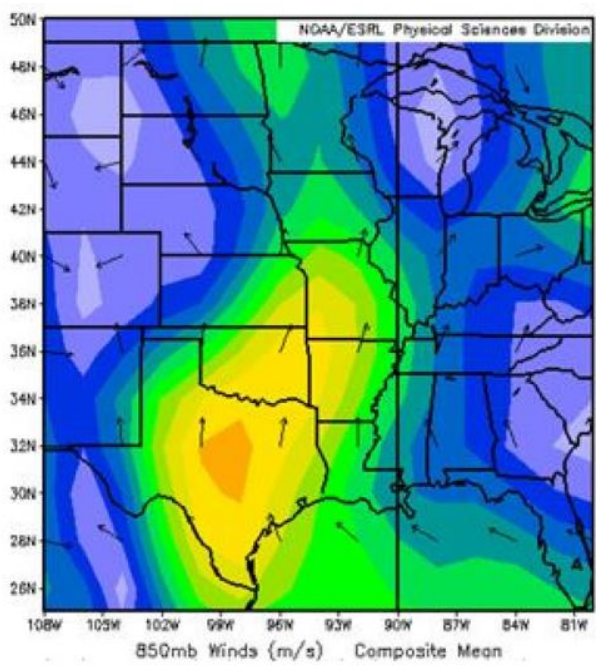

(a)
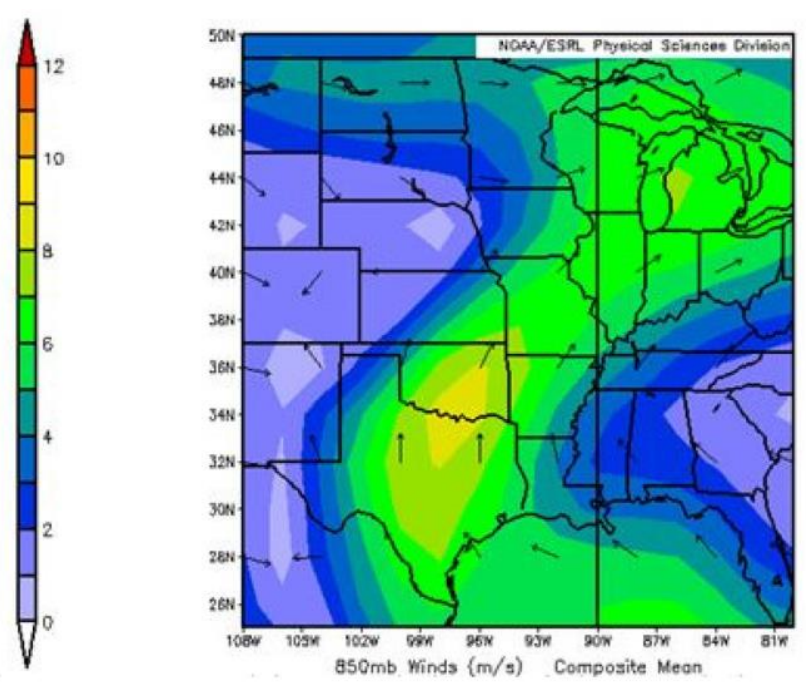

(b)

Figure 2.6. The $850-\mathrm{hPa}$ isotach wind (shaded; every $\mathrm{m} \cdot \mathrm{s}^{-1}$ ) from 0 to 12 : (a) composites for elevated convection; and (b) composites for surface based convection.

Surface-based composites also showed differences. Precipitable water values (Figure 2.7) were similar for both composite sets in terms of intensity (maximum values of $44 \mathrm{~kg} \cdot \mathrm{m}^{-2}$ for elevated, $40 \mathrm{~kg} \cdot \mathrm{m}^{-2}$ for surface based) which is logical given high moisture content is essential for heavy rain, which both elevated and surface based data sets have in common. However, the elevated composite (Figure 2.7a) clearly exhibits a south-to-north orientation of precipitable water, similar to that of the LLJ, while the surface based composite (Figure 2.7b) displays a less intense southwest-to-northeast oriented pattern of precipitable water. Clearly, the intensity and orientation of the LLJ played a role in moisture advection for these cases. The LLJ, in fact, is one of the main differences between the elevated and surface based composites and likely one of the primary sources of differences in overall rainfall amounts and areal coverage. 


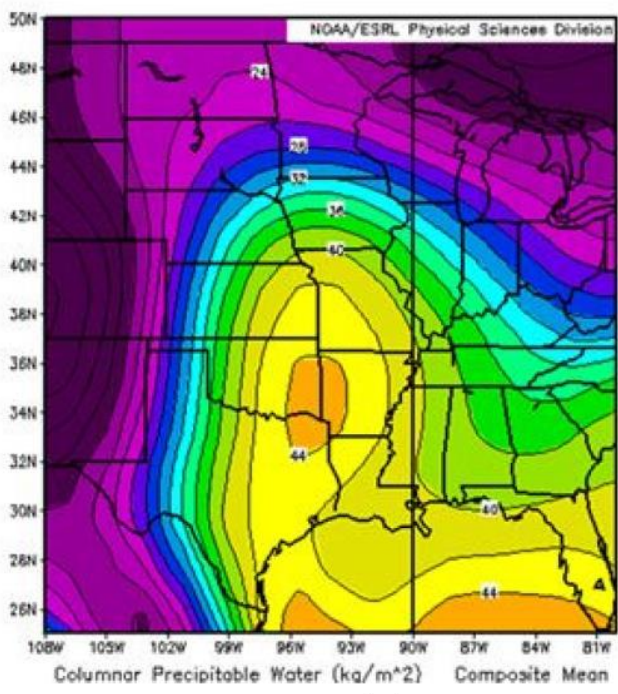

(a)
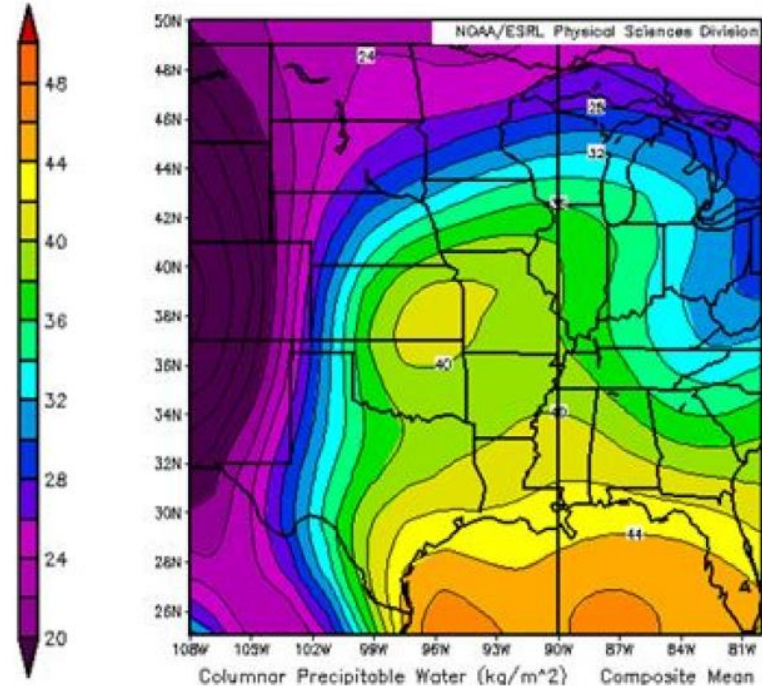

(b)

Figure 2.7. Precipitable water (shaded; every $2 \mathrm{~kg} \cdot \mathrm{m}^{-2}$ from) 20 to 50: (a) composites for elevated convection; and (b) composites for surface based convection.

Figure 2.8 shows the 2-m temperature differences in the elevated (Figure 2.8a) and surface based (Figure 2.8b) composites. Figure 8a clearly shows a tighter thermal gradient across the central United States. Figure 2.9 depicts a sharper mean sea level pressure (MSLP) gradient in the elevated (Figure 2.9a) composite compared to the surface based composite (Figure 2.9b). Both show an inverted surface pressure trough over the Southern Plains and southern Rockies extending into Kansas. However, the elevated composite shows a stronger surface low pressure system and a pressure trough, perhaps a warm front, extending into Missouri. In the surface based composite the influence of the Bermuda High is clearly evident as far west as Missouri. This feature is confined along and to the east of the Appalachian Mountains in the elevated composites. Both modes of convection were associated with upstream $\left(140^{\circ} \mathrm{E}\right.$ to $100^{\circ} \mathrm{W}-$ Pacific Region) blocking (University of Missouri Blocking Archive 2016) about 50\% of the time (Table 2.7). Upstream blocking, especially in the East Pacific, frequently impacts the 
weather during the winter and occasionally summer season weather in the central United States (Lupo et al. 2008). The frequency indicated above is approximately twice the climatological occurrence of blocking in Pacific Region during the warm season (Wiedenmann et al. 2002; Newberry et al. 2016). This association warrants further study.

Clearly, there are significant synoptic differences between the elevated and surface based composites with the elevated composites exhibiting stronger synoptic signals for heavy rainfall. Indeed, these composites support the results of larger rainfall coverage and higher rainfall amounts for elevated convection. These composites also indicate that the specific cases shown throughout the study are representative of synoptic regimes which support heavy rainfall from elevated convection and surface based convection.

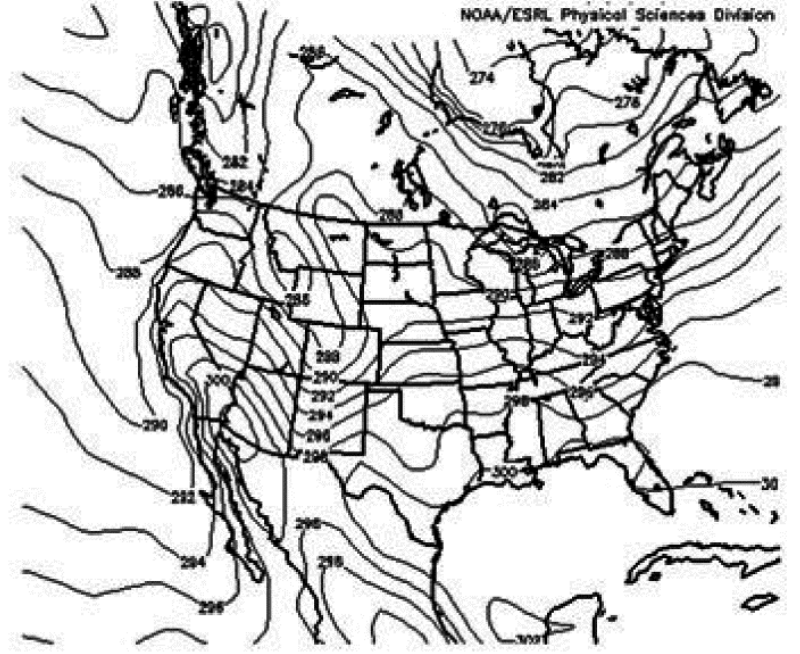

(a)

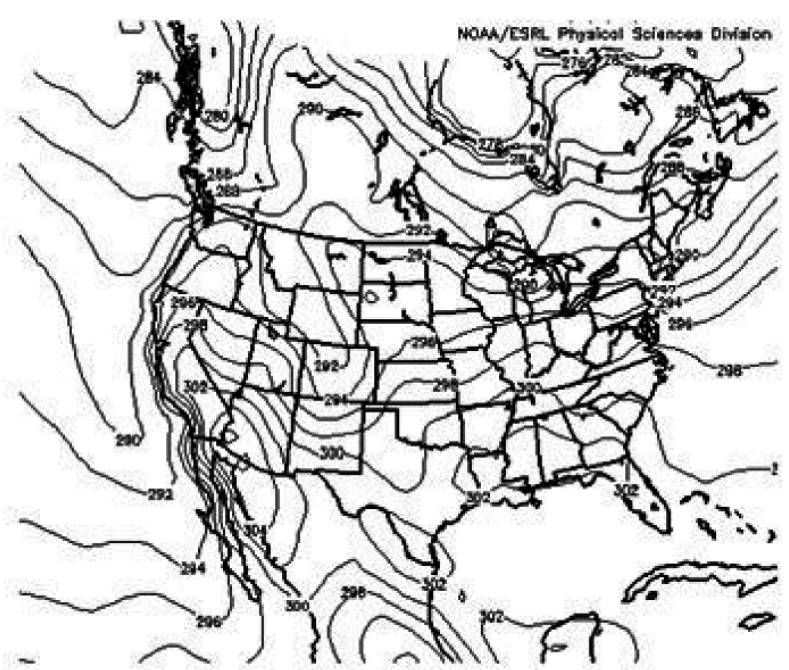

(b)

Figure 2.8. The 2-m temperature (K) every $3 \mathrm{~K}$ from 270 to 320: (a) composites for elevated convection; and (b) composites for surface based convection. 


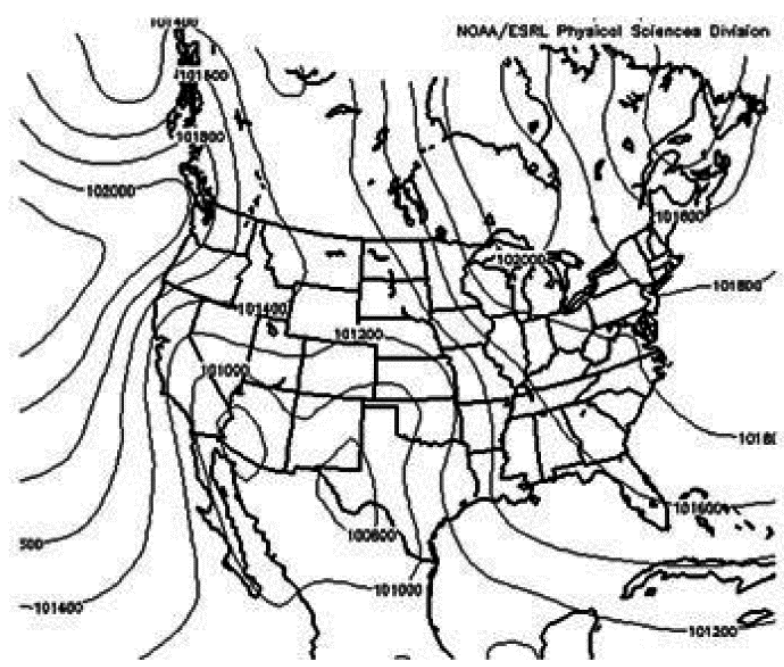

(a)

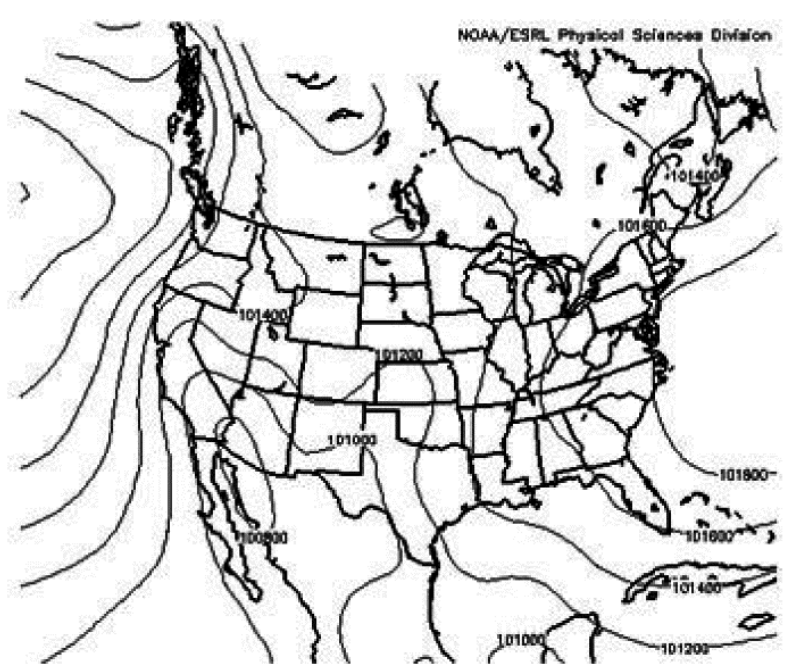

(b)

Figure 2.9. Pressure reduced to mean sea level; every $200 \mathrm{~Pa}$ from 100,000 to 10,300 : (a) composites for elevated convection; and (b) composites for surface based convection.

Table 2.7. Warm cloud depth $(\mathrm{m})$ for all convection cases. An asterisk (*) indicates that atmospheric blocking was present in the Pacific Region $\left(140^{\circ} \mathrm{E}-100^{\circ} \mathrm{W}\right)$.

\begin{tabular}{|l|c|c|}
\hline \multicolumn{1}{|c|}{ Convection Type } & Convection Date & Warm Cloud Depth (m) \\
\hline Elevated Convection & $5 / 6 / 2007$ & 3,529 \\
\hline Surface Based Convection & $5 / 24 / 2007$ & - \\
\hline Elevated Convection & $6 / 2 / 2007$ & 4,210 \\
\hline Surface Based Convection & $6 / 18 / 2007$ & 4,393 \\
\hline Elevated Convection & $8 / 23 / 2007$ & 4,4921 \\
\hline Surface Based Convection & $8 / 7 / 2007$ & 4,442 \\
\hline Elevated Convection & $6 / 13 / 2008$ & 4,409 \\
\hline Surface Based Convection & $6 / 19 / 2008$ & 4,398 \\
\hline Elevated Convection & $7 / 25 / 2008$ & 4,408 \\
\hline Surface Based Convection & $7 / 22 / 2008$ & 5,141 \\
\hline Elevated Convection & $5 / 12 / 2010$ & 3,565 \\
\hline Surface Based Convection & $5 / 12 / 2010$ & 4,127 \\
\hline Elevated Convection & $7 / 20 / 2010$ & 4,982 \\
\hline Surface Based Convection & $7 / 25 / 2010$ & 5,108 \\
\hline Elevated Convection & $9 / 11 / 2010$ & 5,260 \\
\hline Surface Based Convection & $9 / 15 / 2010$ & 4,989 \\
\hline
\end{tabular}




\subsubsection{Sounding Analysis}

In addition to seeking pairs of events from similar geographic areas and similar time frames, finer-scale aspects of the convection cells and their parent MCS were also examined. NARR profiles were used to compare the atmospheres that engendered the elevated and surface-based classes of soundings, both on a case-by-case basis, and as composites (Figure 2.10). The composite figure shows two atmospheres with different characteristics. The composite for surface-based convection is warmer at the surface, but cools with height at a nearly adiabatic lapse rate. Above the surface, the surface-based convection sounding is uniformly and drier than its elevated counterpart. Additionally, the flow is nearly unidirectional from the southwest, and only modest speed increases with height. By contrast, the composite elevated convection sounding is warmer, moister, with easterly flow near the surface (below the inversion) and significant veering up to $\sim 700 \mathrm{hPa}$, and a low-level speed maximum in the profile at $825 \mathrm{hPa}$. Indeed, the stronger wind speeds are corroborated by the low-level plan view analyses discussed earlier (Figure 2.6). Most unstable convective available potential energy (MUCAPE) values roughly double those of the surface-based composite. Even when examining the original NARR soundings on a case-by-case basis, the mean MUCAPE value of the elevated cases was $1984 \mathrm{~J} \cdot \mathrm{kg}^{-1}$, as opposed to $1612 \mathrm{~J} \cdot \mathrm{kg}^{-1}$ for the surface-based case collection. 

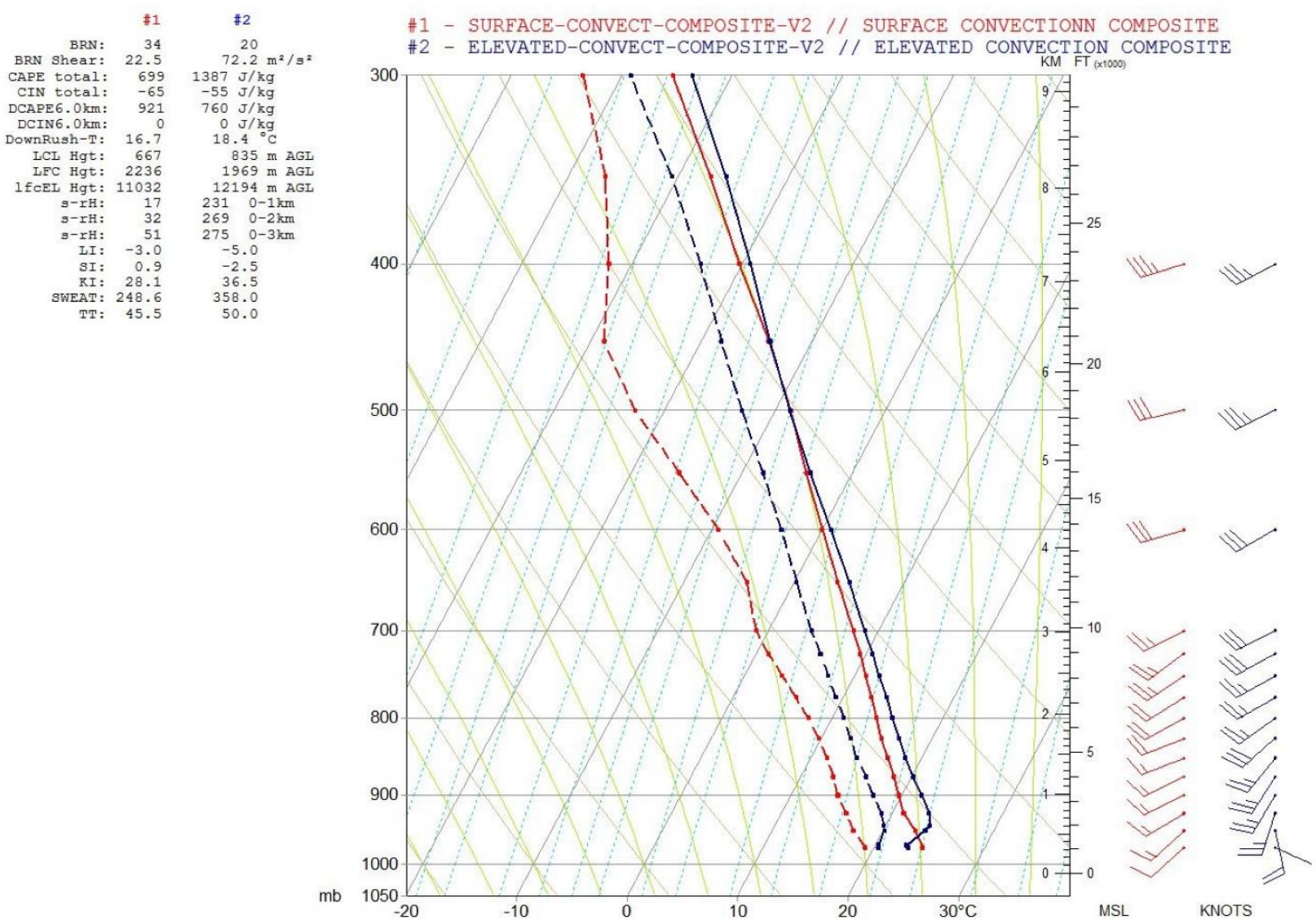

Figure 2.10. Composite sounding profiles for surface-based convection (red) and elevated convection (blue) on a standard skew-T log p diagram. Temperature traces $\left({ }^{\circ} \mathrm{C}\right.$; solid) and dew point traces $\left({ }^{\circ} \mathrm{C}\right.$; dashed) are accompanied by standard wind plots (right) with speeds in represented in knots.

Additionally, warm cloud depths were examined between the surface based convective events and those in the elevated group (Table 2.7). Previously, Anip (Anip and Market 2007) had shown that warm cloud depth was more of a seasonal control on MCS precipitation efficiency, and analyses of these two sets support that conclusion, with no significant difference between storm types under a Mann-Whitney test. Indeed, the mean (median) values for warm cloud depth for surface based parcel were $4300 \mathrm{~m}$ (4183 m), and for elevated parcels were 4358 m (4409 m). In addition, Level II Doppler radar data were examined to determine MCS mode. Most individual cases in the elevated convection set were of the trailing stratiform morphology (Parker and Johnson 2000), 
with a scattering of other modes in the surface-based convection cases (Table 2.8). These two sets of cases are rather similar, with the presence of a thermal inversion for elevated cases being the primary difference between them. However, the elevated case set is known to be dominated by trailing stratiform (TS) precipitation (Table 2.8). Such a precipitation configuration is known to favor a higher number of positive flashes, as the depth of the cloud decreases (Engholm et al. 1990), with the upper portion of most cumulonimbi known to be dominated by positive charge.

Table 2.8. Classification of thunderstorm complexes for all cases. TS indicates trailing stratiform; PS indicates parallel stratiform; LS indicates leading stratiform; and NL indicates the system was non-linear and was not classified.

\begin{tabular}{|l|c|c|}
\hline \multicolumn{1}{|c|}{ Convection Type } & Convection Date & MCS Classification \\
\hline Elevated Convection & $5 / 6 / 2007$ & TS \\
\hline Surface Based Convection & $5 / 24 / 2007$ & NL \\
\hline Elevated Convection & $6 / 2 / 2007$ & TS \\
\hline Surface Based Convection & $6 / 18 / 2007$ & PS \\
\hline Elevated Convection & $8 / 23 / 2007$ & TS \\
\hline Surface Based Convection & $8 / 7 / 2007$ & PS \\
\hline Elevated Convection & $6 / 13 / 2008$ & PS \\
\hline Surface Based Convection & $6 / 19 / 2008$ & LS \\
\hline Elevated Convection & $7 / 25 / 2008$ & LS \\
\hline Surface Based Convection & $7 / 22 / 2008$ & TS \\
\hline Elevated Convection & $5 / 12 / 2010$ & TS \\
\hline Surface Based Convection & $5 / 12 / 2010$ & TS \\
\hline Elevated Convection & $7 / 20 / 2010$ & NL \\
\hline Surface Based Convection & $7 / 25 / 2010$ & TS \\
\hline Elevated Convection & $9 / 11 / 2010$ & TS \\
\hline Surface Based Convection & $9 / 15 / 2010$ & \\
\hline
\end{tabular}




\subsection{Conclusions}

This study aims to investigate environmental and observed differences between elevated thunderstorms and surface based thunderstorms that produced heavy rain and sheds light on some of the sensible weather differences between sets of elevated thunderstorms and surface based thunderstorms. Cases were selected only if an elevated and surface based case occurred during a similar timespan and geographic location. The heavy rain area (the area covered by $>50.8 \mathrm{~mm} \cdot$ day -1 of rainfall) was chosen as the crucial area to explore for each of the cases. It should be noted that dangerous CG lightning will occur outside of the heavy rainfall area throughout the MCS regardless of the system being elevated or surface based. The nonparametric Mann-Whitney test was performed on various parameters within the heavy rain area. It was found that the RLR tests, CG flashes per area and extent of the heavy rain area failed to reach the $90 \%$ confidence interval. However, it was shown that CG flashes, CG flashes per hour, positive CG flashes, positive CG flashes per hour and percentage of positive flashes were all higher in the elevated convection dataset. All of these observed parameters passed the $90 \%$ confidence interval indicating that the differences were statistically meaningful. The same was true for elevated thunderstorm cases in regard to maximum and mean rainfall amounts within the heavy rainfall area.

Composites of the mesoscale environment for elevated convection surface based convection were examined and depicted several key differences, particularly in the 850$\mathrm{hPa}$ vector wind field and 700-hPa omega field. The composites support the result that elevated convection produced rain longer and over a larger area which leads to higher rainfall amounts and a longer opportunity for CG lightning strikes to occur. 
Although a low number of cases were used in each dataset, the lightning and rainfall categories had very strong statistical signals associated with them. The results indicate that for the groups of thunderstorms studied, elevated thunderstorm events pose a statistically significantly greater risk of heavy rainfall and have a higher potential for flash flooding than surface based thunderstorms. The results also show that higher frequencies of positive CG lightning flashes were found in the elevated thunderstorm set. These two results are significant as positive lightning flashes and heavy rain are serious threats to life and property.

Acknowledgments: The authors would like to thank the two anonymous reviewers for their time and effort and constructive comments that made this work stronger. This work is supported in part by the National Science Foundation (NSF), Award No. AGS1258358. Any opinions, findings, conclusions or recommendations expressed herein are those of the author(s) and do not necessarily reflect the views of NSF. The lightning data were obtained from the National Lightning Detection Network data via Vaisala. Observed precipitation data were provided by the National Weather Service Advanced Hydrologic Prediction Service. Special thanks go out to Ron Holle who helped obtain the lightning data; to Scott Rochette and Anna Kastman for reading prior drafts of the manuscript; and to Clayton Blogett who helped focus attention to CG lightning events during a remote sensing lecture. A special thank you goes out to Bohumil Svoma and Katherine Wunsch for their contributions. 


\subsection{References}

Anip, M.H.M.; Market, P.S. Dominant factors influencing precipitation efficiency in a continental mid-latitude location. Tellus A 2007, 59, 122-126. [Google Scholar] [CrossRef]

Ashley, S.; Ashley, W. Flood fatalities in the United States. J. Appl. Meteorol. Climatol. 2008, 47, 806-818. [Google Scholar] [CrossRef]

Battan, L.J. Some factors governing precipitation and lightning from convective clouds. $J$. Atmos. Sci. 1965, 22, 79-84. [Google Scholar] [CrossRef]

Brown, R.A. A compositing approach for preserving significant features in atmospheric profiles. Mon. Weather Rev.1993, 121, 874-880. [Google Scholar] [CrossRef]

Colman, B.R. Thunderstorms above frontal surfaces in environments without positive CAPE. Part I: A climatology. Mon. Weather Rev. 1990a, 118, 1103-1122. [Google Scholar] [CrossRef]

Colman, B.R. Thunderstorms above frontal surfaces in environments without positive CAPE. Part II: Organization and instability mechanisms. Mon. Weather Rev. 1990b, 118, 1123-1144. [Google Scholar] [CrossRef]

Cooper, M.A.; Andrews, C.J.; Holle, R.L. Lightning injuries. In Wilderness Medicine; Mosby: Maryland Heights, MO, USA, 2007; pp. 67-108. [Google Scholar]

Corfidi, S.F. Cold Pool and MCS Propagation: Forecasting the Motion of DownwindDeveloping MCSs. Weather Forecast. 2003, 18, 997-1017. [Google Scholar] [CrossRef]

Earls, J.; Dixon, B. Spatial Interpolation of Rainfall Data Using ArcGIS: A Comparative Study. ESRI Professional Papers. 2007. Available online: http://www.oalib.com/references/8952057 (accessed on 9 February 2017).

Earth Systems Research Laboratory's (ESRL) 20th Century Reanalysis Tool. Available online: http://www.esrl.noaa.gov/psd/data/composites/subdaily_20thc/(accessed on 10 October 2016).

Engholm, C.D.; Williams, E.R.; Dole, R.M. Meteorological and electrical conditions associated with positive cloud-to-ground lightning. Mon. Weather Rev. 1990, 118, 470487. [Google Scholar] [CrossRef]

Fuquay, D.M. Positive cloud-to-ground lightning in summer thunderstorms. J. Geophy. Res. 1982, 87, 7131-7140. [Google Scholar] [CrossRef]

Grant, B.N. Elevated cold-sector severe thunderstorms: A preliminary study. Natl. Weather Dig. 1995, 19, 25-31. [Google Scholar] 
Gungle, B.; Krider, P. Cloud-to-ground lightning and surface rainfall in warm-season Florida thunderstorms. J. Geophys. Res. 2006, 111, D19203. [Google Scholar] [CrossRef]

Holle, R.L.; Watson, A.I.; López, R.E.; MacGorman, D.R.; Otto, W.D. The life cycle of lightning and severe weather in a 3-4 June 1985 PRE-STORM mesoscale convective system. Mon. Weather Rev. 1994, 122, 1798-1808. [Google Scholar] [CrossRef]

Holle, R.L.; López, R.E.; Navarro, B.C. Deaths, injuries, and damages from lightning in the United States in the 1890s in Comparison with the 1990s. J. Appl. Meteorol. 2005, 44, 1563-1573. [Google Scholar] [CrossRef]

Lupo, A.R.; Kelsey, E.P.; Weitlich, D.K.; Davis, N.A.; Market, P.S. Using the monthly classification of global SSTs and $500 \mathrm{hPa}$ height anomalies to predict temperature and precipitation regimes one to two seasons in advance for the mid-Mississippi region. Nat. Wea. Dig. 2008, 32, 11-33. [Google Scholar]

Market, P.S.; Oravetz, A.M.; Gaede, D.; Bookbinder, E.; Lupo, A.R.; Melick, C.J.; Smith, L.L.; Thomas, R.; Redburn, R.; Pettegrew, B.P.; et al. Proximity soundings of thundersnow in the central United States. J. Geophys. Res. 2006, 111, D19. [Google Scholar] [CrossRef]

McCoy, L.P. Analysis of Heavy-Rain-Producing Elevated Thunderstorms in the MO-KSOK Region of the United States. Master's Thesis, University of Missouri, Columbia, MO, USA, 17 May 2014. [Google Scholar]

Moore, J.T.; Czarnetzki, C.A.; Market, P.S. Heavy precipitation associated with elevated thunderstorms formed in a convectively unstable layer aloft. Meteorol. Appl. 1998, 5, 373384. [Google Scholar] [CrossRef]

Moore, J.T.; Glass, F.H.; Graves, C.E.; Rochette, S.M.; Singer, M.J. The environment of warm-season elevated thunderstorms associated with heavy rainfall over the Central United States. Weather Forecast. 2003, 18, 861-878. [Google Scholar] [CrossRef]

National Weather Service(USA).Available online: http://www.nws.noaa.gov/os/hazstats.shtml (accessed on 3 January 2017).

Newberry, R.G.; Lupo, A.R.; Jensen, A.D.; Rodriges- Zalypinis, R.A. An Analysis of the Spring-to-Summer Transition in the West Central Plains for Application to Long Range Forecasting. Atmos. Clim. Sci. 2016, 6, 375-393. [Google Scholar] [CrossRef]

Orlanski, I. A rational subdivision of scales for atmospheric processes. Bull. Am. Meteorol. Soc. 1975, 56, 527-530. [Google Scholar]

Parker, M.D.; Johnson, R.H. Organizational modes of midlatitude mesoscale convective systems. Mon. Weather Rev.2000, 128, 3413-3436. [Google Scholar] [CrossRef] 
Peterson, W.A.; Rutledge, S.A. On the relationship between cloud-to-ground lightning and convective rainfall. J. Geophys. Res. 1998, 103, 14025-14040. [Google Scholar] [CrossRef]

Rakov, V.A. A review of positive and bipolar lightning discharges. Bull. Am. Meteorol. Soc. 2003, 84, 767-776. [Google Scholar] [CrossRef]

Reap, R.M.; MacGorman, D.R. Cloud-to-ground lightning: Climatological characteristics and relationships to model fields, radar observations, and severe local storms. Mon. Weather Rev. 1989, 117, 518-535. [Google Scholar] [CrossRef]

Rochette, S.M.; Moore, J.T. Initiation of an elevated mesoscale convective system associated with heavy rainfall. Weather Forecast. 1996, 11, 443-457. [Google Scholar] [CrossRef]

Rutledge, S.A.; MacGorman, D.R. Cloud-to-ground lightning activity in the 10-11 June 1985 mesoscale convective system observed during the Oklahoma-Kansas PRE-STORM Project. Mon. Weather Rev. 1988, 116, 1393-1408. [Google Scholar] [CrossRef]

Soriano, L.R.; de Pablo, F.; Díez, E.G. Relationship between convective precipitation and cloud-to-ground lightning in the Iberian Peninsula. Mon. Weather Rev. 2001, 129, 29983003. [Google Scholar] [CrossRef]

Tapia, A.; Smith, J.A.; Dixon, M. Estimation of convective rainfall from lightning observations. J. Appl. Meteorol. 1998, 37, 1497-1509. [Google Scholar] [CrossRef]

Uman, M.A. The Lightning Discharge; Academic Press: Cambridge, MA, USA, 1987. [Google Scholar]

University of Missouri Blocking Archive: Global Climate Change Group. Available online: http://weather.missouri.edu/gcc/blocknh.pdf (accessed on 10 December 2016).

Wiedenmann, J.M.; Lupo, A.R.; Mokhov, I.I.; Tikhonova, E.A. The climatology of blocking anticyclones for the Northern and Southern Hemispheres: Block intensity as a diagnostic. J. Clim. 2002, 15, 3459-3473. [Google Scholar] [CrossRef]

Xu, W.; Adler, R.F.; Wang, N. Improving geostationary satellite rainfall estimates using lightning observations: Underlying lightning-rainfall-cloud relationships. J. Appl. Meteorol. Climatol. 2013, 52, 213-229. [Google Scholar] [CrossRef] 


\section{Chapter 3. An Example of Synergistic Coupling of Upper and Lower- Level Jets Associated with Flash Flooding}

Kastman, J. S., Mccoy, L. D., Market, P. S., \& Fox, N. I. (2017). An example of synergistic coupling of upper-and lower-level jets associated with flash flooding. Meteorological Applications, 24(2), 206-210.

\subsection{Abstract:}

A brief case study is provided of a striking example of vertical and horizontal jet coupling associated with upper jet-level as well as upper- and lower-level jet coupling; these jet interactions also supported the development of elevated convection and led to flash flooding. The case constitutes a faithful, real-world verification of what has been suggested in idealized conceptual models by several investigators for similar situations of elevated convection with excessive precipitation.

\subsection{Introduction}

Synergistic interactions between coupled upper-level jet (ULJ) and low-level jet (LLJ) streaks and regions of diabatic heating are known to enhance intense upward motions before and during rapid cyclogenesis (e.g. Uccelini et al. 1987; Alpert et al. 1995), interactions which can result in excessive precipitation rates and accumulations (see also Hakim and Uccellini, 1992). Flow through a linear ULJ establishes a thermally direct (indirect) transverse circulation in its entrance (exit) region (e.g., Uccellini 1976; Uccellini and Johnson, 1979), and in certain cases the transverse ageostrophic circulations around a ULJ can enhance pre-existing circulations closer to the surface, manifesting in an enhanced low level flow field characterized by a low level jet (LLJ). Additionally, elevated convection is a known producer of flash flooding (e.g. Grant,1995; Rochette et al., 1999; Markowski and Richardson, 2010). On 11 July 2006, elevated convection (north of a decaying stationary boundary) associated with a coupled upper level and low level jet 
system (similar to that described by Keyser and Johnson, 1984) occurred over southern Missouri, resulting in over $100 \mathrm{~mm}$ of rain in 6 hours and subsequent flash flooding (maximum amount denoted by the black star in the figures below). This case provides important supporting evidence because it is a striking real-world example of how the ingredients that produce excessive rainfall and contribute to an extreme flash floods (suggested by Moore et al, 2003) are brought together in a synergistic manner within a vertically coupled jet system.

Coupled vertical and horizontal jet conditions were short lived, yet excessive rainfall occurred. Though this upper jet streak featured a compact equatorward jet core, vertical velocities were generated in its divergent right-entrance region. In keeping with suggested conceptual models of similar rain events (Augustine and Caracena, 1994; Moore et al., 2003), the pre-established direct thermal circulation associated with the ULJ encouraged rising parcels to continue moving vertically. Elevated instability enhanced the magnitude of this vertical circulation through the release of latent heat in deep cumulonimbus columns (Keyser and Johnson 1984). The convergence along (and to the left of) the exit region of the LLJ was responsible for aiding in convergence and the lifting of parcels into the ageostrophic thermally direct circulation (e.g., Means 1952; Palmen and Newton, 1969; Uccellini and Johnson, 1979).

Indeed, the exit region of the LLJ has been identified as an area where convergence leads to vertical accelerations and at times excessive precipitation from elevated convection (Colman 1990; Augustine and Caracena, 1994; Moore et al. 2003). This case exemplifies that phenomenon and is a well-defined case of the LLJ coupling with the ULJ, as made evident by the direct thermal circulation. This example supports the Moore model and 
shows the LLJ-influenced isentropic ascent participating in the transverse ageostrophic circulation. The meso- $\alpha$ conditions and interactions will be discussed and the analysis of the event will culminate in the discussion of the cross-sections.

This cross section example was discovered in the process of other, parallel research aimed at developing plan view and cross section composites parameters conducive to heavy rainfall events with elevated convection (McCoy, 2014). The dataset used for that study (and the current paper) was the North American Regional Reanalysis (NARR; Mesinger et al., 2006). The NARR is a dynamically consistent atmospheric and surface hydrology dataset, with a 32-km grid spacing, that is created by assimilating surface and upper air observations from multiple sources. The time period for this dataset is 1979 to the present, with eight grids created each day for the three hourly synoptic times.

\subsection{Discussion}

Upper level divergence developed rapidly between 0000 UTC 11 July 2006 (Fig. 3.1a) and 0300 UTC on the same date (Fig. 3.1b) as a horizontally and vertically compact, $25 \mathrm{~ms}^{-1}$ jet streak formed over northern Missouri just to the west of a stronger jet streak located over the Great Lakes region; this development is in keeping with the predictions of Uccellini and Kocin (1987). Concurrently the LLJ was developing from Texas through Oklahoma and western Arkansas (Fig. 3.2a). The exit region of this LLJ feature was oriented in the direction of the 250-hPa jet coupling region (Keyser and Johnson, 1984), and also toward south central Missouri, where the heaviest rainfall occurred. Divergence aloft is maximized in the region between right entrance region of the ULJ and the exit region of the LLJ (Fig. 3.1a-b, 3.2a-b) 
By 0300 UTC 11 July 2006 the LLJ strengthened and built into southern Illinois and Kentucky (Fig. 3.2b) while the ULJ jet streak remained nearly stationary. This created an environment that was favorable for the formation of heavy precipitation from elevated convection. As the LLJ intensified over the region, additional moisture was transported into the environment, increasing precipitable water values to exceed $50 \mathrm{~mm}$ at 0000 UTC (Fig. 3.3a), and still at 0300 UTC (Fig. 3.3b), over the area which reported over $100 \mathrm{~mm}$ of rainfall. These values were well above the 75 th percentile of the climatological normal for July (Bunkers and Lincoln, 2014). These figures combine to depict the necessary ingredients (moisture, ULJ and LLJ placement) for heavy rainfall associated with elevated convection as described by Moore (2003).

Cross sectional analyses shown in Figs. 3.4a and 3.4b, reveal that a well-developed ageostrophic thermal circulation intensified beneath the divergence maximum in the right entrance region of the upper level jet streak. As a result, upward vertical motions were pronounced in the $850-\mathrm{hPa}$ to $200-\mathrm{hPa}$ layer. The end result of this case was that the LLJ fed parcels into the well-developed ageostrophic thermally direct circulation. This caused parcels to achieve strong vertical velocities above $850-\mathrm{hPa}$ and to feed convective towers. Evidence for this is best seen in the $\theta_{e}$ pattern (especially the bifurcated $338 \mathrm{~K}$ contour, shown in red and known informally as the 'X') at 0300 UTC (Fig. 3.4b). This signature depicts significant elevated potential instability, but also a region that was potentially neutral where the strongest vertical motions are diagnosed. Cross sections indicate the window for precipitation was limited to less than 6 hours, as the conditions deteriorated completely by 0600 UTC. The combination of these factors lead to heavy rain (in excess of $100 \mathrm{~mm}$ ) and flash flooding. 
Between 00 UTC and 03 UTC 11 July 2006, a potential vorticity (PV) anomaly is depicted in the 700-500 $\mathrm{hPa}$ layer. This $\mathrm{PV}$ anomaly was mostly due to diabatic heating. PV there more than doubles in that layer (Fig. 3.5a,b); meanwhile, plan view plots of 700-500-hPa PV (not shown) hovered around 0.5 PVU, are more or less uniform, and revealed no coherent advection pattern. The same was true for the higher (500-300 hPa) PV anomaly that developed above and south of the one aforementioned. However, the lower, more northern PV anomaly appeared to be the more dynamically important of the two; that PV anomaly appeared to be propagating downward, and there was a noticeable trough in the isentrope pattern (340-348-K layer). These behaviors are consistent with our understanding of diabatically-induced PV anomalies (e.g. Bluestein, 1993).

This event featured mechanisms for encouraging upward vertical velocity including coupling of upper level jets streaks (e.g., Uccelini and Kocin, 1987), and the participation of the low level jet in the thermally direct circulation associated with the upper level jet streak (e.g., Keyser and Johnson, 1984), both in the presence of an ample moisture and a weakly potentially unstable atmosphere (Moore et al., 2003). Cross sectional analysis clearly reveals that the low-level jet and upper level jet streak coupled, allowing for enhanced vertical accelerations. Additionally, a $700-500 \mathrm{hPa} \mathrm{PV}$ anomaly formed as a result of diabatic heating caused by convection. This is a striking example of upper level and lower level jets synergistically impacting the weather. Moreover, this case exemplifies meso- $\alpha$ scale phenomena coming together during a brief window, yet having a dramatic impact. This case study highlights the impacts of elevated convection that resulted in over $100 \mathrm{~mm}$ of rainfall and observed flash flooding. 


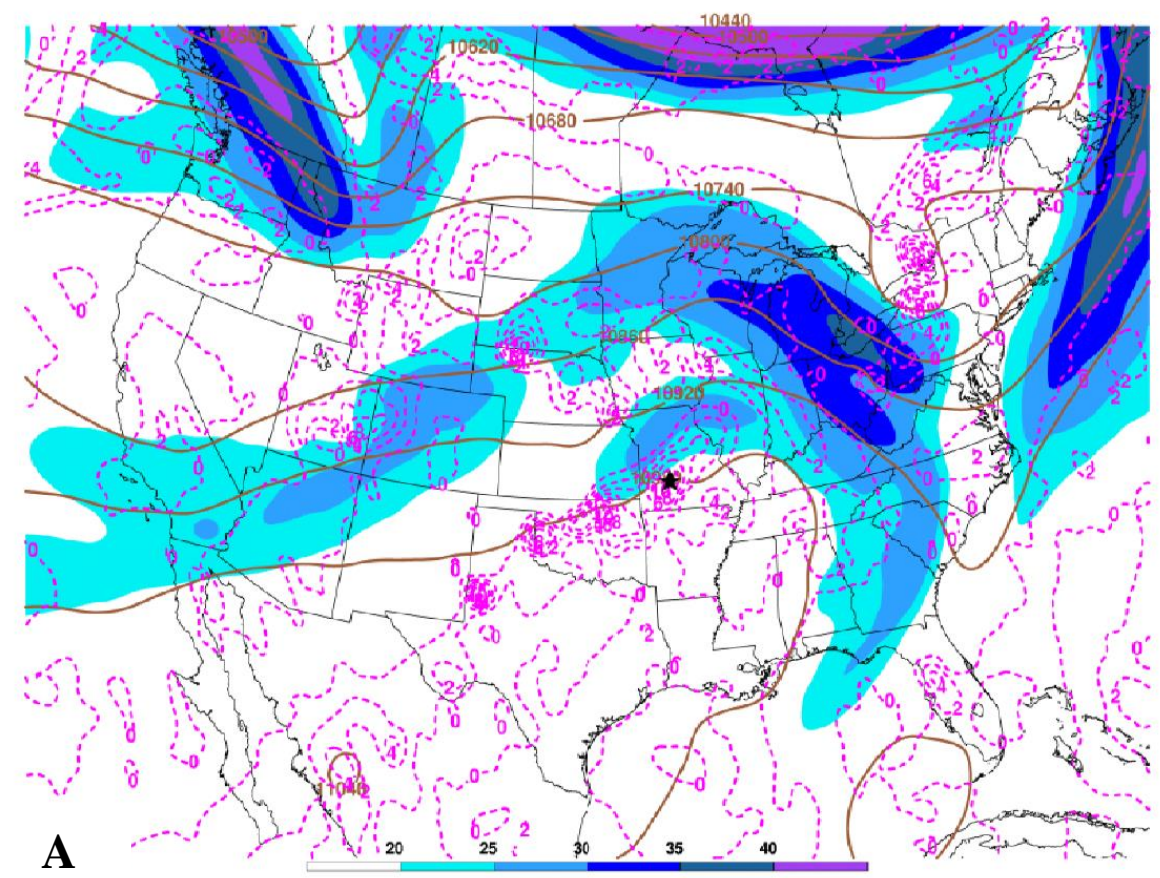

$00 \mathrm{Z} 11$ July 2006 Case: 250 -hPa Heights [m], Wind [ms-1], and Divergence [1 $10^{\star *}-5 \mathrm{~s}-1$ ]

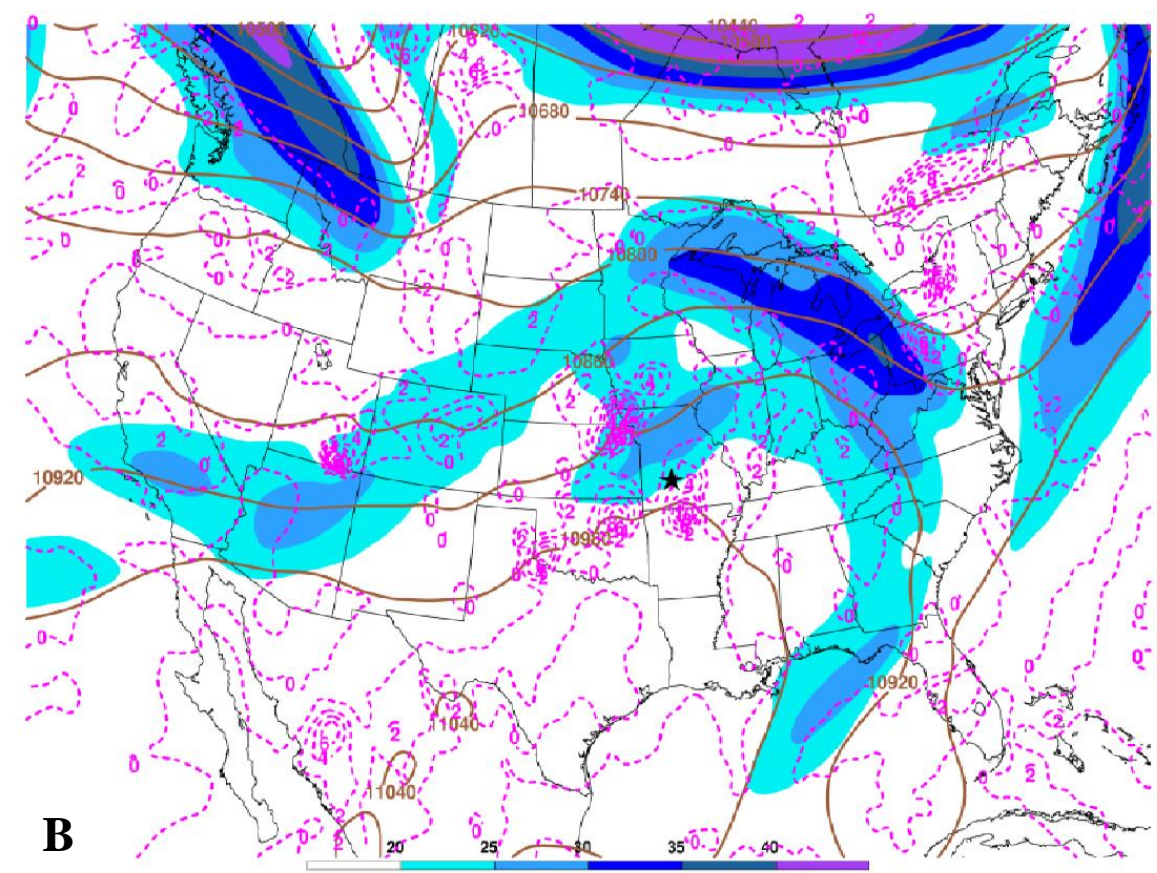

03211 July 2006 Case: 250-hPa Heights [m], Wind [ms-1], and Divergence [10"* -5 s-1]

Figure 3.1. a) 250-hPa geopotential heights (every 120 gpm; solid, brown lines), wind speed (every $5 \mathrm{~ms}^{-1}$, starting at $20 \mathrm{~ms}^{-1}$; shaded) and divergence (every $2 \times 10^{-5} \mathrm{~s}^{-1}$; pink dashes) at 0000 UTC 11 July 2006. b) As in a) but at 0300 UTC 11 July 2006. Black star (located in Missouri) in Figures 1a-b represent location of heaviest rainfall. 

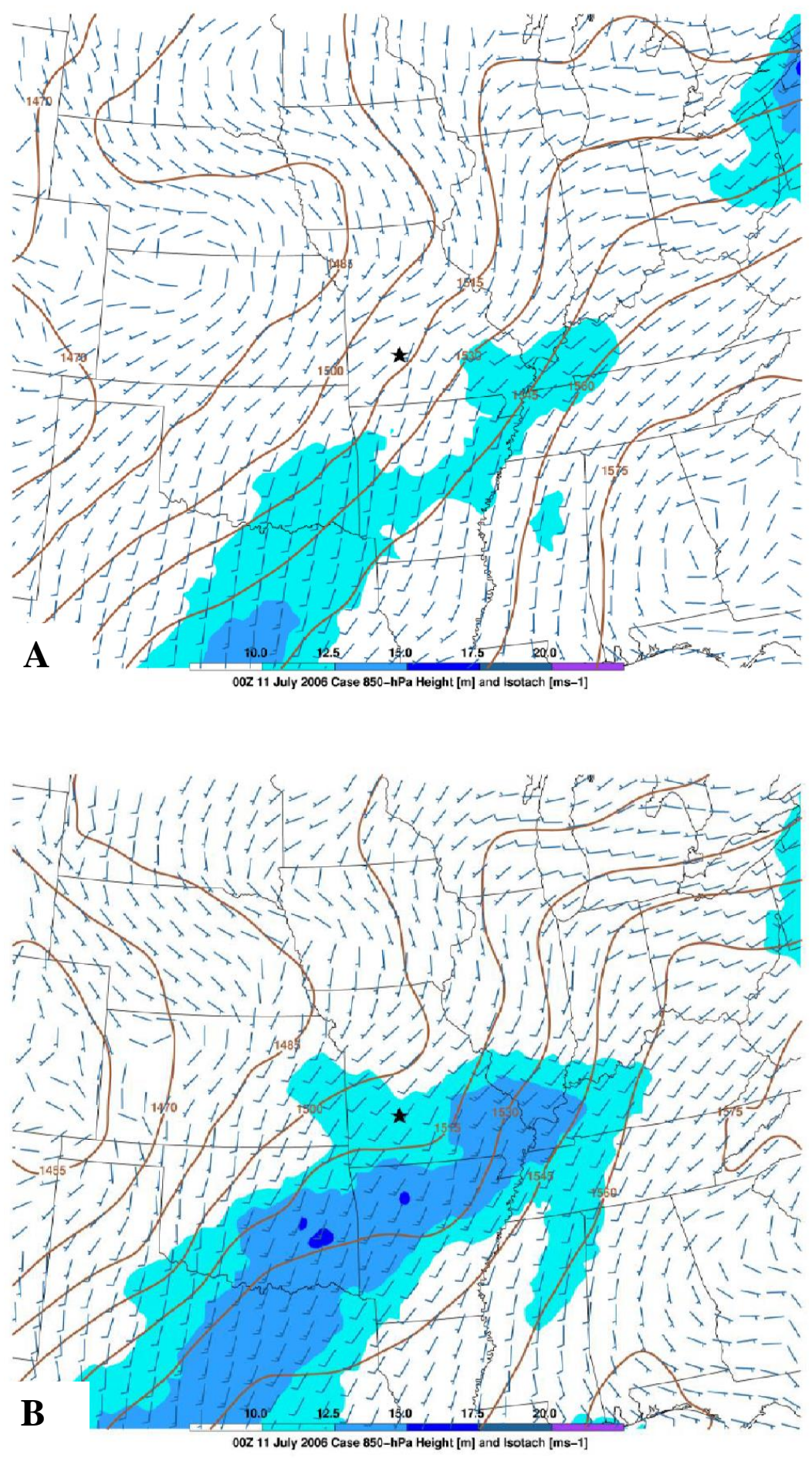

Figure 3.2. a) 850 -hPa geopotential heights, (every $15 \mathrm{gpm}$; solid, black lines), wind barbs ( $\mathrm{ms}^{-1}$, blue barbs) and isotachs wind speed (every $2.5 \mathrm{~ms}^{-1}$, starting at $10 \mathrm{~ms}^{-1}$; shaded) at 0000 UTC 11 July 2006. b) As in a) but at 0300 UTC 11 July 2006. Black stars (located within Missouri) in Figures 1a-b represent location of heaviest rainfall. 

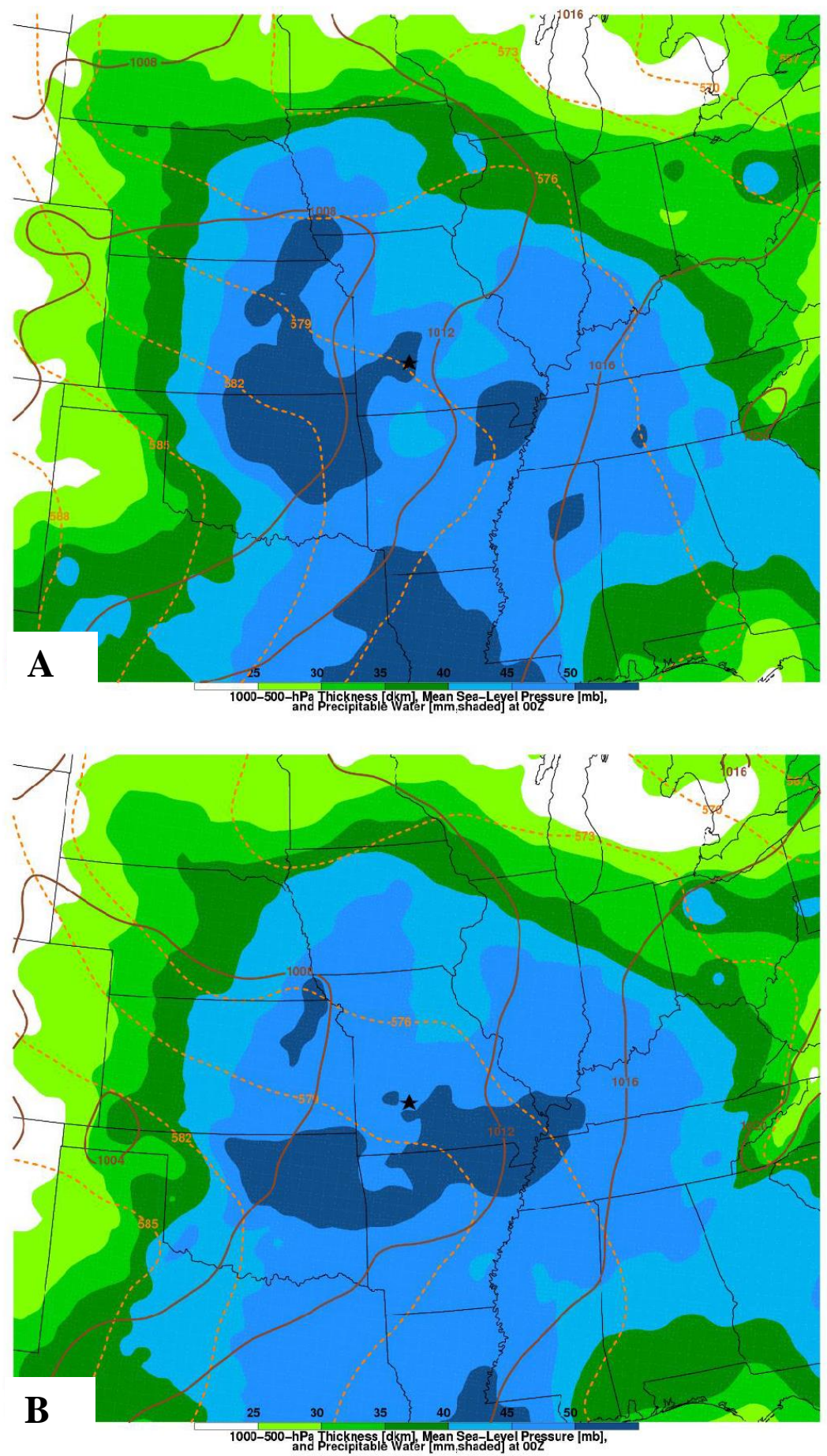

Figure 3.3. a) Mean sea-level pressure (every $2 \mathrm{hPa}$; solid, brown), 1000-500-hPa thickness (every $30 \mathrm{gpm}$, dashed), and precipitable water (every $5 \mathrm{~mm}$, starting at $25 \mathrm{~mm}$, shaded). b) As in a) but at 0300 UTC 11 July 2006. Black stars (located within Missouri) in Figures 1a-b represent location of heaviest rainfall. 

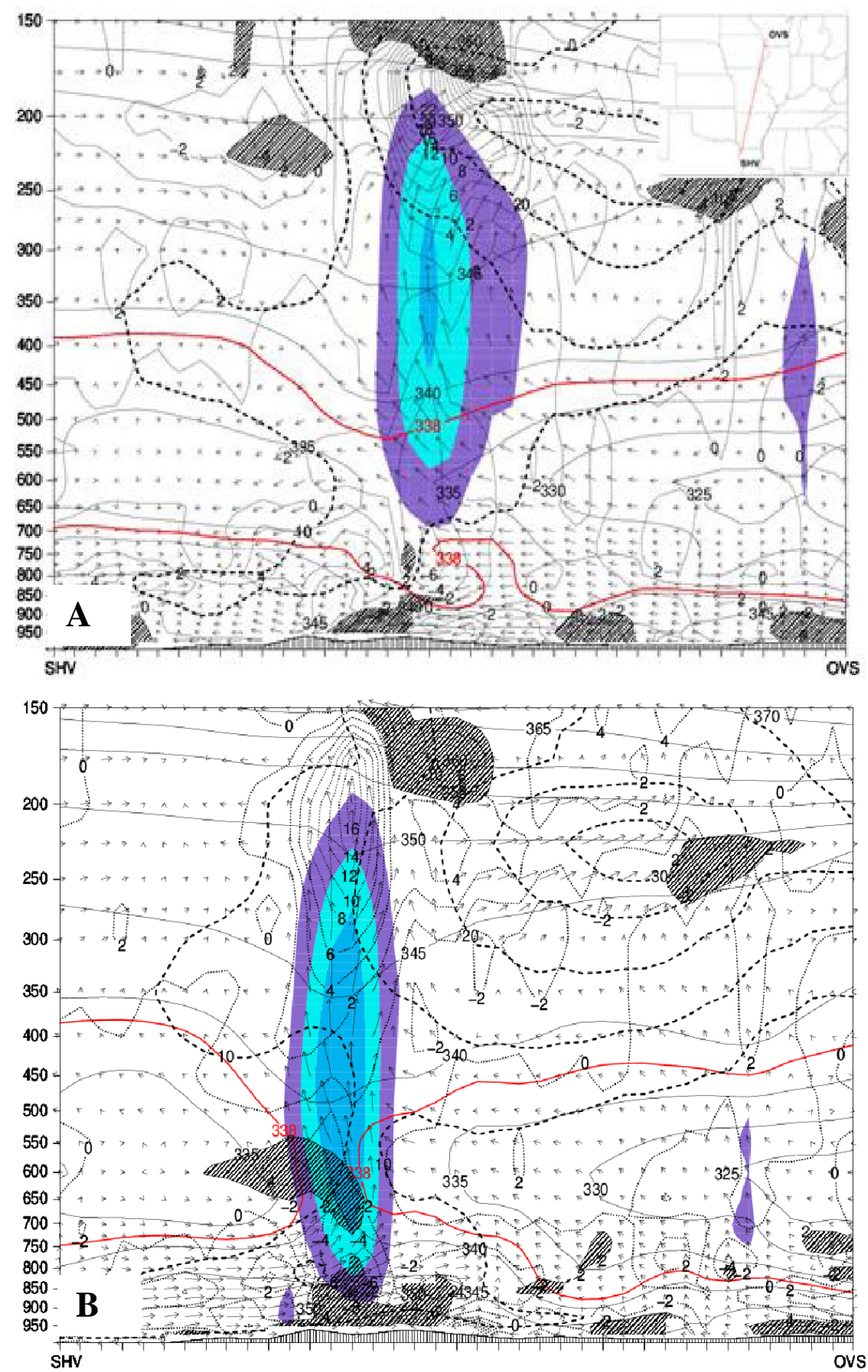

Figure 3.4. Cross sections from Shreveport, Louisiana (SHV), to Boscobel, Wisconsin (OVS), taken through the event on 11 July 2006 at a) 0000 UTC and b) 0300 UTC. Cross section path (red line), and end points, are visible in the map in the upper right hand corner of a). Each figure features $\theta_{e}$ (every $5 \mathrm{~K}$; solid lines) with $338 \mathrm{~K}$ highlighted in red, scaled ageosotrophic circulation vectors (arrows), isotachs (every $10 \mathrm{~ms}^{-1}$; heavy dashes), divergence (every $4 \times 10^{-5} \mathrm{~s}^{-1}$; dotted), upward 


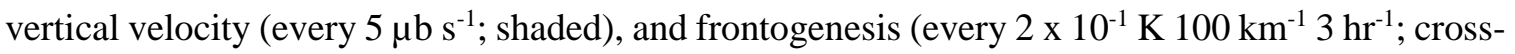
hatched).
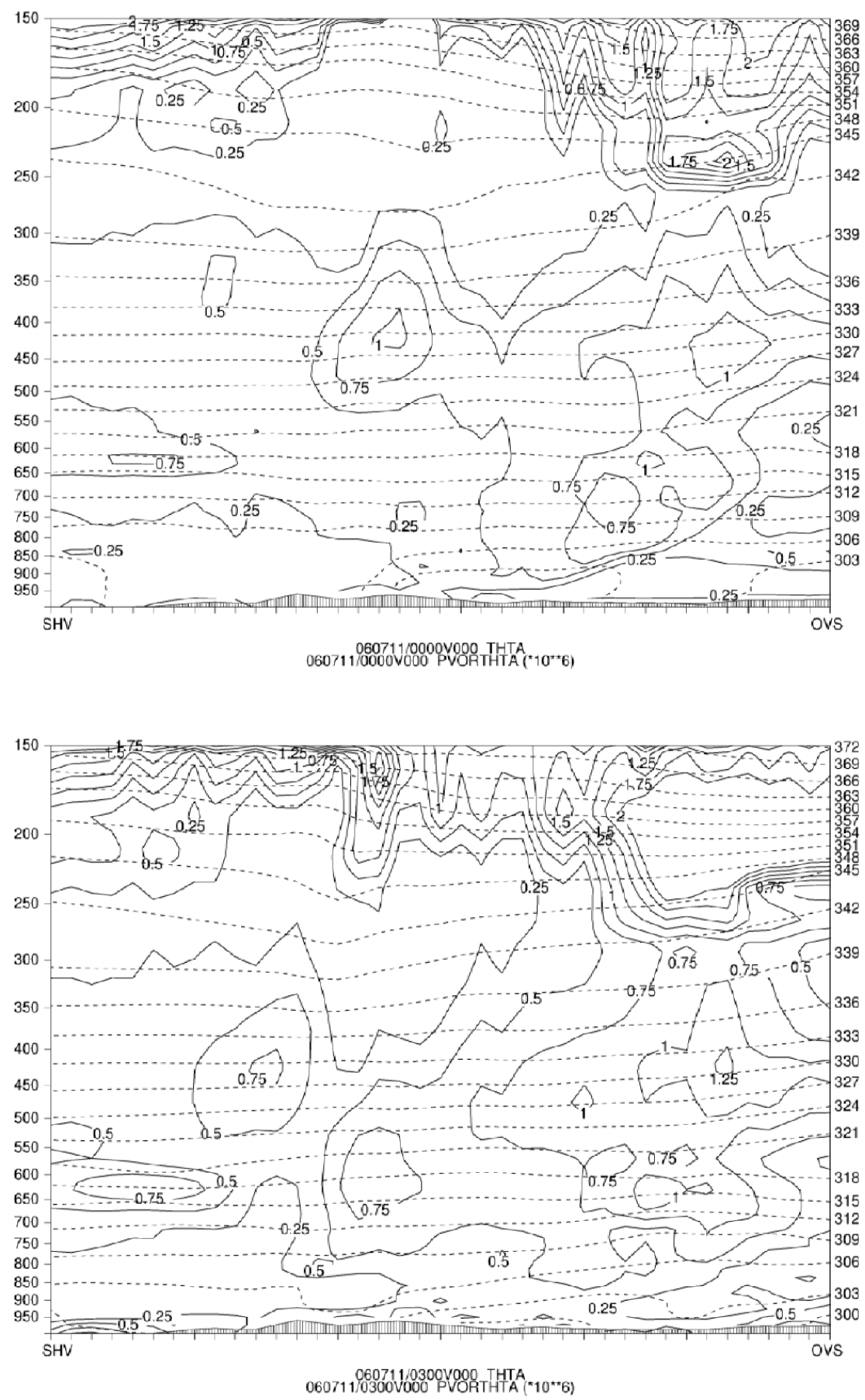

Figure 3.5. Cross sections from Shreveport, Louisiana (SHV), to Boscobel, Wisconsin (OVS), taken through the event on 11 July 2006 at a) 0000 UTC and b) 0300 UTC. Each figure features $\theta_{e}$ (every $3 \mathrm{~K}$; dashed lines) and potential vorticity (every $0.25 \times 10^{-6} \mathrm{~m} \mathrm{~Pa} \mathrm{~K}^{-1} \mathrm{~s}^{-3}$; solid lines). 


\subsection{Summary}

On 11 July 2006 elevated convection caused over $100 \mathrm{~mm}$ of rain to occur over southern Missouri (maximum amount located denoted by the black stars in the figures). The intensification of the LLJ caused parcels to ascend along isentropic surfaces into a well-developed ageostrophic thermally direct circulation that had developed in response to a $250-\mathrm{hPa}$ jet streak and shortwave. With the addition of low-level convergence along the exit region of an amplifying LLJ, vertical velocities were enhanced in this portion of the direct thermal circulation. These strong upward vertical velocities aided in the development of elevated convective towers above the inversion and the production of heavy rainfall. This event provides a nearly textbook example of LLJ interaction with a thermally direct ageostrophic circulation above a frontal inversion, as envisioned by prior investigators. The event is also one of note because it featured upper and lower-level jet streaks of seemingly modest sizes that coupled and still managed to produce heavy rainfall.

Acknowledgments. A special thank you goes out to Dr. Louis Uccellini for his contributions to the paper. This work is supported in part by the National Science Foundation (NSF), Award No. AGS-1258358. Any opinions, findings, conclusions or recommendations expressed herein are those of the author(s) and do not necessarily reflect the views of NSF. Our thanks go to Micheal Simpson, who helped with the cross sections. 


\subsection{REFERENCES}

Alpert P, Tsidulko M, and Stein U, 1995: Can Sensitivity Studies Yield Absolute Comparisons for the Effects of Several Processes?. J. Atmos. Sci.,52, 597-601. doi: http://dx.doi.org/10.1175/1520-0469(1995)052<0597:CSSYAC>2.0.CO;2

Augustine JA, and Caracena F. 1994. Lower-tropospheric precursors to nocturnal MCS development over the central United States. Wea. Forecasting 9: 116-135.

Bluestein, HB., 1993: Observations and Theory of Weather Systems. Vol. 2, SynopticDynamic Meteorology in Midlatitudes, Oxford University Press, 594 pp

Bunkers M, and Lincoln S. 2014. Upper-Air Climatology Plots. [Accessed online at http://www.crh.noaa.gov/unr/?n=pw ]

Colman RC. 1990a. Thunderstorms above frontal surfaces in environments without positive CAPE. Part I: A climatology. Mon. Wea. Rev. 118: 1103-1121.

Grant BN. 1995. Elevated cold-sector severe thunderstorms: A preliminary study. Natl. Wea. Dig. 19(4): 25-31.

Hakim GJ, and Uccellini LW, 1992: Diagnosing Coupled Jet-Streak Circulations for a Northern Plains Snow Band from the Operational Nested-Grid Model. Wea.

Forecasting, 7, 26-48.

doi: http://dx.doi.org/10.1175/1520-0434(1992)007<0026:DCJSCF>2.0.CO;2

Keyser DA, and Johnson DR, 1984: Effects of Diabatic Heating on the Ageostrophic Circulation of an Upper Tropospheric Jet Streak.Mon. Wea. Rev., 112, 1709-1724. doi: http://dx.doi.org/10.1175/1520-

0493(1984)112<1709:EODHOT>2.0.CO;2

Markowski P, and Richardson Y. 2010. Mesoscale Meteorology in Midlatitudes. John Wiley and Sons, 407 pp. Means LL. 1952. On thunderstorm forecasting in the central United States. Mon. Wea. Rev. 80: 165-189.

McCoy, L.P., 2014: Analysis of Heavy-Rain-Producing Elevated Thunderstorms in the MO-KS-OK Region of the United States. M.S. Thesis, University of Missouri, 203 pp.

Mesinger F, and Coauthors. 2006. North American Regional Reanalysis. Bull. Amer. Meteor. Soc. 87: 343-360.

Moore JT, Glass FH, Graves CE, Rochette SM, Singer M. 2003. The environment of warmseason elevated thunderstorms associated with heavy rainfall over the Central United States. Wea. Forecasting 18: 861-878.

Palmen E, and Newton CW. 1969. Atmospheric Circulation Systems. Their Structural and 
Physical Interpretation. 155 Academic Press, New York, 606 pp.

Rochette SM, Moore JT, Market PS. 1999. The importance of parcel choice in elevated CAPE computations. Nat. Wea. Dig. 23(4): 20-32.

Uccellini LW, Ralph A. Petersen, Paul J. Kocin, Keith F. Brill, and James J. Tuccillo, 1987: Synergistic Interactions between an Upper-Level Jet Streak and Diabatic Processes that Influence the Development of a Low-Level Jet and a Secondary Coastal Cyclone. Mon. Wea. Rev., 115, 2227-2261. doi: http://dx.doi.org/10.1175/1520-0493(1987)115<2227:SIBAUL>2.0.CO;2

Uccellini LW, and Kocin PJ, 1987: The Interaction of Jet Streak Circulations during Heavy Snow Events along the East Coast of the United States. Wea. Forecasting, 2, 289308.doi: http://dx.doi.org/10.1175/1520-0434(1987)002<0289:TIOJSC>2.0.CO;2

Uccellini, LW, and D. R. Johnson, 1979: The coupling of upper and lower tropospheric jet streaks and implications for the development of severe convective storms. Mon. Wea. Rev., 107, 682-703.

Uccellini LW, 1976. Operational diagnostic applications of isentropic analysis. Natl. Wea. Dig. 1(1): 4-12. 


\section{Chapter 4. Evaluating elevated convection with the downdraft convective inhibition}

Market, P. S., Rochette, S. M., Shewchuk, J., Difani, R., Kastman, J. S., Henson, C. B., \& Fox, N. I. (2017). Evaluating elevated convection with the downdraft convective inhibition. Atmospheric Science Letters, 18(2), 76-81.

It should be noted that I was not the first author on this published work. However, my advisor has requested the presence of this paper in its entirety as be presented here as I was a contributor to the work.

4.1 Abstract: A method for evaluating the penetration of a stable layer by an elevated convective downdraft is discussed. Some controversy exists on the community's ability to define truly elevated convection from surface-based convection. By comparing the downdraft convective inhibition (DCIN) to the downdraft convective available potential energy (DCAPE), we determine that downdraft penetration potential is progressively enabled as the DCIN is progressively smaller than the DCAPE; inversely as DCIN increases over DCAPE, so does the likelihood of purely elevated convection. Serial vertical soundings and accompanying analyses are provided to support this finding.

\subsection{Introduction}

Elevated convection has long been known as a producer of both significant convective rainfall (Rochette and Moore, 1996) and snowfall (Moore et al., 1998) in the United States as well as Europe (Browning et al., 2012). The unique combination of the shallow thermal boundary and low-level jet (Trier and Parsons, 1993; Augustine and Caracena, 1994), and favorable upper-level flow structure (Moore et al., 2003) often provide for prolonged moisture inflow and a wind profile suitable for slow-moving and/or training echoes. In addition, recent work for the central United States has also shown that elevated convection produces more precipitation as well as more positive 
lightning flashes than geographically and seasonally comparable surface-based convection (Kastman et al., 2015).

For some time, there have been valid concerns about how to assess whether deep moist convection is purely elevated (Corfidi et al., 2008). Recent modeling (Parker, 2008; Nowotarski et al., 2011; Billings and Parker, 2012; Schumacher, 2015) and observational studies (Marsham et al., 2011; Billings and Parker, 2012) suggest that when some amount of near-surface (boundary-layer-based) convective available potential energy (CAPE) is available, despite much higher amounts of elevated or most unstable CAPE, there is often still some degree of boundary-layer air contributing to the convection. Based on these studies, it appears safe to conclude that if some amount of near-surface CAPE is available, even with significant convective inhibition (CIN) in the profile (Parker, 2008; Schumacher, 2015), then the convection is likely surface-based to some degree. That is, not to say that convection might not be dominated by elevated convection, which did seem to be the case in the parcel tracer results of Nowotarski et al. (2011) and Schumacher (2015). But, given that elevated convection is defined by not having any surface parcel influence (Colman, 1990a, 1990b; Corfidi et al., 2008), it seems only safe to consider convection elevated when no surface-based CAPE is present (Nowotarski et al., 2011). Certainly, convection can be elevated even when near-surface parcels have positive CAPE, as suggested by Nowotarski et al. (2011) in the case that had $1171 \mathrm{~J} \mathrm{~kg}-1$ of surface-based CAPE but no surface parcels were ingested in the tracer results, though this seems to be the exception. Thus, improved methods of assessing whether convection is elevated are needed in situations where there are appreciable amounts of CIN due to a low-level inversion, yet some degree of near-surface CAPE may remain. 
This work examines the downdraft convective available potential energy (DCAPE), and compares it to the sounding's downdraft convective inhibition (DCIN). In much, the same way that one might assess a thunderstorm updraft and the negative area above the equilibrium level to estimate the height of the overshooting top of a cumulonimbus (Djurić, 1994, cf. Fig. 1-1), one may assess a thunderstorm downdraft and compare its DCAPE to its DCIN. We propose that, as the DCIN becomes progressively larger than the DCAPE, it is progressively more difficult for a downdraft to penetrate down toward the surface; the condition where DCIN > DCAPE further confines nearsurface parcels to the subinversion layer.

\subsection{Data and methods}

Our work focuses on determining means by which surface-based parcels may become incorporated into the larger convective circulation above. As such, we examine the DCAPE, and how it can represent the potential for a downdraft to penetrate the nearsurface stable layer. The DCAPE posed for elevated convection is similar to that in Gilmore and Wicker (1998):

$$
D C A P E=g \int_{z_{n b}}^{z_{n}} \frac{\theta_{v}(z)-\theta_{v}{ }^{\prime}(z)}{\theta_{v}(z)} d z
$$

where, $\theta v(z)$ and $\theta v^{\prime}(z)$ are the virtual potential temperatures of the environment and saturated downdraft parcels, respectively (following Doswell and Rasmussen, 1994); $\mathrm{Z}_{\mathrm{n}}$ is the height from which the saturated parcel begins its descent and $\mathrm{Z}_{\mathrm{nb}}$ is the level of neutral buoyancy. The lower bound, $\mathrm{Z}_{\mathrm{nb}}$, is of course the significant change, as we consider here the presence of near-surface layers beneath an inversion that can act to slow/stop a downdraft's descent. DCAPE represents the negative buoyancy of a parcel within the saturated downdraft and has become well established in the meteorological 
community in the last $\sim 20$ years. However, this value has commonly been used in conjunction with studies of surface-based convection, and so it is presumed that the downdraft will travel all the way to the surface, unabated.

With elevated convection, this is not necessarily the case. Indeed, a negative area on a thermodynamic diagram can be represented for the downrushing parcel that becomes warmer than its environment in the near-surface stable layer; we label this quantity the DCIN, and represent it mathematically as:

$D C A P E=g \int_{z_{s f c}}^{z_{n}} \frac{\theta_{v}(z)-\theta_{v}^{\prime}(z)}{\theta_{v}(z)} d z$

where, the values are identical to those for DCAPE, except for the limits of integration, which are now the level of neutral buoyancy Znb above, and the surface of the earth, Zsfc. Graphical examples of DCIN are provided in the ensuing section, using new functionality in the RAOB software. DCAPE and DCIN values are based upon parcels originating from the coldest wet bulb temperature in the lowest $6 \mathrm{~km}$.

Data for these cases came from rawinsonde flights conducted during the summers of 2014 and 2015 as a part of the North American study of elevated convection known as the Program for Research on Elevated Convection with Intense Precipitation (PRECIP, http://weather.missouri.edu/PRECIP/). We also revisit five soundings from a previous study on elevated convection with severe wind reports (Horgan et al., 2007) for comparison purposes.

\subsection{Analysis}


Consecutive soundings are examined for warm season dates in 2014 and 2015 for locations on the North American interior. Both cases of elevated convection occurred in the central United States, over the state of MO specifically.

\subsubsection{Case 1: 2 April 2014}

The first case to be examined occurred on 2 April 2014 over Clinton, MO, USA, north of a slow-moving warm frontal boundary (Figure 4.1). Sounding balloons were released every $2 \mathrm{~h}$ from 0000 UTC to 1200 UTC 2 April 2014. Here, we focus on the flights from 0534 UTC (Figure 4.2(a)), 0753 UTC (Figure 4.2(b)) and 0937 UTC (Figure 4.2(c)).

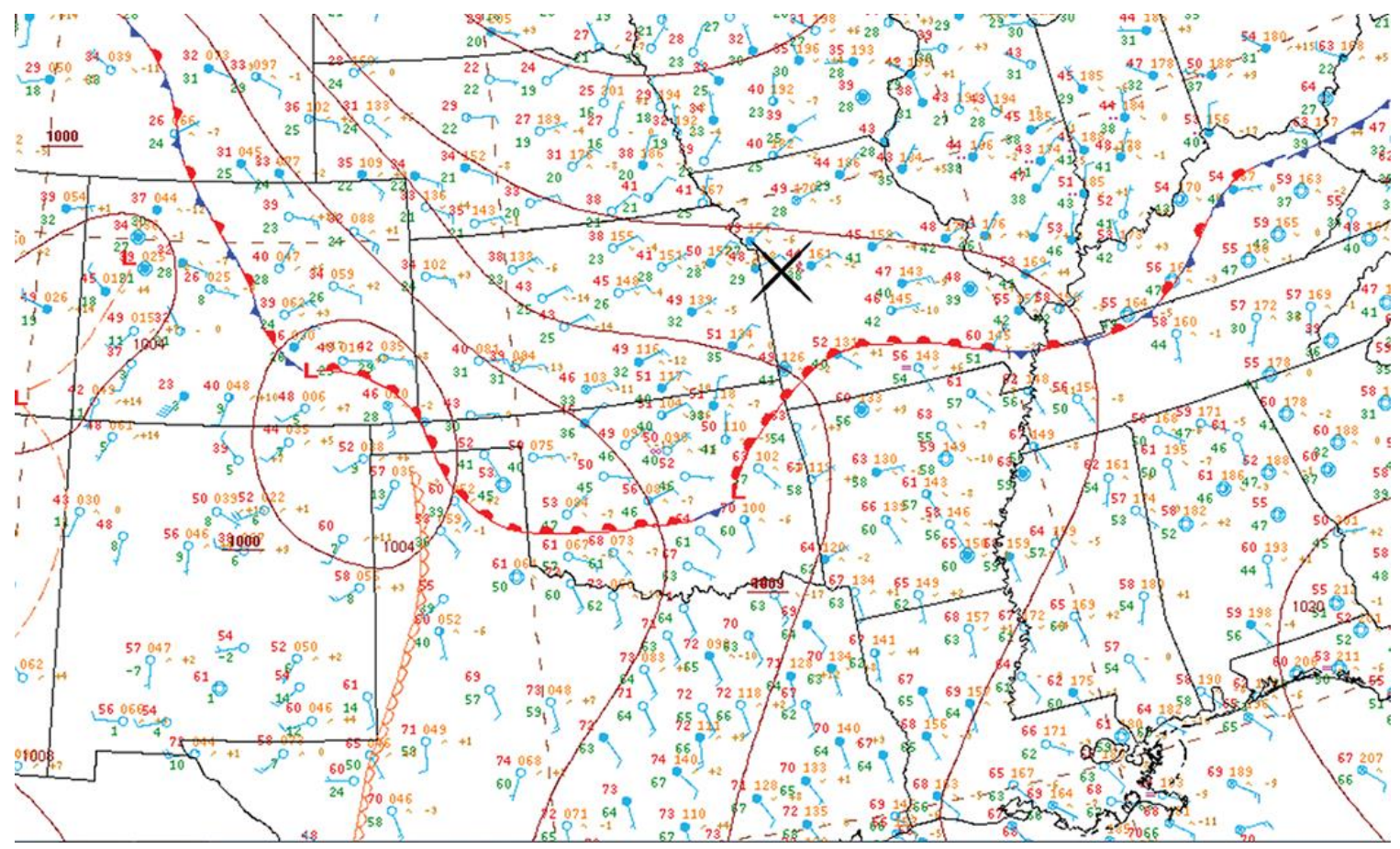

Figure 4.1. Standard surface analysis for the central United States valid at 0600 UTC 2 April 2014 from the United States Weather Service Weather Prediction Center. Bold ' $\mathrm{X}$ ' marks the location of Clinton, MO. 
(a)

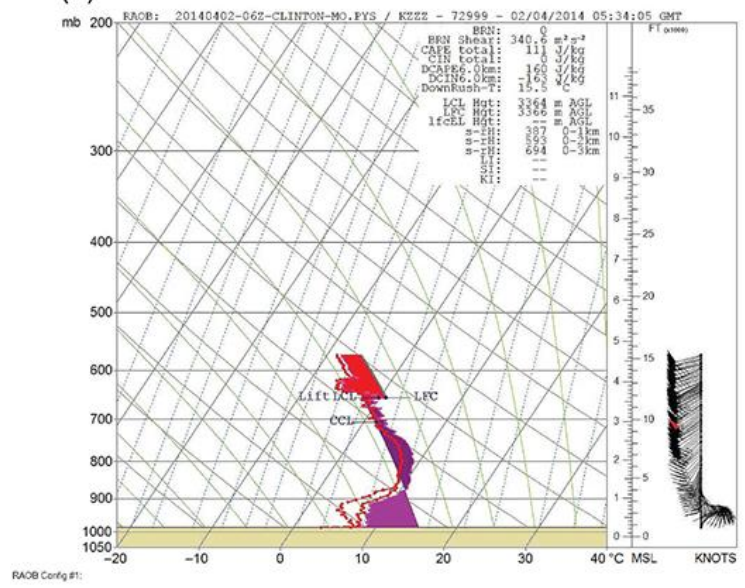

(b)

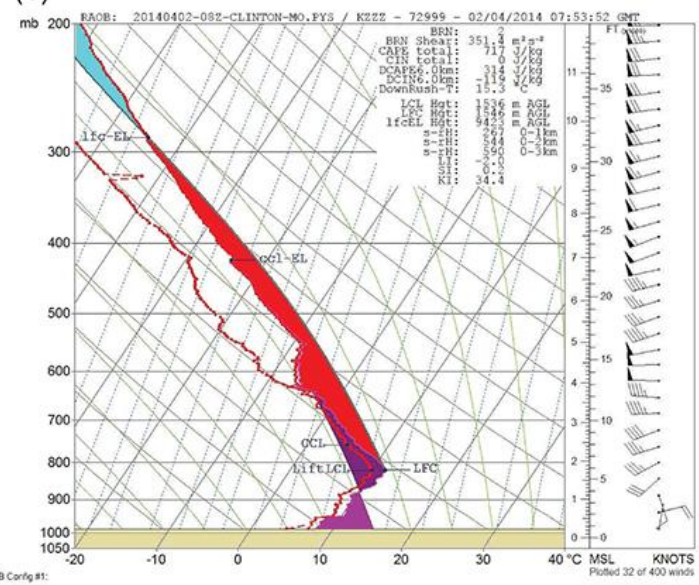

(c)

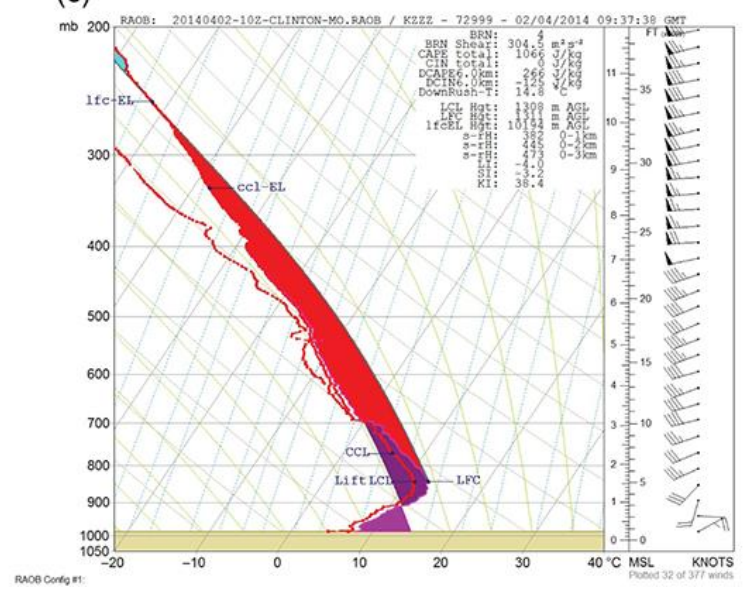

Figure 4.2. Sounding analyses from Clinton, MO, flown on 2 April 2014, and launched at (a) 0534 UTC, (b) 0753 UTC and (c) 0937 UTC. The right and left red traces represent the temperature and dew point temperatures, respectively; the purple trace to the right of the temperature trace is the virtual temperature. The convective available potential energy (CAPE) for the most unstable parcel is shaded in red, convective inhibition (CIN), if any, for that same parcel is shaded in light blue, DCAPE for the coldest wet bulb temperature in the lowest $6 \mathrm{~km}$ is shaded in dark purple, and the DCIN for that same parcel is shaded in a lighter purple; each of these values is calculated with the virtual temperature correction applied.

Convection had just begun in the area by the time of the 0534 UTC launch (Figure 4.2(a)), and the flight terminated early at $\sim 571 \mathrm{hPa}$. Yet this depth was sufficient to provide an estimate of the DCAPE [the upper, darker purple area in Figure 2(a); $160 \mathrm{~J} \mathrm{~kg}-1$ ] as well as the comparable DCIN [the lower, lighter purple area in Figure 2(a); $163 \mathrm{~J} \mathrm{~kg}-1$ ]. Surface winds are examined for gusts above background for both cases 
(Figure 3). A background easterly flow of $\sim 8$ knots was noted at this time, with no gustiness noted at the launch site, or the nearby ( $\sim 6.4 \mathrm{~km}$ east of the launch site) automated surface observing station (ASOS) in Clinton, MO [KGLY; Figure 4.3(a)].
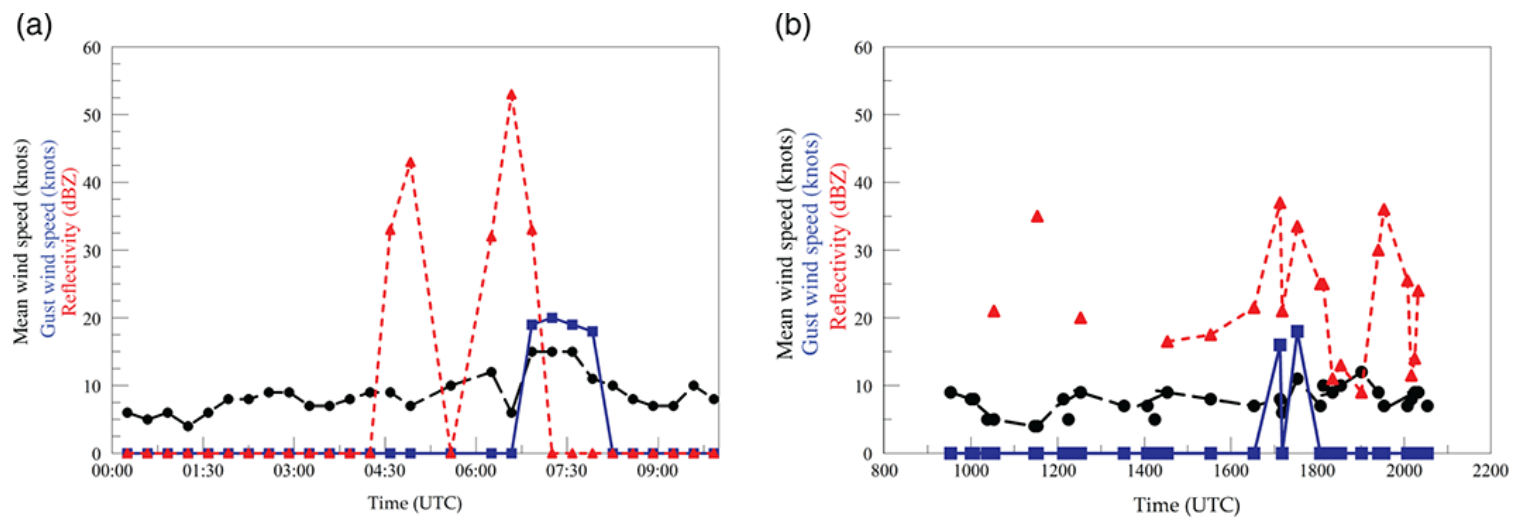

Figure 4.3. Plots of time (abscissa) versus wind speed (knots; ordinate) and reflectivity (dBz; ordinate) for (a) the location of the Clinton, MO, airport (KGLY) on 2 April 2014 and (b) the location of the Jefferson City, MO, airport (KJEF) on 8 July 2015. Wind speeds are represented by black filled circles (joined by a line of long dashes), wind gusts by blue filled squares (joined by a solid line), and reflectivity values (from a) Pleasant Hill, MO, National Weather Service radar; and (b) the University of Missouri radar) by red filled triangles (joined by a line of short dashes).

The ensuing flight at 0753 UTC (Figure 4.2(b)) featured a dramatic increase in the DCAPE (314 J kg-1) along with a diminished DCIN (119 J kg-1). A second wave of convection had just passed by the sounding launch site, and nearly directly over the KGLY ASOS site (Figure 4.3(a)). Gusts of 18-20 knots occurred between 0655 UTC and 0755 UTC, beginning immediately after a reflectivity core of $53 \mathrm{dBz}$ (observed from the nearby National Weather Service radar at Pleasant Hill, MO; centerline of lowest tilt $\sim 880 \mathrm{~m}$ above ground level) passed over KGLY. Given the excess of DCAPE over DCIN, and the observed changes at the surface, penetration of the elevated convective downdraft to the surface appears to have occurred. 
The final flight examined was launched at 0937 UTC (Figure 4.2(c)) revealing a DCAPE that had diminished some to $266 \mathrm{~J} \mathrm{~kg}-1$, and the DCIN had grown to $125 \mathrm{~J} \mathrm{~kg}-1$. Even so, the balloon was launched in the absence of precipitation, or nearby strong $(>40 \mathrm{dBz})$ reflectivity cores on the radar. Surface-observed gustiness had abated (Figure 4.3(a)).

\subsubsection{Case 2: 7 July 2015}

For the 2015 case, each of the three flights examined also occurred north of a surface quasi-stationary frontal boundary (Figure 4.4). Sounding balloons were released at 1448 UTC (Figure 4.5(a)), 1737 UTC (Figure 4.5(b)) and 2035 UTC (Figure 4.5(c)) on 8 July 2015, from the University of Missouri South Farm, just south of Columbia, MO, USA.

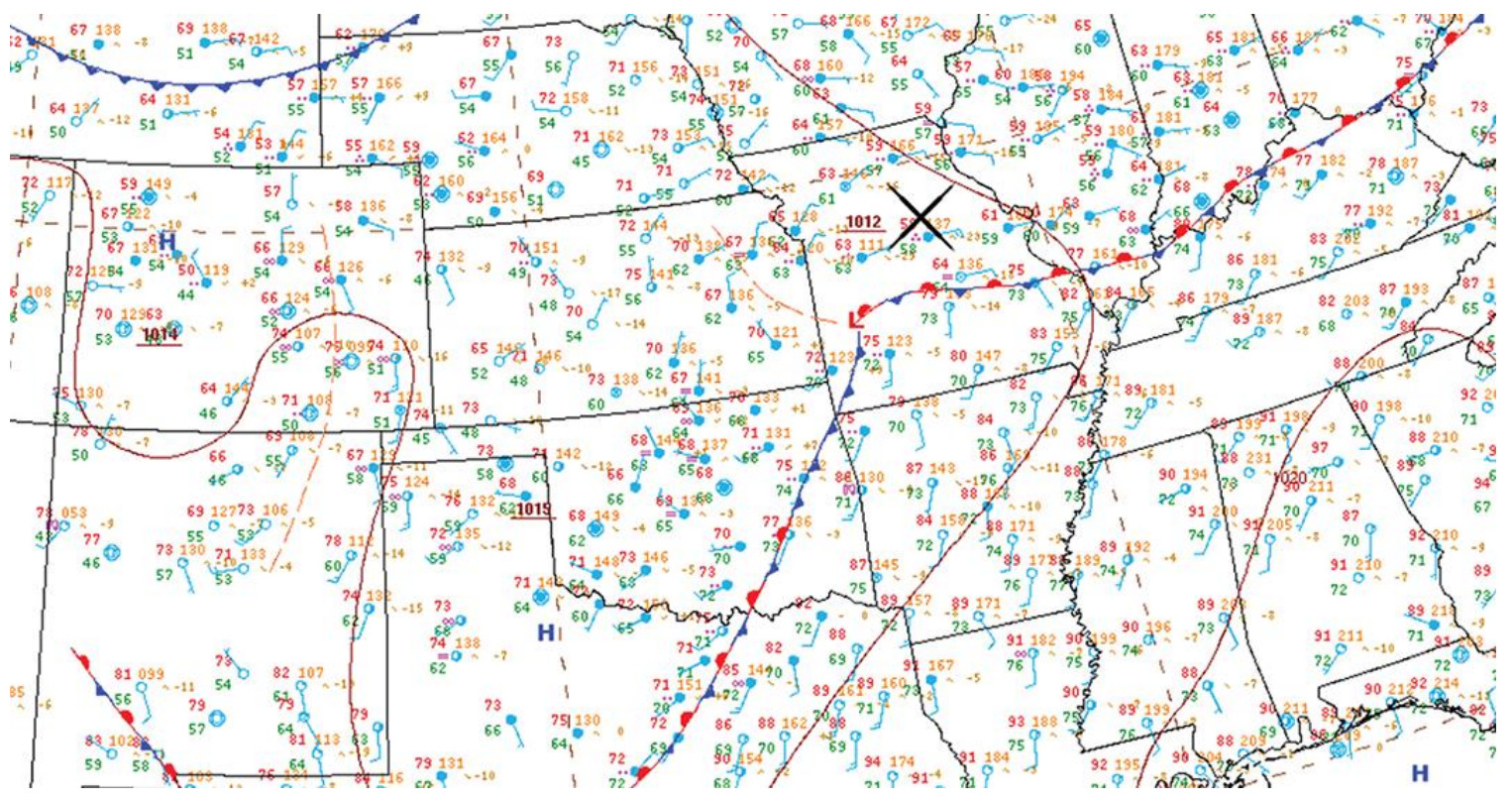

Figure 4.4. Standard surface analysis for the central United States valid at 1800 UTC 8 July 2015 from the United States Weather Service Weather Prediction Center. Bold ' $X$ ' marks the location of Columbia, MO. 

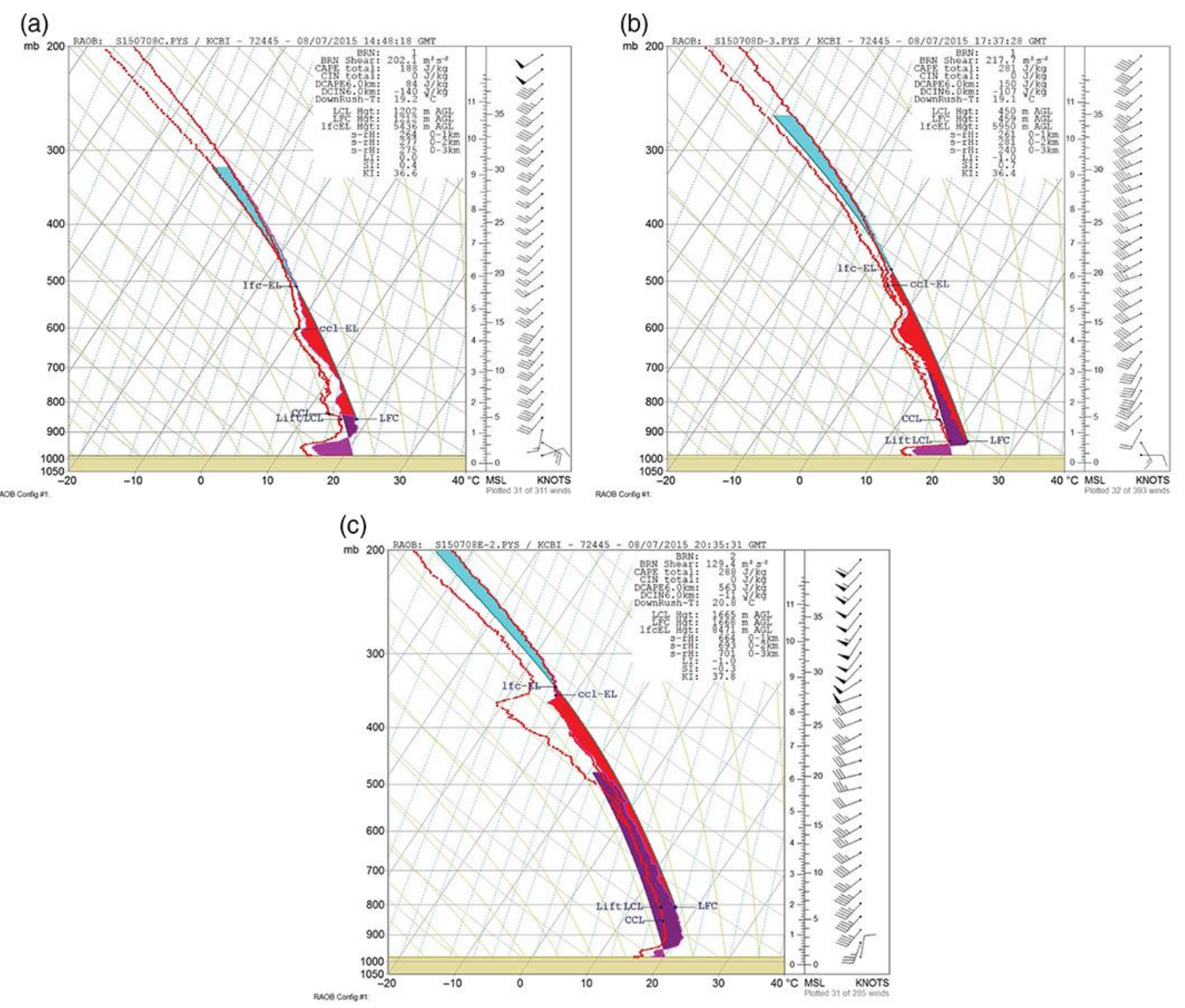

Figure 4.5. As in Figure 1, except for sounding analyses from Columbia, MO, flown on 8 July 2015, and valid at (a) 1448 UTC, (b) 1737 UTC and (c) 2035 UTC.

The first flight (Figure 4.5(a)) clearly identified elevated CAPE $\left(188 \mathrm{~J} \mathrm{~kg}^{-1}\right)$ for parcels initiated above the top of the inversion. Indeed, a steady light to moderate rain occurred during all the three flights, with embedded showers scattered about the region as verified by radar (not shown). Also, surface winds at 1448 UTC ranged from 5 to 9 knots, with no gustiness noted at the time. A comparison of the DCAPE at $84 \mathrm{~J} \mathrm{~kg}^{-1}$ to the DCIN at $140 \mathrm{~J} \mathrm{~kg}^{-1}$, shows that the DCAPE $<$ DCIN, thus suggesting an inability for the downdraft to penetrate all the way to the surface.

By 1737 UTC (Figure 4.5(b)), the elevated CAPE had grown to $281 \mathrm{~J} \mathrm{~kg}^{-1}$ and some drying aloft had allowed the DCAPE to grow to $150 \mathrm{~J} \mathrm{~kg}^{-1}$, while the DCIN shrunk 
some to $107 \mathrm{~J} \mathrm{~kg}^{-1}$. Embedded convection became more plentiful by this time, with several areas having radar returns of $40 \mathrm{dBz}$ or more (not shown); higher rainfall rates $\left(\sim 6 \mathrm{~mm} \mathrm{~h}^{-1}\right)$ were observed at this time. Surface wind gusts began in the ensuing few hours, corroborated by the surface weather observations at the Columbia Regional Airport (KCOU), located $\sim 11 \mathrm{~km}$ south-southeast of the radiosonde launch site. There, surface wind gust criteria were met briefly, and reached 22 knots at 1950 UTC. Wind data from the nearby surface station at Jefferson City, MO (KJEF; 29 km southsoutheast of the radiosonde launch site), were also examined and compared to the radar reflectivity (Figure 4.3(b)) from the University of Missouri radar, as the KJEF site experienced stronger radar reflectivities (centerline of lowest tilt at $\sim 550 \mathrm{~m}$ above ground level). Clearly, there are several periods that day with reflectivities in excess of $30 \mathrm{dBz}$, but the period with the strongest reflectivity values over KJEF also corresponds to the period of surface wind gusts.

The sounding at 2035 UTC (Figure 4.5(c)) largely conformed to a moist adiabatic profile, and while rain persisted, there were fewer radar-depicted convective cores (not shown). The elevated CAPE was essentially unchanged $\left(288 \mathrm{~J} \mathrm{~kg}^{-1}\right)$, so the weak convective towers that were observed were no surprise. Meanwhile, the DCAPE had grown to $563 \mathrm{~J} \mathrm{~kg}^{-1}$, while the DCIN shrunk to $11 \mathrm{~J} \mathrm{~kg}^{-1}$. There is also an agricultural monitoring station at South Farm, immediately adjacent to the sounding launch site. For most of the day, wind speeds recorded by the station's anemometer (3-m exposure) did not stray above 7 knots; at 2137 UTC, $1 \mathrm{~h}$ after the 2035 UTC balloon launch, the day's peak gust, 16 knots, was recorded. 


\subsubsection{Previous work}

The work of Horgan et al. (2007) provides additional soundings to test the utility of DCIN. Horgan et al. (2007) examined five cases of elevated convection that produced convectively induced severe weather reports (mostly winds) at the surface. Each of these cases had a significant inversion that was based at the surface. The soundings from each case in their work were acquired, and DCAPE (DCIN) values were calculated for each one, with the results shown in Table 1. Clearly, DCAPE is much larger than DCIN in most of the Horgan et al. (2007) cases, except for Case 2. However, they did mention the possibility that the profile above the inversion may have been contaminated by existing convection. No other of their cases generated similar concerns.

Table 4.1. Dates, Times (UTC), DCAPE and DCIN values (units of $\mathbf{J} \mathrm{kg}-1$ ) for Case 1 (Clinton, MO) and Case 2 (Columbia, MO) collected by the authors for this work as well as the individual values from the five severe cases from the Horgan et al. (2007) study.

\begin{tabular}{|c|c|c|c|c|}
\hline Case & Date & Time & DCAPE & DCIN \\
\hline 1 & 2 April 2014 & 0534 & 160 & 163 \\
\hline 1 & 2 April 2014 & 0753 & 314 & 119 \\
\hline 1 & 2 April 2014 & 0937 & 266 & 140 \\
\hline 2 & 8 July 2015 & 1448 & 84 & 107 \\
\hline 2 & 8 July 2015 & 1737 & 150 & 11 \\
\hline 2 & 8 July 2015 & 2035 & 563 & 541 \\
\hline HSC1 & 20 November 1986 & 1200 & 713 & 1 \\
\hline HSC2 & 28 December 1983 & 1200 & 7 & 0 \\
\hline HSC3 & 1 February 1983 & 1200 & 538 & 0 \\
\hline HSC5 & 3 November 1983 & 1200 & 555 & 1226 \\
\hline
\end{tabular}

\subsection{Summary}

The DCIN is examined as a means to help confirm whether convection is elevated or surface-based. Although, Nowotarski et al. (2011) contend that convection is only truly elevated when no surface-based CAPE is present, having such a sounding where the DCIN is larger than DCAPE should prohibit surface-based parcels from becoming part of the deeper convective circulation via continuity. 
The two accompanying case studies corroborate this idea, bolstered further by the coincidence of non-severe surface wind gusts accompanying the strongest radar reflectivities and (presumably) the most vigorous downdrafts. In addition, we reexamined five cases from a recent study of severe weather (high wind) reports from elevated convection (Horgan et al., 2007), and found soundings that tended to have small to nonexistent DCIN values and much greater DCAPE values. Indeed four of the five severe weather cases featured the condition where DCIN «DCAPE, and parcels aloft were able to penetrate to the subinversion layer. The DCIN and comparisons to its DCAPE appear to be viable diagnostics for aiding in the assessment of elevated convection. As DCIN becomes less than DCAPE, downdraft penetration will become more likely; where DCIN is greater than DCAPE, downdraft penetration will become less likely and elevated convection will become more preferred.

While the idea proposed is supported by the observations, these results could be more quantitative. Given the limited number of soundings, it is difficult, at present, to determine a precise threshold of DCIN/DCAPE for the onset of surface downdraft winds. Additional factors, including the downdraft speed, wind profile above the inversion and the height of the level of neutral buoyancy, will need to be examined. Ongoing work on this topic seeks to (1) build a larger observational dataset (via simultaneous radar, rawinsonde and tall tower measurements) of similar cases and (2) use numerical modeling experiments, to better understand the aforementioned processes that influence downdraft behavior.

Acknowledgements: We begin by thanking the several anonymous reviewers for their valuable comments and input. This work is supported in part by the United States National Science Foundation (NSF), Awards AGS-1258358 and IIA-1355406. Any 
opinions, findings, conclusions or recommendations expressed herein are those of the author(s) and do not necessarily reflect the views of NSF. 


\subsection{References}

Augustine JA, Caracena F. 1994. Lower-tropospheric precursors to nocturnal MCS development over the central United States. Weather and Forecasting 9: 116-135.

Billings JM, Parker MD. 2012. Evolution and maintenance of the 22-23 June 2003 nocturnal convection during BAMEX. Weather and Forecasting 27: 279-300.

Browning KA, Marsham JH, White BA, Nicol JS. 2012. A case study of a large patch of billows surmounted by elevated convection. Quarterly Journal of the Royal Meteorological Society 138(668): 1764-1773.

Colman BR. 1990a. Thunderstorms above frontal surfaces in environments without positive CAPE. Part I: climatology. Monthly Weather Review 118: 1103-1121.

Colman BR. 1990b. Thunderstorms above frontal surfaces in environments without positive CAPE. Part II: organization and instability mechanisms. Monthly Weather Review 118: 1123-1144.

Corfidi SF, Corfidi SJ, Schultz DM. 2008. Elevated convection and castellanus: ambiguities, significance, and questions. Weather and Forecasting 23: 1280-1303.

Djurić D. 1994. Weather Analysis. Prentice Hall; 304.

Doswell CA, Rasmussen EN. 1994. The effect of neglecting the virtual temperature correction on CAPE calculations. Weather and Forecasting 9: 625-629.

Gilmore MS, Wicker LJ. 1998. The influence of midtropospheric dryness on supercell morphology and evolution. Monthly Weather Review 126: 943-958.

Horgan KL, Schultz DM, Hales JE, Corfidi SF, Johns RH. 2007. A five-year climatology of elevated severe convective storms in the United States east of the Rocky Mountains. Weather and Forecasting 22: 1031-1044.

Kastman JS, Market PS, Foscato A. 2015. Rainfall-Lightning Ratio Calculations for Elevated Thunderstorms With Heavy Rainfall. Seventh Conference on the Meteorological Applications of Lightning Data. American Meteorological Society: Phoenix, AZ.

Marsham JH, Trier SB, Weckwerth TM, Wilson JW. 2011. Observations of elevated convection initiation leading to a surface-based squall line during 13 June IHOP 2002. Monthly Weather Review 139: 247-271.

Moore JT, Czarnetzki AC, Market PS. 1998. Heavy precipitation associated with elevated thunderstorms formed in a convectively unstable layer aloft. Meteorological Applications 5: 373-384.

Moore JT, Glass FH, Graves CE, Rochette SM, Singer MJ. 2003. The environment of warm-season elevated thunderstorms associated with heavy rainfall over the central United States. Weather and Forecasting 18: 861-878. 
Nowotarski CJ, Markowski PM, Richardson YP. 2011. The characteristics of numerically simulated supercell storms situated over statically stable boundary layers. Monthly Weather Review 139: 3139-3162.

Parker MD. 2008. Response of simulated squall lines to low-level cooling. Journal of the Atmospheric Sciences 65: 1323-1341.

Rochette SM, Moore JT. 1996. Initiation of an elevated mesoscale convective system associated with heavy rainfall. Weather and Forecasting 11: 443-457.

Schumacher RS. 2015. Sensitivity of precipitation accumulation in elevated convective systems to small changes in low-level moisture. Journal of the Atmospheric Sciences 72: 2507-2524.

Trier SB, Parsons DB. 1993. Evolution of environmental conditions preceding the development of a nocturnal mesoscale convective complex. Monthly Weather Review 121: 1078-1098. 


\title{
Chapter 5. Dynamic Ensemble Reanalysis of Frontal Placement Impacts in the Presence of Elevated Thunderstorm during PRECIP Events
}

\author{
J. S. Kastman ${ }^{1}$, P. S. Market ${ }^{1}$, and N. I. Fox ${ }^{1}$ \\ ${ }^{1}$ Department of Soil, Environmental and Atmospheric Sciences, University of Missouri, \\ 302 ABNR, Columbia, MO 65211, USA.
}

This section has been formatted to the standards of Journal of Geophysical Research Atmospheres.

5.1 Abstract: The Program for Research on Elevated Convection with Intense Precipitation (PRECIP) field campaign sampled ten cases of elevated convection during 2014 and 2015. These intense observing periods (IOP) mostly featured well-defined stationary or warm frontal zones, over whose inversion elevated convection would form. However, not all frontal zones translated as expected, with some poleward motions being arrested and even returning equatorward. Prior analyses of the observed data highlighted the downdrafts in these events, especially diagnostics for their behavior: the downdraft convective available potential energy (DCAPE) and the downdraft convective inhibition (DCIN). With the current study, the DCAPE and DCIN are examined for four cases: two where frontal motion proceeded poleward, as expected, and two where the frontal motions were slowed significantly or stalled altogether. Ensembles with the Weather Research and Forecasting (WRF) model were created for each of the four cases, and the best performers were selected for additional deterministic examination. Analyses of frontal motions and surface cold pools are explored in the context of DCAPE and DCIN. These analyses further establish the DCAPE and DCIN, not only as a means to classify elevated convection, but also to aid in explaining frontal motions in the presence of elevated convection.

\subsection{Introduction}

Elevated thunderstorm complexes pose numerous threats and are well established producers of heavy rainfall (Rochette and Moore, 1996; Market et al., 2003; Moore et al., 2003, McCoy et al., 2017), flash flooding (Moore et al. 2003, Kastman et al. 2017a, McCoy et al., 2017) and cloud-to-ground lightning flashes (Kastman et al., 2015b; McCoy et al., 2017). Furthermore, these elevated complexes are suspected in disrupting synoptic boundary location and movement (Smull and Augustine, 1993; Kastman et al., 2015a) as cold pools from convection interact with surface boundaries. Understanding 
what conditions cause frontal displacement to happen or not happen is a worthwhile pursuit as it could lead to better, more timely forecasting of heavy rains. Such storms were sampled during the Program for Research on Elevated Convection with Intense Precipitation (PRECIP) field campaigns during the warm seasons of $2014-2015$.

During the PRECIP campaigns it was observed several times that convection north of a boundary would cause the boundary to stall and retrograde against its prior advancement as cold pools unified and spread in the direction of the advancing front. When this was observed, heavy precipitation occurred where the front and cold pools were interacting. This phenomena did not occur during every instance of observed elevated convection. It was noted when elevated convection retained a single cellular radar appearance, boundaries were not observed to stall.

Market et al. (2017) introduced the concept of downdraft convective inhibition (DCIN) and its potential utility when compared to downdraft convective available potential energy (DCAPE). They explain that DCIN is akin to the negative area above the equilibrium level used to estimate the height of the overshooting top of a cumulonimbus, but when applied to DCAPE where the equilibrium level is top of the CIN layer in a sounding. He and his coauthors state that as DCIN becomes progressively larger than the DCAPE, it is progressively more difficult for a downdraft to penetrate down toward the surface; the conditions where DCIN > DCAPE further confines near-surface parcels to the subinversion layer. This was found to be the delineating factor in the PRECIP cases examined in which boundaries stalled and which they did not. It is therefore thought to be a main contributor to frontal stalling.

\subsection{Background and Discussion}

\subsubsection{Defining Elevated Convection}


Coleman (1990a, 1990b) established the definition of elevated convection as a storm that is isolated from surface diabatic effects and found above a frontal inversion. He further refined this definition to include that observations must lie on the cold side of an analyzed front with clear contrast in the mass and momentum fields with surrounding stations recording similar conditions. Similar criteria were also used by Grant (1995), Rochette and Moore (1996), Moore et al. (1998), Moore et al. (2003), and McCoy et al., (2017) for studies involving elevated thunderstorms. However, this definition is rather specific and, while being useful in determining if a given cell is surface based or elevated by way of synoptic map interrogation, it falls short in defining elevated convection in scenarios which a boundary is not well defined. Indeed, there have been valid concerns about how to assess whether deep moist convection is purely elevated (Corfidi et al., 2008). In his earlier work Corfidi et al. (2006) explains that surface-based convection will often incorporate elevated parcels, and that elevated convection also include surface parcels into its updraft. This can blur the line between what is elevated convection and what is surface based convection. This becomes especially hard to distinguish as convection transitions from surface-based to elevated and vice-versa. A more applicable definition Was proposed by with Corfidi et al.(2006) in which elevated thunderstorms are defined as convection occurring over a stable layer near the surface, essentially cut off from surface-based instability. Certainly, convection can be elevated even when nearsurface parcels have positive CAPE, as suggested by Nowotarski et al. (2011). However, one should consider convection purely elevated when no surface-based CAPE is present (Nowotarski et al., 2011). Thus many of the cases sampled during PRECIP, of which all 
were north of a boundary, fall into the category of mostly elevated convection, but perhaps not purely elevated.

\subsubsection{Forecasting Elevated Convection and Cold Pools}

Forecasting the evolution and movement of elevated complexes and the impacts to the surrounding environment has been a struggle for forecasters (Smull and Augustine, 1993; Schumacher et. al 2013) and numeric weather prediction (NWP) models (Cofidi 2003; Corfidi et. al 2008; Schumacher et. al 2013) alike. One of the primary causes of this complexity is how cold pools from thunderstorms interact with the surrounding environment (Cofidi 1996; 2003). It is well established that thunderstorms are often generated or enhanced at the leading edge of the gust front (e.g. Droegemeier and Wilhelmson, 1987; Mahoney, 1988; Cofidi 1996; 2003; Jeong et al. 2009). It has been shown that cells forming along and behind the gust front can form as high as $2 \mathrm{~km}$ above the depth of the cold pool (Mahoney , 1988). Thus making these new cell somewhat elevated convection. It has also been demonstrated that cold pools with a larger deficit compared to its environment produced deeper cold pools with more lift (Droegemeier and Wilhelmson, 1987). The location, depth and longevity of cold pools can have dramatic impacts on how much rain is able to be produced and sustained (Schumacher et. al 2013).

\subsubsection{Cold pool behavior in PRECIP}

In the PRECIP events investigated for this paper it will be shown that during some of the cases, cold pools associated with convection north of a synoptic boundary were in juxtaposition with warm air the south of the boundary. These cases are listed in Table 5.1, and show the dates the occurred as well as a brief description of the geographical location and synoptic set up. This created a scenario in which cooler air north of a boundary enveloped an area of even cooler air from cold pools generated by 
convection north of a boundary. Enhanced convection and heavy rainfall were observed where this coolest region interacted with the warm air along and south of the boundary. Cases in which this was observed occurred in environments that were favorable for elevated MCSs, consistent with what was shown by Moore et al., (2003). Convection was able to sustain itself in this optimal region if cold pools were able to push the boundary south, thus putting the cold air in contact with a fresh, undisturbed warm air environment. In addition to being similar to the environments described by Market et al., (2003), Moore et al., (2003) and Rochette and Moore, (1996) these environments also had DCAPE > DCIN. Indicating downdrafts would be able to push through any DCIN layer present below an inversion and turn into cold pools. When this scenario was observed the boundary was forced to stall out and the effective front was pushed to the south.

Table 5.1. A listing of the cases discussed throughout this paper. This table provides details on the case that include date, location and brief synoptic description.

\begin{tabular}{|l|l|l|}
\hline Date: & Location: & Brief Synoptic Description: \\
\hline IOP 1: 1-2 April 2014 & West Central MO & $\begin{array}{l}\text { Warm front lifting northward, front did not } \\
\text { stall }\end{array}$ \\
\hline IOP 2: 3-4 June 2014 & Southeast NE & Warm front stalled and sank southward \\
\hline IOP 5: 4-5 June 2015 & Southeast NE & Warm front stalled and sank southward \\
\hline IOP 8: 7-8 July 2015 & Central MO & $\begin{array}{l}\text { Warm front lifting northward, front did not } \\
\text { stall }\end{array}$ \\
\hline
\end{tabular}

\subsubsection{High Resolution Ensemble Modeling of Heavy Rainfall}

Numerous efforts have been undertaken to study heavy rainfall from MCSs using high resolution models (Billings and Parker, 2012; Clark et al. 2010; Done, 2004; 
Schwartz, and Coauthors, 2010; Tapiador and Coauthors, 2012; Schumacher et al, 2013; Schumacher, 2015). The best method to study this phenomena is via an ensemble (Clark et al. 2010; Schumacher, 2009 Schumacher et. al 2013) contingent upon the spread of the ensemble being comprehensive enough to cover high end heavy rainfall scenarios. A very simplified breakdown of ensembles can be viewed as those that rely on perturbations in the initial conditions (IC) and/or Lateral Boundary Conditions (LBC) to generate a spread in solutions, as seen in the Global Ensemble Forecasting System (GEFS), and those that rely on spread developed by using multiple microphysics, or alterations in physical parameterizations such as the storm-scale ensemble of opportunity (SSEO) (Jirak, 2012). An ensemble needs to have enough spread to cover a range of realistic outcomes to avoid being under dispersive, while avoiding washing out a real threat with an over dispersive solution. In the world of high-resolution modeling the choice between explicit, convective allowing models and parameterized convection has been brought to the forefront. Some studies have shown that ensembles using mixed physics provided forecasts with greater skill and less overall bias compared to the single-physics ensembles (Schumacher and Clark, 2014; Tapiador and Coauthors, 2012). Tapiador and Coauthors, 2012 also show that the dispersion of the dynamic ensemble is larger than that of the perturbation initial condition ensemble in terms of storm center location; spatial structure of the precipitation; and maximum, mean, and standard deviation of the daily precipitation estimates. Romine et al. (2014) found IC perturbation alone leads to skillful but under dispersive ensemble forecasts. Schwartz and Coauthors (2010) found ensemble spread increases more rapidly with the inclusion of mixed-physics ensembles. 


\subsection{Discussion and Methods}

In an effort to better understand the scenario in which convection north of a boundary forces the boundary southward due to cold pool expansion (as described in a foregoing section) a model ensemble was constructed. The numerous studies above provided much guidance into the ensemble construction. The goal of this ensemble was to provide a variety of configurations in order to see if members could accurately simulate what was observed. The forecasts were for $18-24$ hours and initiated three hours before convective initiation. A dynamic, mixed physics approach was used as purely IC/LCB perturbations can take up to day before they provide enough spread (Schumacher et al., 2013).

The ensemble, named the Weather Research and Forecasting - High Resolution Heavy Precipitation Ensemble Forecasting System (WRF-HRHPEFS) was created using the Weather Research and Forecasting (WRF) model with the Advanced Research WRF (ARW) core. It contained 48 individual members which varied microphysics, cumulus parameterization, boundary layer physics and moisture advection. Each member used RAP initial fields for lateral boundary and initial conditions, and was run with a 9-km grid spacing with a 3-km inner nest. Both of the domains were centered on the area of heaviest precipitation. The model was broken down into eight families with one of the following parameterizations varied: microphysics scheme, Planetary Boundary Layer (PBL) scheme, cumulus physics and moisture advection scheme. There were six microphysics schemes used; the Lin (Lin et al, 1983), Ferrier (NOAA, 2001), WSM 6 (Hong and Lim, 2006), Thompson (Thompson et al, 2008), Morrison (Morrison er al., 2009), WDM 6 (Lim and Hong, 2010). There were two options for convection, explicit or parameterized with the Grell 3-D (Grell and Freitas, 2014) scheme. There were three 
different boundary layer physics schemes used; the Yonsei University Scheme (YUS) (Hong et al., 2006), Mellor-Yamada-Janic (MYJ) scheme (Janjic, 1994) and the MellorYamada Kanishi Niino (MYNN3) scheme (Nakanishi and Niino, 2009). Concerning the PBL schemes the MYJ \& MYNN3 feature local vertical mixing and the YUS is a nonlocal vertical mixing scheme. Two moisture advection schemes were used; the positive definite scheme and the Weighted Essentially Non-Oscillatory (WENO) scheme (Skamarock, 2015), which was only used for double moment microphysics schemes. The WRF creators have suggested that the WENO advection scheme may be beneficial when noise is a problem, such as in quantified precipitation forecasts (QPF). Combining all of these options yields the 48 members which are listed by name and component in Table 5.2 .

All 48 member of the model were run for the cases, referred to as Intense Observation Period (IOP), seen in Table 5.1. Each of these events occurred within the Nebraska - Iowa - Kansas -Missouri domain and featured rainfall amounts in excess of two inches with convection occurring north (thermal cool side) of a synoptic boundary. Grid stats were calculated for each IOP for each member and compared via a Roebber performance diagram (Roebber, 2009) which depicts the model configurations performance with regard to the Critical Success Index (CSI), Frequency Bias (FBIAS), Success Ratio (SR) (which is one minus the False Alarm Ratio (FAR)), and the Probability of Detection (POD). The Model Evaluation Toolkit's (MET) Method for Object-Based Diagnostic Evaluation (MODE) tools was also used to assess how similar the one inch $(25.4 \mathrm{~mm})$ model QPF compared to Stage IV Quantified Precipitation 
Estimate (QPE). The best performing model was used further to estimate the presence of DCIN during the convective events and the evolution of the 2-meter temperature field.

\subsection{Results}

The following subsections will provide a synoptic discussion on the event and proceed to discuss the results of the models in the framework of the Roebber performance diagram and MODE analyses. When viewing results on a performance diagram keep in mind that the perfect forecast would be in the upper right hand corner with an unusable forecast occurring at the origin. Deviations from the line, labeled one, towards the bottom right of the graph indicates low FBIAS and deviations towards the upper left corner indicate high FBIAS. Since we are considering QPF, lower FBIAS will indicate an underforecast of QPF while those models towards upper left will indicate an overforecast of QPF. Those points with FBIAS of $\sim$ one but are not in the upper right hand corner indicate that there was a displacement of the QPF from the observation.

Each section will also discuss the presence (or lack thereof) of DCIN and how downdrafts impacted surface weather and the synoptic boundary.

\subsubsection{IOP 1: 1 -2 April 2014}

IOP occurred 1-2 April 2014 with the elevated convection occurring over central Missouri. A low pressure system ejected from Texas into southern Missouri. An associated warm front advanced northward through the duration of the event, even as elevated convection was ongoing. Rainfall amounts approaching two inches were observed across central Missouri, north of the warm front. The front advanced northward as anticipated and the event was well sampled by a PRECIP team.

Figure 5.1 shows the Roebber performance diagram for all 48 models for the IOP 1. A wide dispersion of points is seen in the figure. However, there are clearly errors in 
both placement and amounts. Three distinct groupings emerge. Nearly half of the models reside in the lowest left corner of the figure indicating poor performance and limited utility as guidance. This group is made up of most of the parameterized convection configurations (denoted by a ' $G$ ' appearing within the last two letters), many of the Morrison microphysics members (leading ' $\mathrm{M}$ ') and WENO (ending in ' $\mathrm{W}$ ') advection scheme members are found within this group. This group struggled with precipitation amounts and placement of the warm front leading to poor guidance and low CSI scores. The second clustering (around the 0.15 CSI curve) general had the correct frequency of 1 inch QPF but had timing and location errors that lead to low scores. This grouping contained the best performing parameterized convection model (LMG). While the LMG configuration graded out the highest for the parameterized convection subgroup, it was still far inferior to the better performing explicit convection models. The best performing cluster (located above the 0.3 CSI curve) was made up solely of explicit convective models. The best performing member for this case (by CSI) was the WDME model. However, it, like most of the other WD microphysics models, did have a low frequency bias. Thus indicating it was slightly lacking in coverage where QPE was observed, compared to the other model configurations forecast. Most of the top performing models by CSI had lower FBIAS scores (with the notable exception being the WSME model). This lower precipitation coverage can easily be seen in Fig. 5.2, which shows the MODE identified cluster of 1.0 inch QPF from the WDME and QPE. Notice that the QPE stretches further west into Kansas than the WDME forecasted (Fig 5.2. Additionally the MODE analysis, seen in Fig. 5.2, reveals that there was a small under forecast in coverage of the one inch threshold, showing 4,401 grid squares forecasted compared to 
4,582 grid squares observed. Still, this forecast is skillful and provides useful guidance for the domain. The small angle difference $\left(2^{\circ}\right)$ suggests the orientation of convection was excellent and centroid distance (27.99 grid squares) suggest some displacement (west in this case) of the one inch QPC. Overall the combined analysis shows that the WDME model had a good handle on the location and coverage of the 1.0 inch QPF.

This event featured elevated convection along the warm front with numerous individual cells. They were efficient rain producers and trained over the same area giving way to widespread 1.0 inch amounts. However, these elevated cells remained single cell in nature and did not congeal into a large MCS (until 2100 UTC 4 April 2014, 3 hours after the period of study). This lead to a region north of the boundary that was relatively unaffected by convective cold pools and allowed the warm front to advance northward as anticipated. This is depicted well in Fig. 5.3 which shows $2 \mathrm{~m}$ temperature and $975 \mathrm{mb} \theta_{e}$ from the WDME model. Fig 5.3a. is valid at 0000 UTC 2 April while Fig. 5.3b is valid at 1800 UTC 2 April. At 0000 UTC 2 April 2014 UTC we see a developing warm front across southern Missouri, and by 1800 UTC, it is well defined and has surged north. This is important to note because elevated convection north of this boundary started around 0600 UTC, thus demonstrating that the convection did not impede frontal progress. The front progressed as the lowest levels of the atmosphere were unaffected by any expansive cold pool region (often seen with larger organized MCS's).

Figure 4 shows model reflectivity (filled gray) greater than $40 \mathrm{dBZ}$ and contours of DCIN less than $0 \mathrm{Jkg}-1$ at $1200 \mathrm{UTC}$. Where DCIN values are less than zero down drafts are being impeded by the DCIN layer. By this time, elevated convection had been ongoing for nearly six hours and coverage had increased to include much of eastern 
Kansas and western Missouri. DCIN contours surround each area of reflectivity. Indeed it is shown most of the DCIN values exceed $100 \mathrm{Jkg}-1$ in the presence of the shading convective areas. This explains the lack of strong cold pools in the $2 \mathrm{~m}$ temperature field shown in Fig. 5.4 as downdrafts could not penetrate to the surface. Thus, the temperature and low-level boundary remained unaffected by the elevated convection and the warm front advanced northward.

Explicit convection based configurations handled this scenario much better than the parameterized convection configurations as demonstrated by the analysis above. This makes senses as the isolated convective cores were well represented by the explicit convection, which kept the convection as single cores, whereas the parameterized convection tried to create a large MCS with a unified cold pool that disrupted the frontal motion and changes the location of the QPF. Figure 5.5a shows an observed sounding launched by PRECIP near Clinton, MO. (38.36003 N., 93.75366 W., 232.8 m MSL) and Fig. 5.5b shows a model sounding from the WDME configuration. Both are valid at 09 UTC 02 April 2014. This figure shows the model had a very similar vertical profile of temperature, dew point temperature and winds. More mid-level cooling was found in the observed sounding which lead to increased elevated instability compared to what was forecasted by the model, but the general structure is fairly representative of reality. 


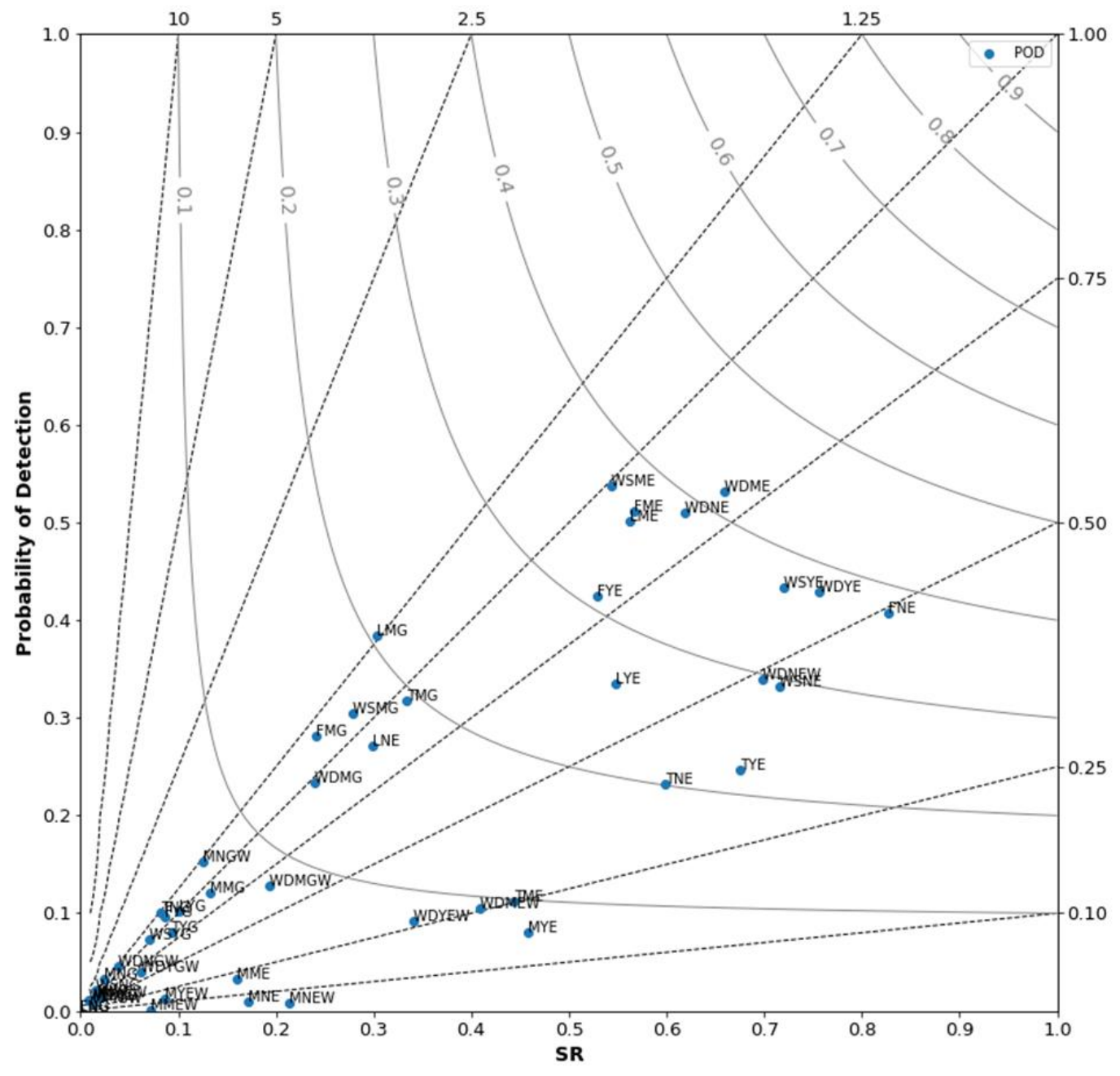

Figure 5.1. Roebber performance diagram showing each member (labeled blue dots) of the WRF-HRHPEFS for IOP 1. X -Axis shows the Success Ratio (SR), Y-Axis shows the Probability of Detection, curved lines represent Critical Success Index (CSI) values and the dashed diagonal lines represent Frequency Bias (FBIAS). A full description of each member can be found in Table 5.2. 


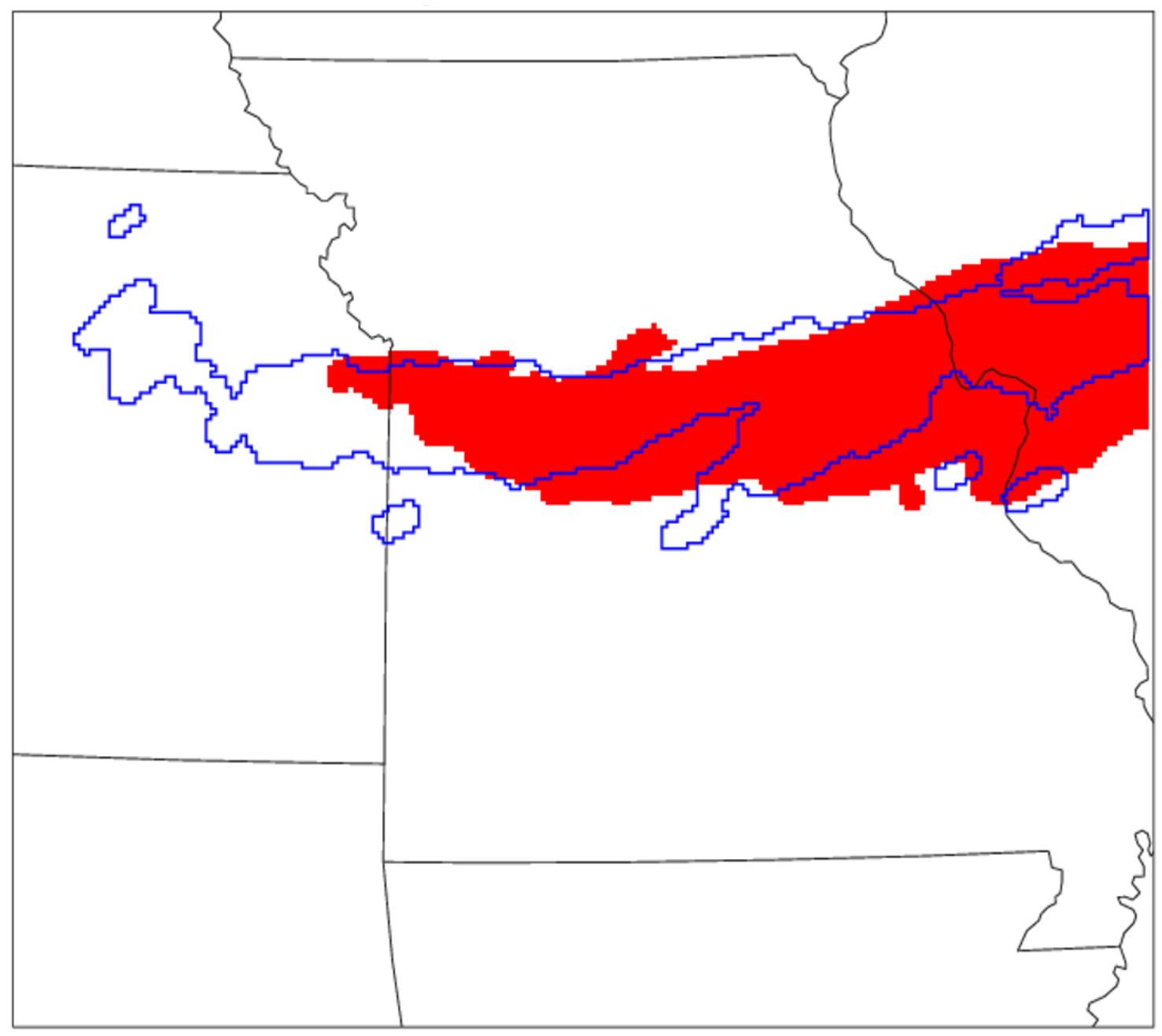

\begin{tabular}{|c|c|c|c|c|c|c|c|c|c|c|c|c|}
\hline LU & $\begin{array}{l}\text { CEN } \\
\text { DIST }\end{array}$ & $\begin{array}{l}\text { ANG } \\
\text { DIFF }\end{array}$ & & $\begin{array}{c}\text { OBS } \\
\text { AREA }\end{array}$ & & & $\begin{array}{l}\text { SYMM } \\
\text { DIFF }\end{array}$ & & & & $\begin{array}{c}\text { OBS } \\
\text { INT } 90\end{array}$ & \\
\hline & 27.9 & 2.09 & 4401 & 4582 & 3035 & 5948 & 2913 & 32.68 & 38.00 & 44.41 & 60.17 & 991 \\
\hline
\end{tabular}

Figure 5.2. MODE output showing observed (red color filled area) QPE and forecast QPF (blue outline) from the WDME model configuration for IOP 1. The Table at the bottom of the image describes comparison of the forecasted (blue outline) to observed object (red color filled); these values are discussed in the text. 


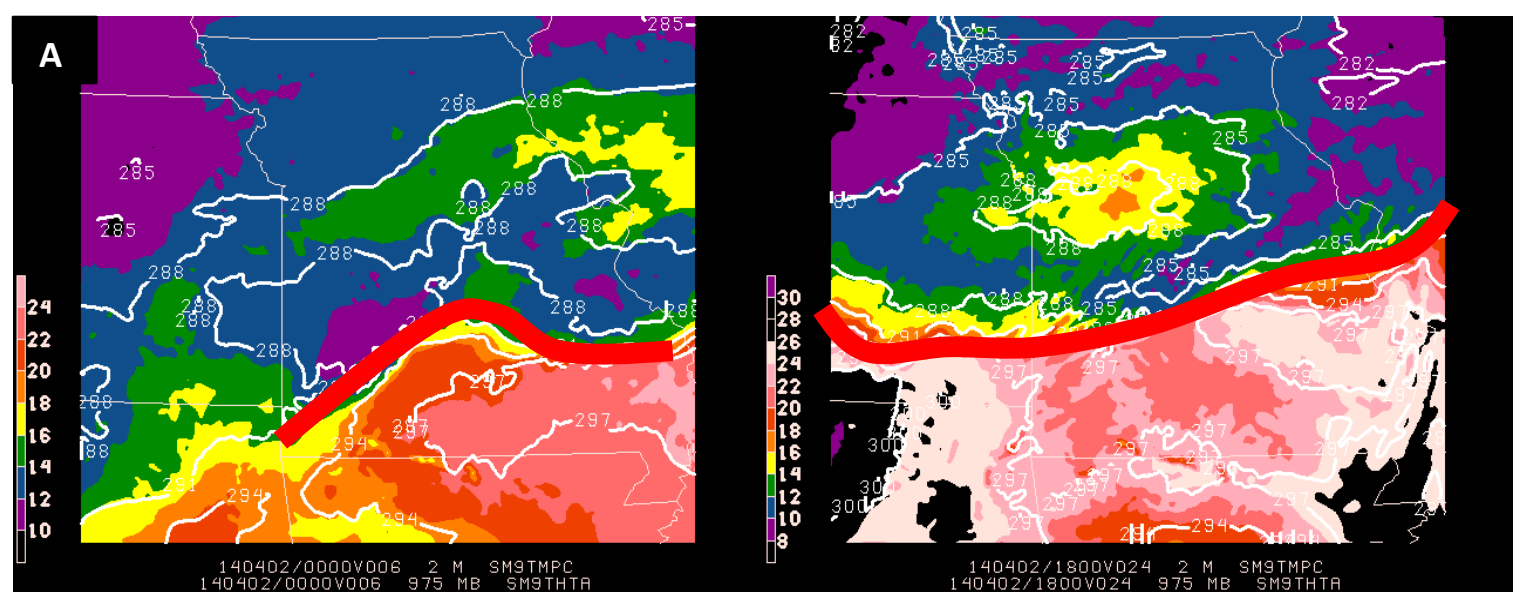

\section{B}

Figure 5.3. WDME model configuration 2-meter temperature (every $2{ }^{\circ} \mathrm{C}$; color filled) and $975-\mathrm{mb} \theta_{e}$ (every $3 \mathrm{~K}$; white contours) during IOP 1 . The approximate location of the warm front is denoted $b$ the solid red line, Valid at a) 0000 UTC 2 April 2014, and b) 1800 UTC 2 April 2014.

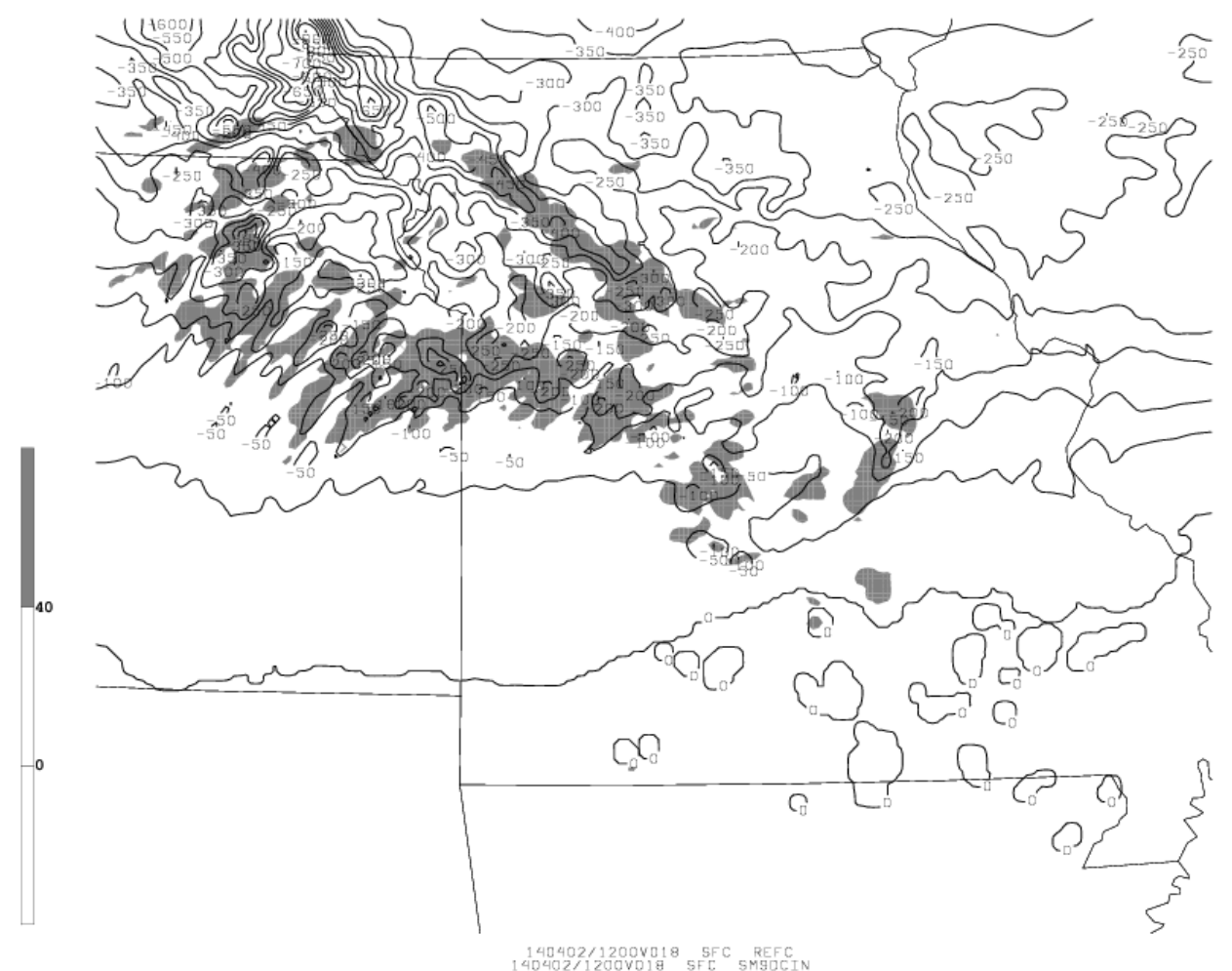

Figure 5.4. Showing DCIN values (every $-50 \mathrm{Jkg}^{-1}$; solid black contours) and simulated reflectivity (over $40 \mathrm{dBZ}$ gray color fill) from the WDME model configuration. Valid 1200 UTC 02 April 2014. 


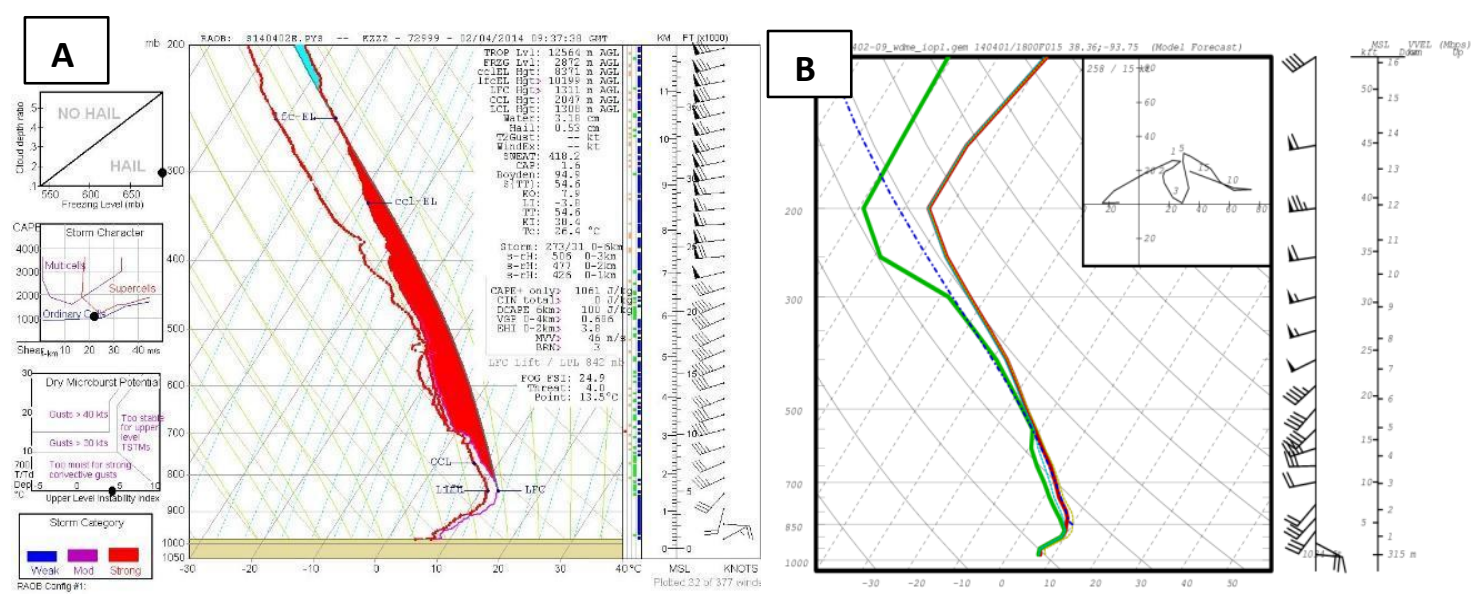

Figure 5.5. Soundings from IOP 1 valid 0900 UTC 2 April 2014 for a location near Clinton, MO. (a) observed from PRECIP balloon launch, (b) model sounding from the WDME model configuration.

\subsubsection{IOP 2: 3 - 4 June 2014}

A weak leeside low and attendant boundary was present across western Kansas and eastern Colorado. A low level jet oriented perpendicularly to this boundary fed moisture north of this boundary, and fueled several rounds or elevated convection. This event featured a large elevated MCS that formed over central Nebraska and rode along and north of a warm front that stretched from western Nebraska into Iowa. The convection took the form of a QLCS with large unified cold pools advancing southward towards the warm air. The ability of downdrafts, and thus cold pools, to reach the surface was key to how this event unfolded. As we will see, no DCIN values were analyzed during the duration of this event. As cool pools reached the surface the air acted to sharpen the thermal gradient and drive it southward, deeper into the warmer air. The sharper gradient lead to enhanced low-level ascent and the redevelopment of convection. This process lead to a wide $(250 \mathrm{~km})$ swath of heavy precipitation. This event was a classic example of elevated convection north of a boundary, which forced the boundary 
southward. This case featured strong, unified cold pools from a large MCS, compared to the cellular type convection observed in IOP1. It was noted that in IOP1 the cold pools from convection were not able to penetrate to the surface, therefore the rain that was falling had a minimal and local cooling effect. This was starkly different in IOP 2 as we see clear evidence in the cold pools reached the surface.

Figure 5.6 shows the Roebber Performance Diagram for all 48 models for IOP 2 which occurred 03-04 June 2014 with the elevated convection occurring over southern Iowa and northern Missouri. This figure shows all 48 members provided at least somewhat skillful guidance for this event. Figure 6 shows that 9 of the top 10 CSI scores came from model configurations with parameterized convection while 9 of the bottom 10 CSI scores came from models with explicit convection configurations. Additionally 6 of the top ten CSI scores came from models with Mellor-Yamada Kanishi Niino (MYNN3) planetary boundary parametrization (which uses local vertical mixing).

Parameterized convection model configurations (Anything with ' $G$ ' in the name in Table 5.2) handled the large MCS much better than the explicit convection configurations. There was a clear over forecast of QPF from all the parameterized convection configurations, as indicated by all parameterized convection configurations to left of the 1.0 FBIAS line bisecting Fig. 5.6. Figure 5.7 depicts the MODE analysis for the one inch threshold and shows that the over forecast is seen in the best performing model configuration the TNG (29,257 forecasted grid squares compared to 25,415 observed grid squares). MODE analysis reveals that the TNG had a nearly perfect orientation of the 1.0 inch QPF being only $3^{\circ}$ different than the observed QPF. The centroid distance was also excellent at only 14.61 grid squares away from the observed 
QPE centroid. Figure 5.7 illustrates this excellent forecast showing the observed QPE (red color filled) just inside the TNG QPF contour (blue solid line).

Figure 5.8a shows the pre-convective environment from the TNG model valid at 2100 UTC 03 June 2014. Note the northwest to southeast oriented boundary stretching through from Nebraska through Iowa. Figure $5.8 \mathrm{~b}$ shows this boundary displaced southward with a protrusion in the TNG modeled 2 meter temperature fields as a result of the elevated MCS. Figure 5.8c shows how far southward the boundary has been pushed by 1200 UTC 4 June 2014, all the way from central Nebraska to northern Missouri. The reinforcement of low level cool air by convective cold pools eventually pushed the boundary, which began as a warm front from central Nebraska into central Kansas and Missouri at 2100 UTC 03 June 2014. Twenty-one hours later it is analyzed as a cold front across central Missouri, 21 at 1800 UTC 4 June 2014. The TNG model configuration had a fairly good representation of the low-level boundary displacement as is it correctly handled the orientation of convection and the large unified cold pool which initiated the displacement.

By 060004 June 2014 convection was well established across southern Nebraska through northwest Missouri. Yet, Fig. 5.9a shows DCIN values, from the TNG model, are not present in the area of convection. The lack of negative DCIN values at both 0600 UTC and 1200 UTC (Figs. 5.9a and 5.9b) and implies that downdrafts were capable of reaching the surface and thus impacting surface weather. Indeed, we see strong evidence of this as large convective cold pools were able to unify and halt the progress of the analyzed warm front and force it southward as a cold front. Soundings, both simulated and observed, indicated a shallow inversion was present before, during and after 
convection. An example of this environment is seen in Fig. 5.10, which shows an observed sounding near Bethany, Missouri at 0400 UTC 04 June 2014, with a shallow, stout $\left(\sim 8^{\circ} \mathrm{C}\right.$ warm nose over $\left.20 \mathrm{mb}\right)$, inversion. This sounding was flow while convection was being reported near the time of launch and is located just north of the surface warm front. The inversion observed at 0600 UTC at both sites was between 900 $-950 \mathrm{mb}$, much shallower than what was observed during IOP $1(\sim 825 \mathrm{mb})$. The shallow nature of the inversion was unable to develop sufficient DCIN to impede even modest DCAPE values observed between 400 - $800 \mathrm{Jkg}-1$, thus downdrafts reached the surface, modified and the air mass and retrograded the front. 


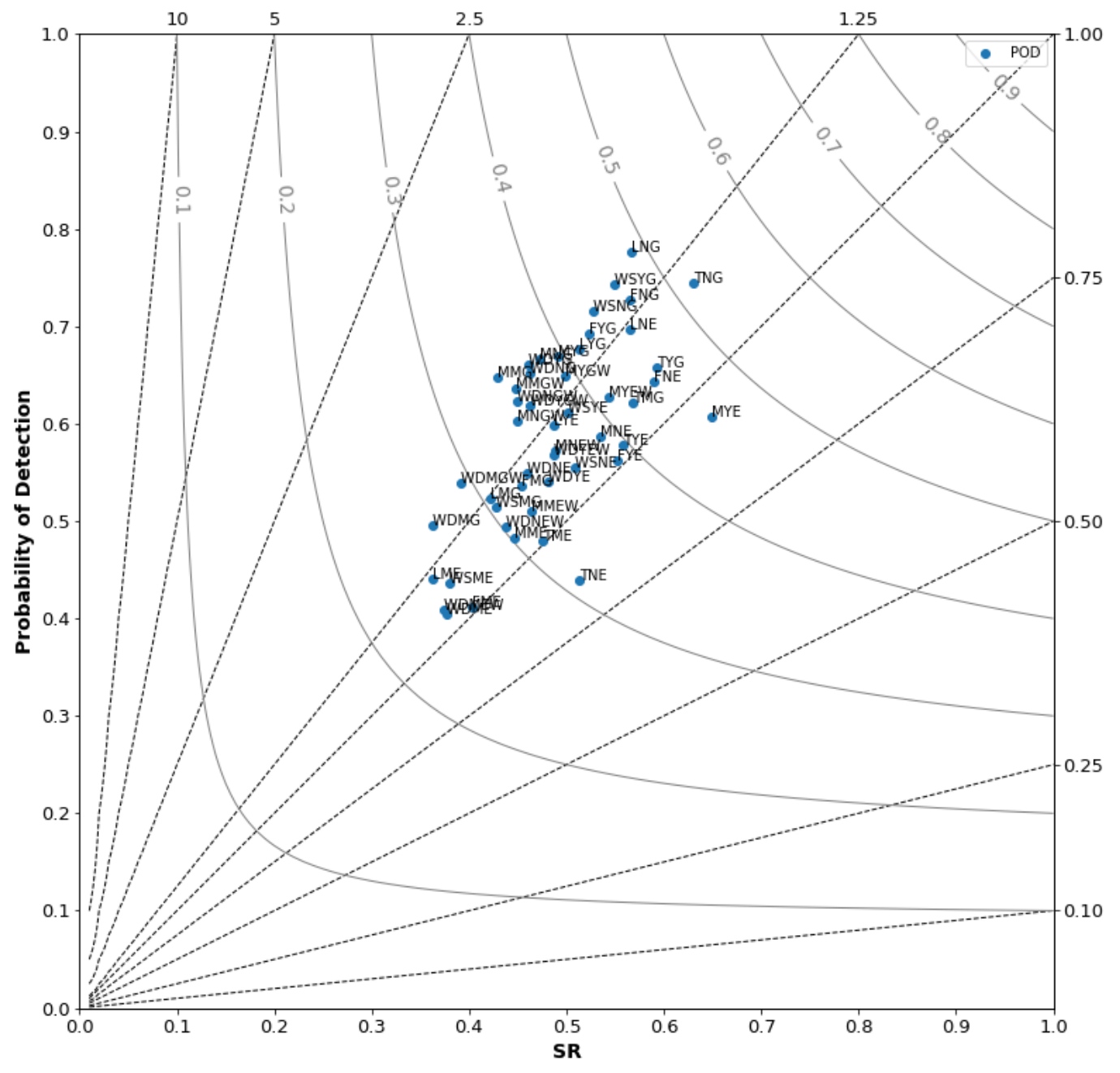

Figure 5.6. Roebber performance diagram showing each member (labeled blue dots) of the WRF-HRHPEFS for IOP 2. X -Axis shows the Success Ratio (SR), Y-Axis shows the Probability of Detection, curved lines represent Critical Success Index (CSI) values and the dashed diagonal lines represent Frequency Bias (FBIAS). A full description of each member can be found in Table 5.2. 


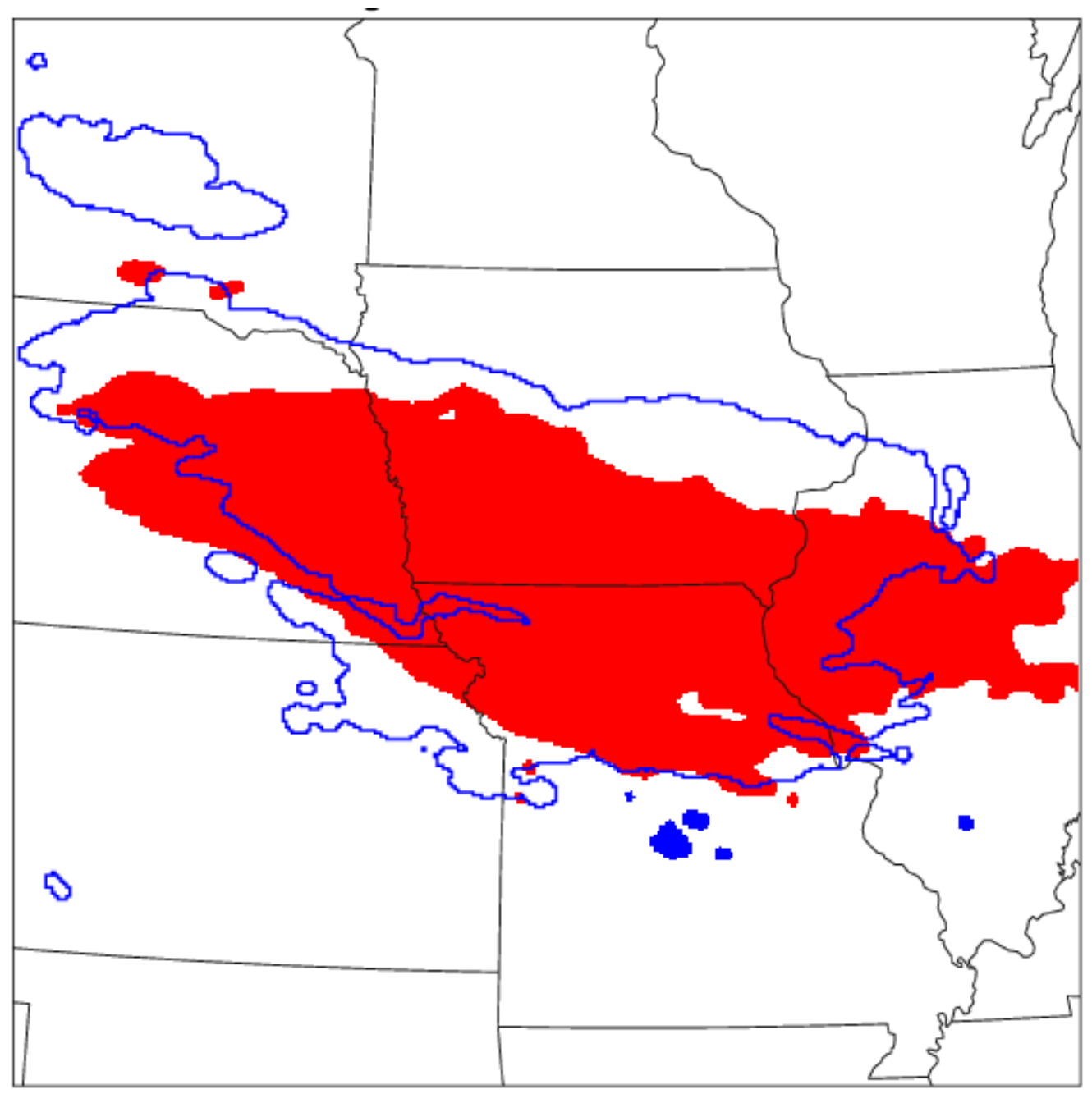

\begin{tabular}{|l|c|c|c|c|c|c|c|c|c|c|c|c|}
\hline $\begin{array}{l}\text { CLUS } \\
\text { PAIR }\end{array}$ & $\begin{array}{c}\text { CEN } \\
\text { DIST }\end{array}$ & $\begin{array}{c}\text { ANG } \\
\text { DIFF }\end{array}$ & $\begin{array}{c}\text { FCST } \\
\text { AREA }\end{array}$ & $\begin{array}{c}\text { OBS } \\
\text { AREA }\end{array}$ & $\begin{array}{c}\text { INTER } \\
\text { AREA }\end{array}$ & $\begin{array}{c}\text { UNION } \\
\text { AREA }\end{array}$ & $\begin{array}{c}\text { SYMM } \\
\text { DIFF }\end{array}$ & $\begin{array}{c}\text { FCST } \\
\text { INT 50 }\end{array}$ & $\begin{array}{c}\text { OBS } \\
\text { INT 50 }\end{array}$ & $\begin{array}{c}\text { FCST } \\
\text { INT 90 }\end{array}$ & $\begin{array}{c}\text { OBS } \\
\text { INT 90 }\end{array}$ & $\begin{array}{c}\text { TOT } \\
\text { INTR }\end{array}$ \\
\hline 1 & 14.61 & 3.20 & 29257 & 25415 & 20214 & 34458 & 14244 & 47.53 & 44.10 & 90.87 & 79.55 & 1.0000 \\
\hline
\end{tabular}

Figure 5.7. MODE output showing observed (red color filled area) QPE and forecast QPF (blue outline) from the TNG model configuration for IOP 2. The Table at the bottom of the image describes comparison of the forecasted (blue outline) to observed object (red color filled); as in Fig. 5.2, these values are discussed in the text. 

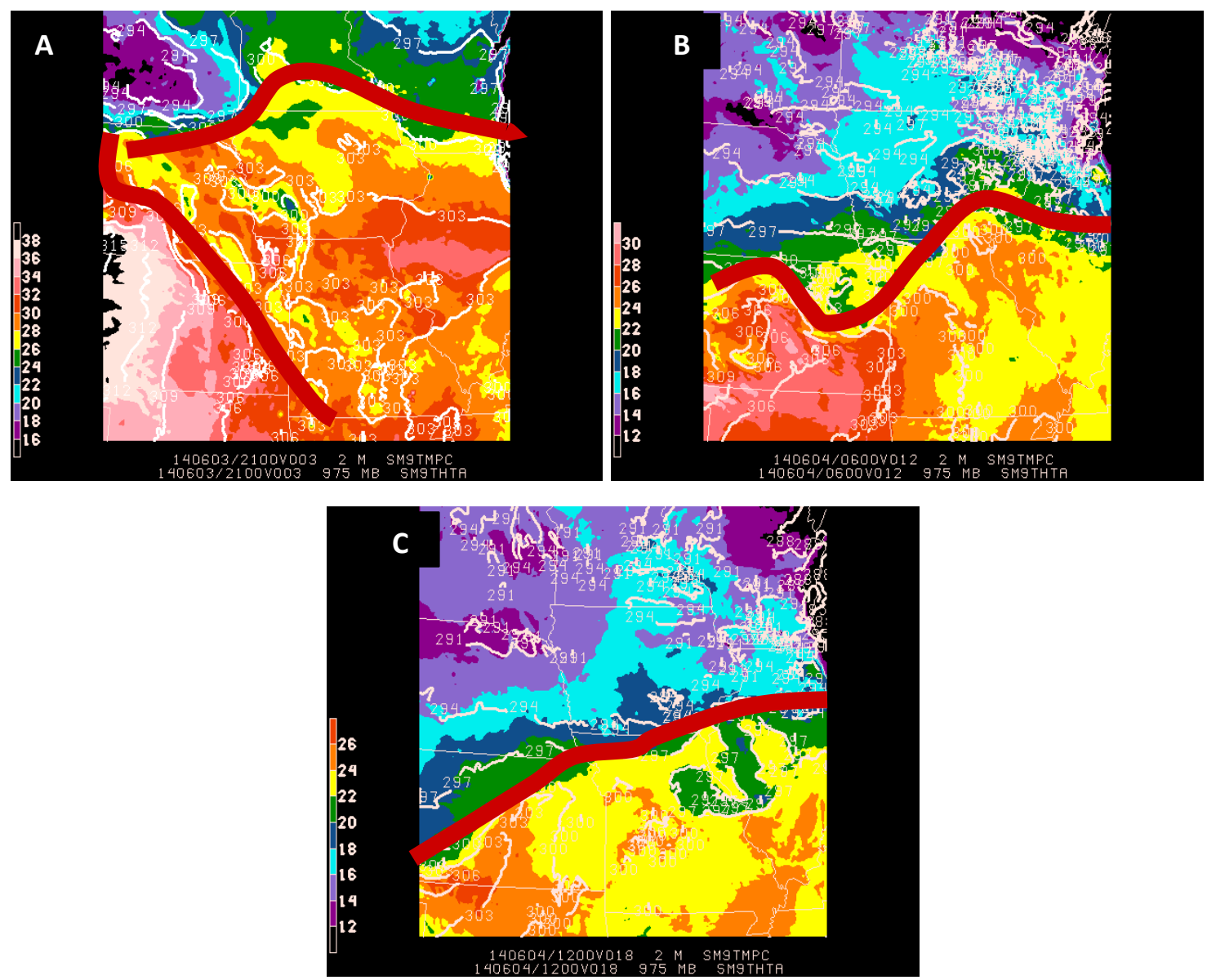

Figure 5.8. TNG model configuration 2-meter temperature ((every $2{ }^{\circ} \mathrm{C}$; color filled) and 975-mb $\theta_{e}$ (every $3 \mathrm{~K}$; white contours) during IOP 2 . The dark ted line indicates the approximate location of the boundary, Valid at a) 2100 UTC 03 June 2014, at b) 0600 UTC 04 June 2014, and at (c 1200 UTC 04 June 2014. 

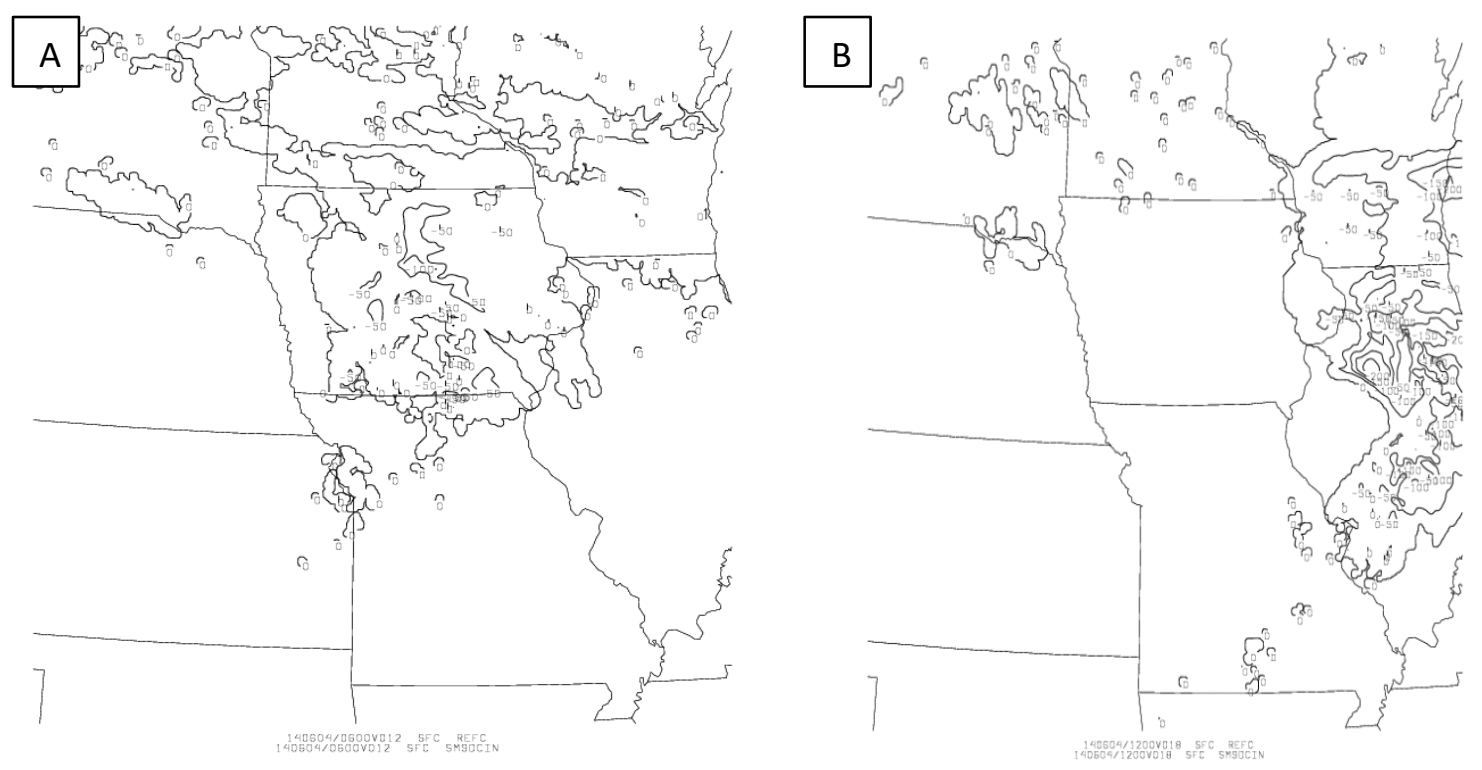

Figure 5.9. Contours of DCIN < 0 from the TNG model configuration for IOP 2. (a) Valid 0600 UTC 04 June 2014, (b) DCIN 1200 UTC 04 June 2014

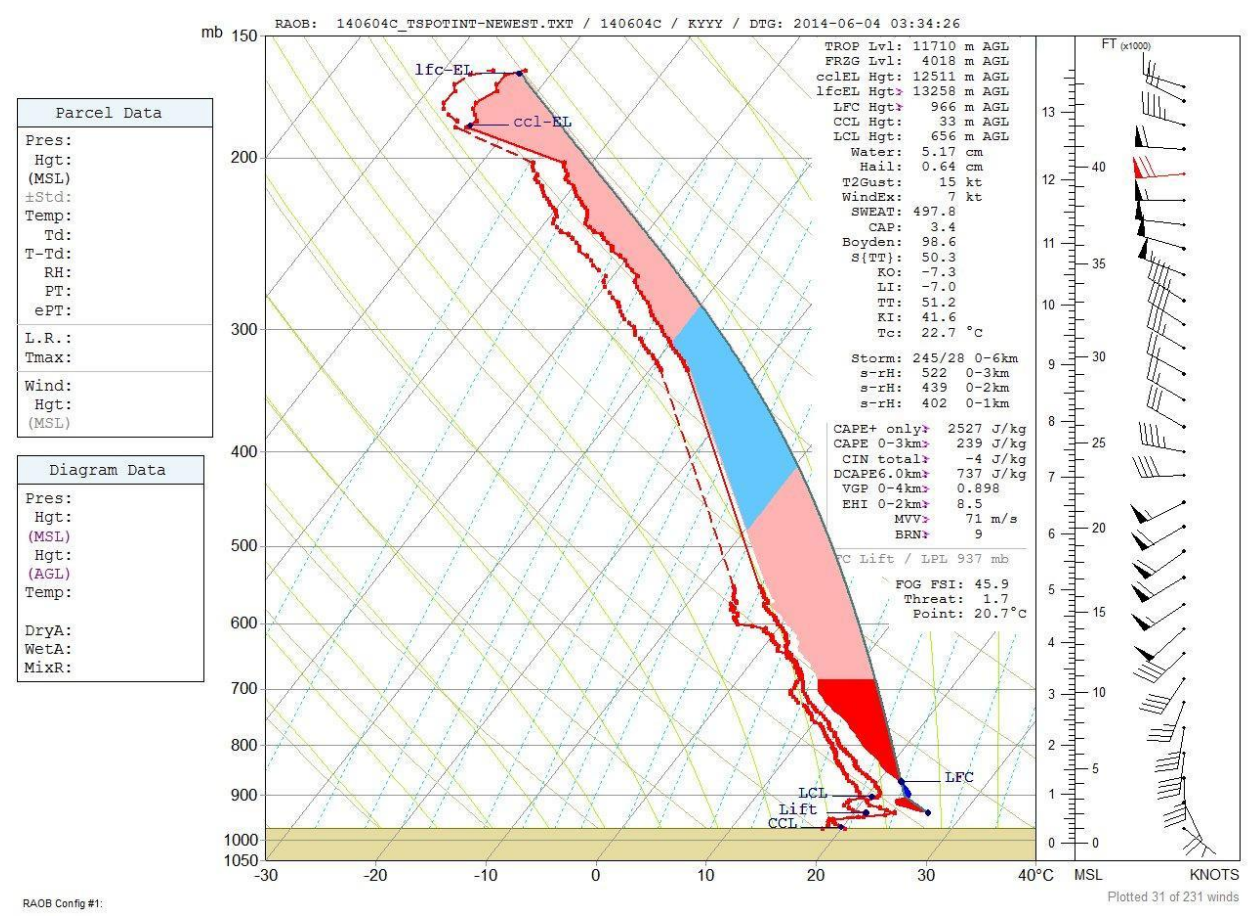

Figure 5.10. 0400 UTC 04 June 2014 sounding launched by PRECIP near Bethany, Missouri. This sounding sampled an environment just north of the surface warm front, and about 15 miles south of ongoing convection. 
Table 5.2. WRF-HRHPEFS model member configurations names and components of each configuration. Working from left to right will describe each member's Name, initial condition (IC), microphysics scheme used, Planetary Boundary Layer (PBL) scheme used, cumulus physics scheme used and the advection scheme used.

\begin{tabular}{|c|c|c|c|c|c|c|}
\hline Number & Name & IC & Microphysics & PBL Scheme & Cumulus Physics & Advection Scheme \\
\hline 1 & $\overline{L Y E}$ & $\overline{\mathrm{RAP}}$ & Lin & YUS & Explicit & $\overline{\mathrm{PD}}$ \\
\hline 2 & LYG & RAP & Lin & YUS & Grell 3D & PD \\
\hline 3 & LME & RAP & Lin & MYJ & Explicit & PD \\
\hline 4 & LMG & RAP & Lin & MYJ & Grell 3D & $\mathrm{PD}$ \\
\hline 5 & LNE & RAP & Lin & MYN & Explicit & PD \\
\hline 6 & LNG & RAP & Lin & MYN & Grell 3D & $\mathrm{PD}$ \\
\hline 7 & FYE & RAP & Ferrier & YUS & Explicit & PD \\
\hline 8 & FYF & RAP & Ferrier & YUS & Grell 3D & PD \\
\hline 9 & FME & RAP & Ferrier & MYJ & Explicit & PD \\
\hline 10 & FMG & RAP & Ferrier & MYJ & Grell 3D & $\mathrm{PD}$ \\
\hline 11 & FNE & RAP & Ferrier & MYN & Explicit & $\mathrm{PD}$ \\
\hline 12 & FNG & RAP & Ferrier & MYN & Grell 3D & PD \\
\hline 13 & WSYE & RAP & WSM 6 & YUS & Explicit & $\mathrm{PD}$ \\
\hline 14 & WSYG & RAP & WSM 6 & YUS & Grell 3D & $\mathrm{PD}$ \\
\hline 15 & WSME & RAP & WSM 6 & MYJ & Explicit & PD \\
\hline 16 & WSMG & RAP & WSM 6 & MYJ & Grell 3D & PD \\
\hline 17 & WSNE & RAP & WSM 6 & MYN & Explicit & $\mathrm{PD}$ \\
\hline 18 & WSNG & RAP & WSM 6 & MYN & Grell 3D & PD \\
\hline 19 & TYE & RAP & Thompson & YUS & Explicit & $\mathrm{PD}$ \\
\hline 20 & TYG & RAP & Thompson & YUS & Grell 3D & PD \\
\hline 21 & TME & RAP & Thompson & MYJ & Explicit & PD \\
\hline 22 & TMG & RAP & Thompson & MYJ & Grell 3D & PD \\
\hline 23 & TNE & RAP & Thompson & MYN & Explicit & PD \\
\hline 24 & TNG & RAP & Thompson & MYN & Grell 3D & $\mathrm{PD}$ \\
\hline 25 & MYE & RAP & Morrison & YUS & Explicit & PD \\
\hline 26 & MYG & RAP & Morrison & YUS & Grell 3D & PD \\
\hline 27 & MME & RAP & Morrison & MYJ & Explicit & PD \\
\hline 28 & MMG & RAP & Morrison & MYJ & Grell 3D & $\mathrm{PD}$ \\
\hline 29 & MNE & RAP & Morrison & MYN & Explicit & PD \\
\hline 30 & MNG & RAP & Morrison & MYN & Grell 3D & PD \\
\hline 31 & MYEW & RAP & Morrison & YUS & Explicit & WENO \\
\hline 32 & MYGW & RAP & Morrison & YUS & Grell 3D & WENO \\
\hline 33 & MMEW & RAP & Morrison & MYJ & Explicit & WENO \\
\hline 34 & MMGW & RAP & Morrison & MYJ & Grell 3D & WENO \\
\hline 35 & MNEW & RAP & Morrison & MYN & Explicit & WENO \\
\hline 36 & MNEG & RAP & Morrison & MYN & Grell 3D & WENO \\
\hline 37 & WDYE & RAP & WDM 6 & YUS & Explicit & PD \\
\hline 38 & WDYG & RAP & WDM 6 & YUS & Grell 3D & PD \\
\hline 39 & WDME & RAP & WDM 6 & MYJ & Explicit & PD \\
\hline 40 & WDMG & RAP & WDM 6 & MYJ & Grell 3D & $\mathrm{PD}$ \\
\hline 41 & WDNE & RAP & WDM 6 & MYN & Explicit & PD \\
\hline 42 & WDNG & RAP & WDM 6 & MYN & Grell 3D & $\mathrm{PD}$ \\
\hline 43 & WDYEW & RAP & WDM 6 & YUS & Explicit & WENO \\
\hline 44 & WDYGW & RAP & WDM 6 & YUS & Grell 3D & WENO \\
\hline 45 & WDMEW & RAP & WDM 6 & MYJ & Explicit & WENO \\
\hline 46 & WDMGW & RAP & WDM 6 & MYJ & Grell 3D & WENO \\
\hline 47 & WDNEW & RAP & WDM 6 & MYN & Explicit & WENO \\
\hline 48 & WDMGW & RAP & WDM 6 & MYN & Grell 3D & WENO \\
\hline
\end{tabular}




\subsubsection{IOP 5: 4 - 5 June 2015}

This event took place 04-05 June 2015 across southwest Nebraska into northern Kansas and western Missouri. Elevated convection along and north of the boundary were able to unify and suppress the northeastward advance of the front. The meteorological situation is reminiscent of IOP 2, in which a warm front was stalled and forced to retrograde by strong unified elevated convection, which produced cold pools strong enough to stall the advancement of the front. As in IOP 2, DCIN was not observed in the area of convection, allowing downdrafts to reach the surface and enhance convection in the interface region of the cold pool - warm front and drive the front southward.

Figure 5.11 shows the Roebber performance diagram for the 48 model configurations for IOP 5. Operations guidance performed very poorly for this case spreading far too much QPF into eastern Nebraska and western Iowa. This was similarly observed in most of the WRF-HRHPEFS members and lead to very poor performance among a bulk of the configurations. Most of these poor performing solutions displaced the bulk of the QPF much too far to the northeast and continued to have the warm front move slowly northeastward into western Iowa. The notable exception was the strong performing cluster of configurations with WRF microphysics and parameterized convection. The WSYG, WDYG, WDMG and WSMG configurations were the only four configurations with CSI scores $>0.30$ as seen in Fig. 5.11. The WDYG configuration rated out as the best as it had the best FBIAS compared to the others within this cluster. As in IOP 2, parameterized convection had the top performing configurations for this event. A cluster of explicit members show up around the 0.20, seen in Fig. 5.11. The very worst performing members in the lowest left cluster of Fig. 5.11 are made up of 
configurations with WENO mass and moisture advection schemes and explicit convection.

Figure 5.12 shows a comparison of the one inch WPF from the WDYG to the Stage IV analysis via MODE. The analysis reveals that even the best performing model configuration had the northern extent of the QPF shield too far to the north and expanding one inch QPF to far east ( as indicated by the centroid distance being off by 47.63 grid squares) into Missouri. That being said, the size (8,403 grid squares forecasted, 8,990 grid squares observed) and angle (3.25 $)$ were very well forecasted. The analysis shows the model configuration correctly forecasted the front being forced southeastward, something most of the other model configurations and operation guidance and did not indicate.

Convection developed over central Nebraska and paralleled a warm front southeastward. The 2-meter temperature field is seen in Fig. 5.13 from the top performing WDYG configuration. It shows a representative atmosphere with two boundaries in the region (a second boundary is located north near the Iowa - Minnesota border). Convection initiated around 2000 UTC 04 June 2015 across south central Nebraska and quickly spread southeastward. DCIN values $<0$ were not observed and expectedly, downdrafts were able to reach the surface, bringing cool air to the surface and spreading rapidly south and eastward. Figure 5.14 shows an observed sounding at 0000 UTC 05 June 2015 that was launched by PRECIP from Nebraska City, NE. Elevated convection was ongoing within 10 miles of this sounding at the time of launch and the location experienced elevated convection within two hours of this launch. This sounding provides an example of an atmosphere conducive to elevated convection, yet supportive 
of enough DCAPE to impact surface weather. In this sounding we see a prominent warm nose just above $900-\mathrm{mb}$, increasing $4-5{ }^{\circ} \mathrm{C}$ in the span of $\sim 20 \mathrm{mb}$. Even with this strong inversion present, dominant downdrafts were able to push through any DCIN that formed in the inversion layer. By 0600 UTC cold pools have expanded southeastward thanks to strong DCAPE, driving the effective front into southern Kansas. Figure 5.15a shows simulated reflectivity and DCIN at $0600 \mathrm{UTC}$, well into a period of elevated convection occurring across southeast Nebraska, northeast Kansans and western Missouri. As in IOP 2 discussed above, DCIN values less than 0 are not observed, indicating downdrafts should be able to penetrate to the surface, unhindered by the DCIN layer. DCAPE values are shown in Fig. 5.15b and show much of the region being impacted by values $>800$ Jkg-1. Observed soundings from southeast Nebraska and northwest Missouri showed a shallow but, pronounced inversion between 925 and $950 \mathrm{mb}$. However, strong DCAPE values were able to easily overcome any DCIN values present thus downdrafts were able to impact surface sensible weather. This is observed as a unified convective cold pool is easily seen in the 2-meter temperature field along the axis of $1+$ inch rainfall. As in IOP 2, the surface boundary was impacted by the convective cold pools and was forced to stall and eventually sag southward. Figure $5.15 \mathrm{~b}$ shows that by 1200 UTC, after hours of heavy rainfall, DCIN values are not able to overcome DCAPE values, thus downdrafts continue to reach the surface and the cool air continues to sag the boundary further south. This is seen in Fig 5.13c which shows the WDYG 2 meter temperature field with the effective boundary driven southeastward all the way into southern Missouri. 


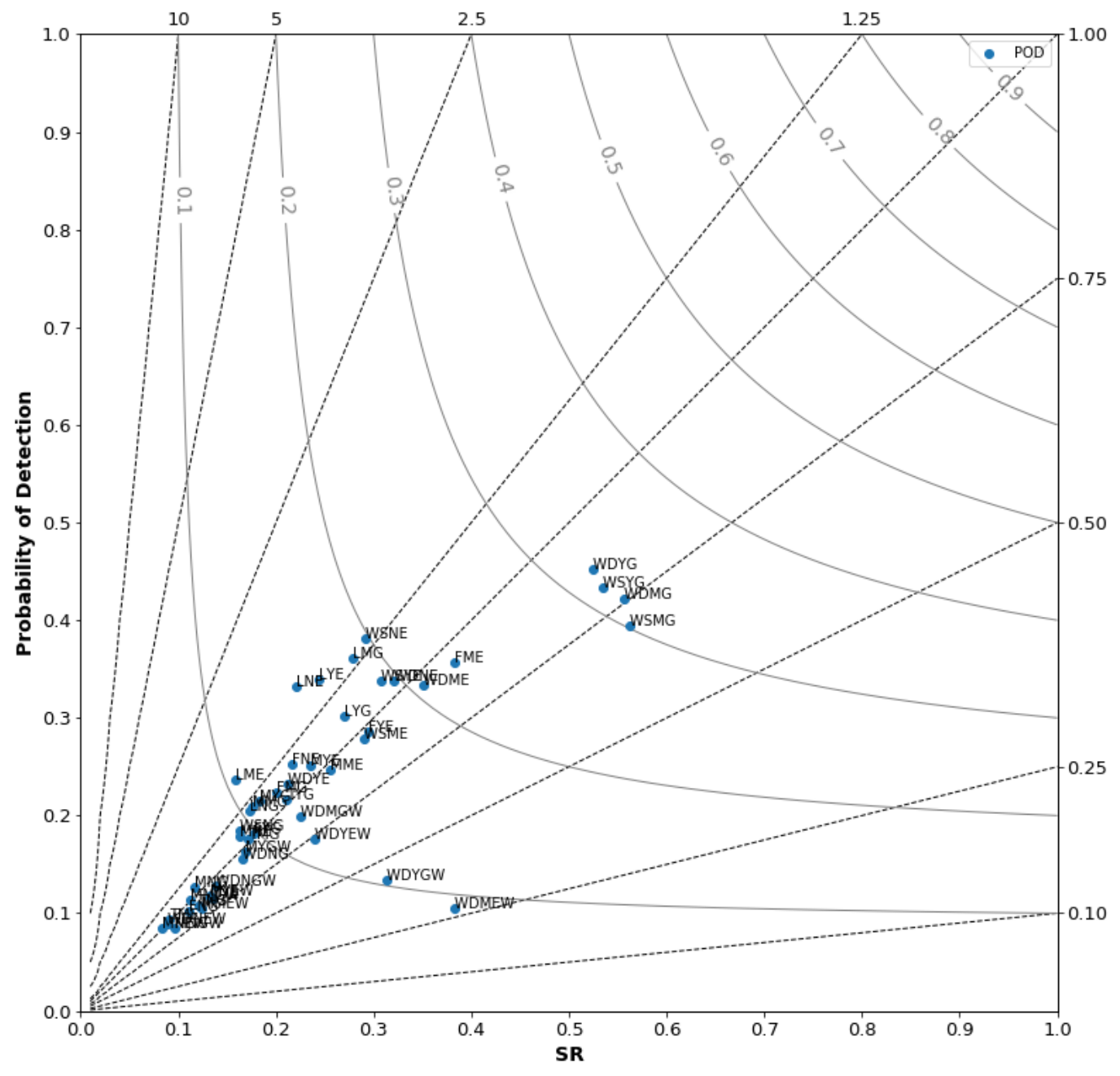

Figure 5.11. Roebber performance diagram showing each member (labeled blue dots) of the WRF-HRHPEFS for IOP 5. X-Axis shows the Success Ratio (SR), Y-Axis shows the Probability of Detection, curved lines represent Critical Success Index (CSI) values and the dashed diagonal lines represent Frequency Bias (FBIAS). A full description of each member can be found in Table 5.2. 


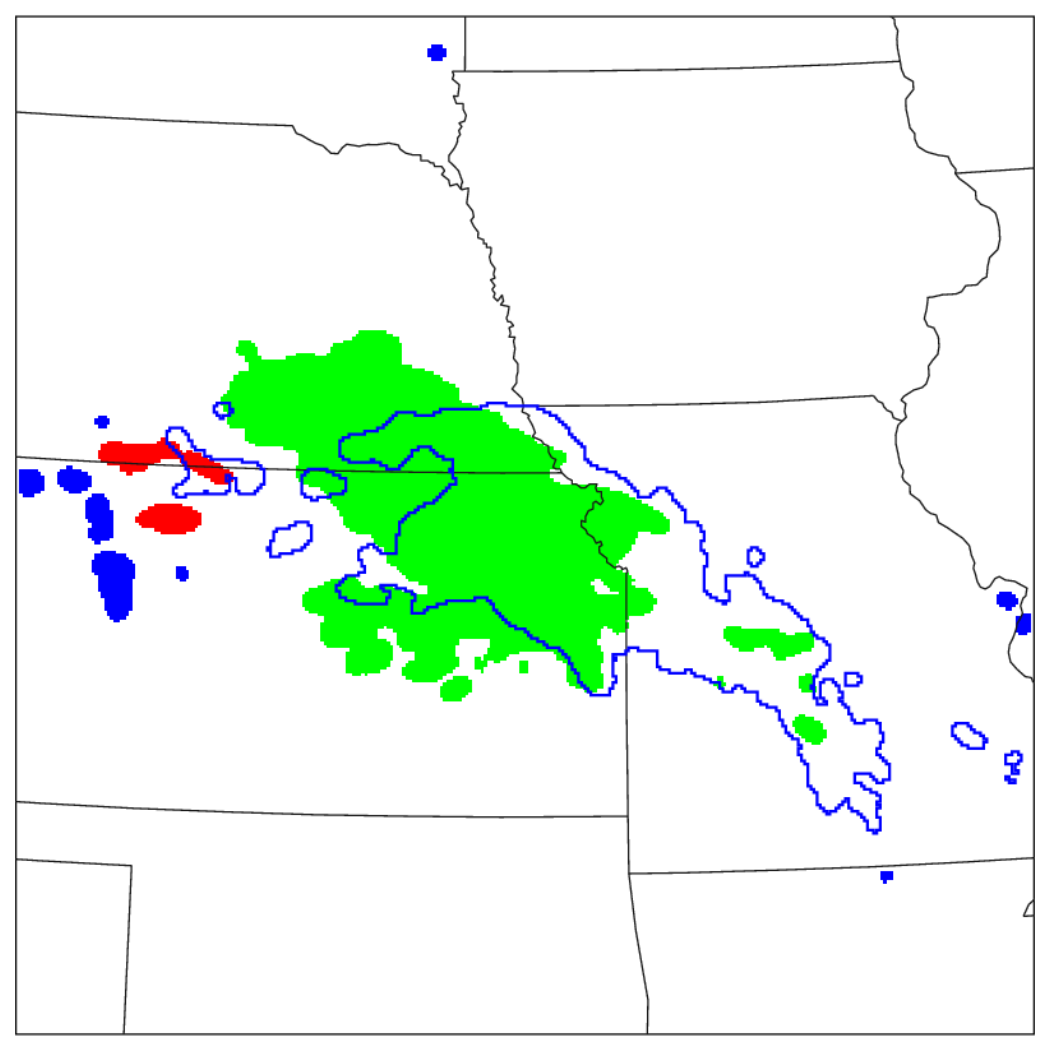

\begin{tabular}{|c|c|c|c|c|c|c|c|c|c|c|c|c|}
\hline $\begin{array}{l}\text { CLUS } \\
\text { PAIR }\end{array}$ & $\begin{array}{l}\text { CEN } \\
\text { DIST }\end{array}$ & $\begin{array}{l}\text { ANG } \\
\text { DIFF }\end{array}$ & $\begin{array}{l}\text { FCST } \\
\text { AREA }\end{array}$ & $\begin{array}{c}\text { OBS } \\
\text { AREA }\end{array}$ & $\begin{array}{c}\text { INTER } \\
\text { AREA }\end{array}$ & $\begin{array}{c}\text { UNION } \\
\text { AREA }\end{array}$ & $\begin{array}{c}\text { SYMM } \\
\text { DIFF }\end{array}$ & $\begin{array}{c}\text { FCST } \\
\text { INT } 50\end{array}$ & $\begin{array}{c}\text { OBS } \\
\text { INT } 50\end{array}$ & $\begin{array}{c}\text { FCST } \\
\text { INT } 90\end{array}$ & $\begin{array}{c}\text { OBS } \\
\text { INT } 90\end{array}$ & $\begin{array}{l}\text { TOT } \\
\text { INTR }\end{array}$ \\
\hline 1 & 154 & 14.63 & 329 & 454 & 101 & 682 & 581 & 28.03 & 32.54 & 32.51 & 56.79 & 0.9894 \\
\hline 2 & 47.63 & 3.25 & 8403 & 8990 & 4913 & 12480 & 7567 & 36.54 & 42.59 & 56.87 & 74.38 & 0.9701 \\
\hline
\end{tabular}

Figure 5.12. MODE output showing observed (red color filled area) QPE and forecast QPF (blue outline) from the WDYG model configuration for IOP 5. The Table at the bottom of the image describes comparison of the forecasted (blue outline) to observed object (red, blue and green color filled); these values are described in the test. 

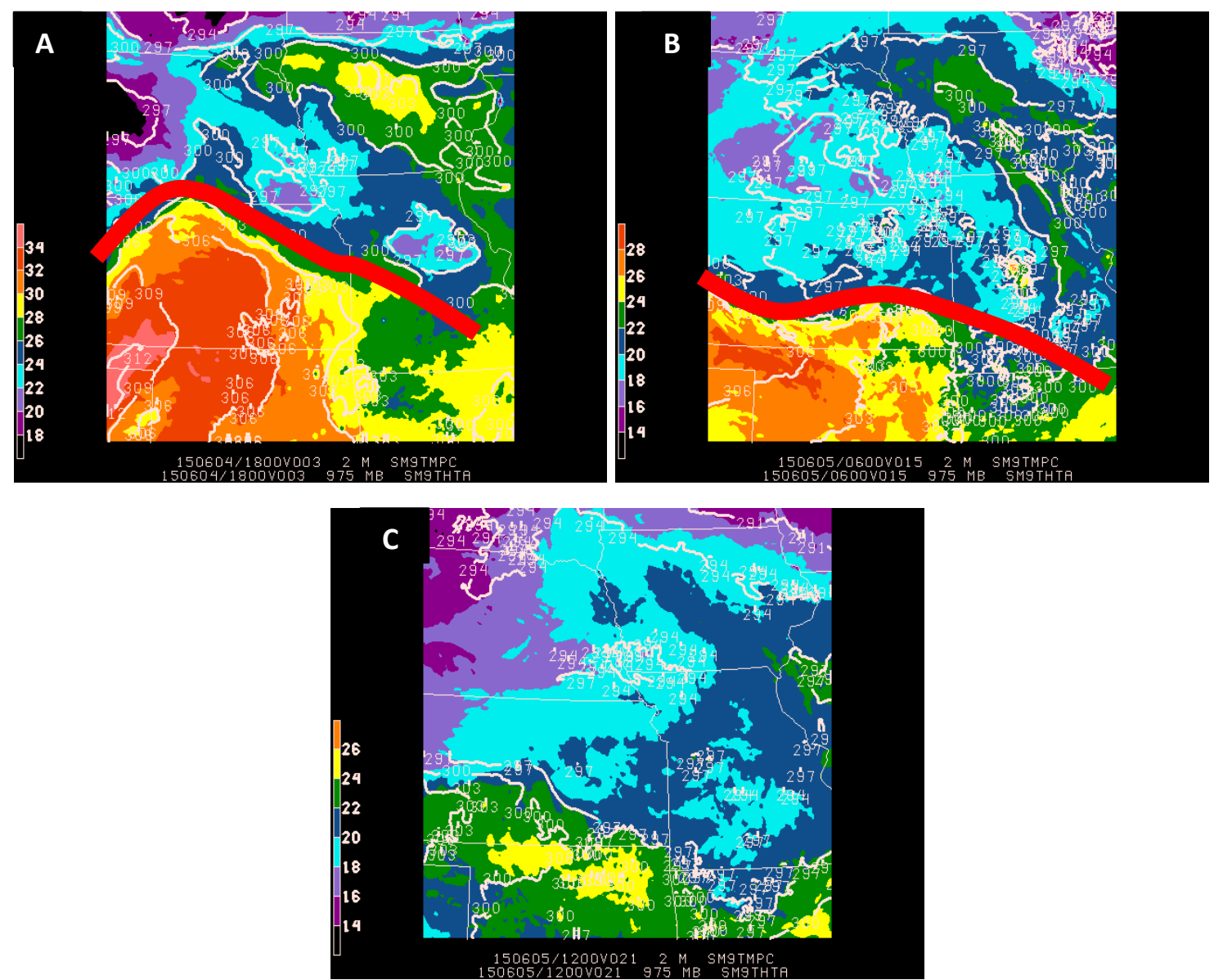

Figure 5.13. WDYG model configuration 2-meter temperature (every $2{ }^{\circ} \mathrm{C}$; color filled) and $975-\mathrm{mb} \theta_{e}$ (every $3 \mathrm{~K}$; white contours) during IOP 5. The red line indicates the approximate location of the boundary; Valid at a) 2100 UTC 04 June 2015, at b) 0600 UTC 05 June 2015, and at c) 1200 UTC 05 June 2015.s 

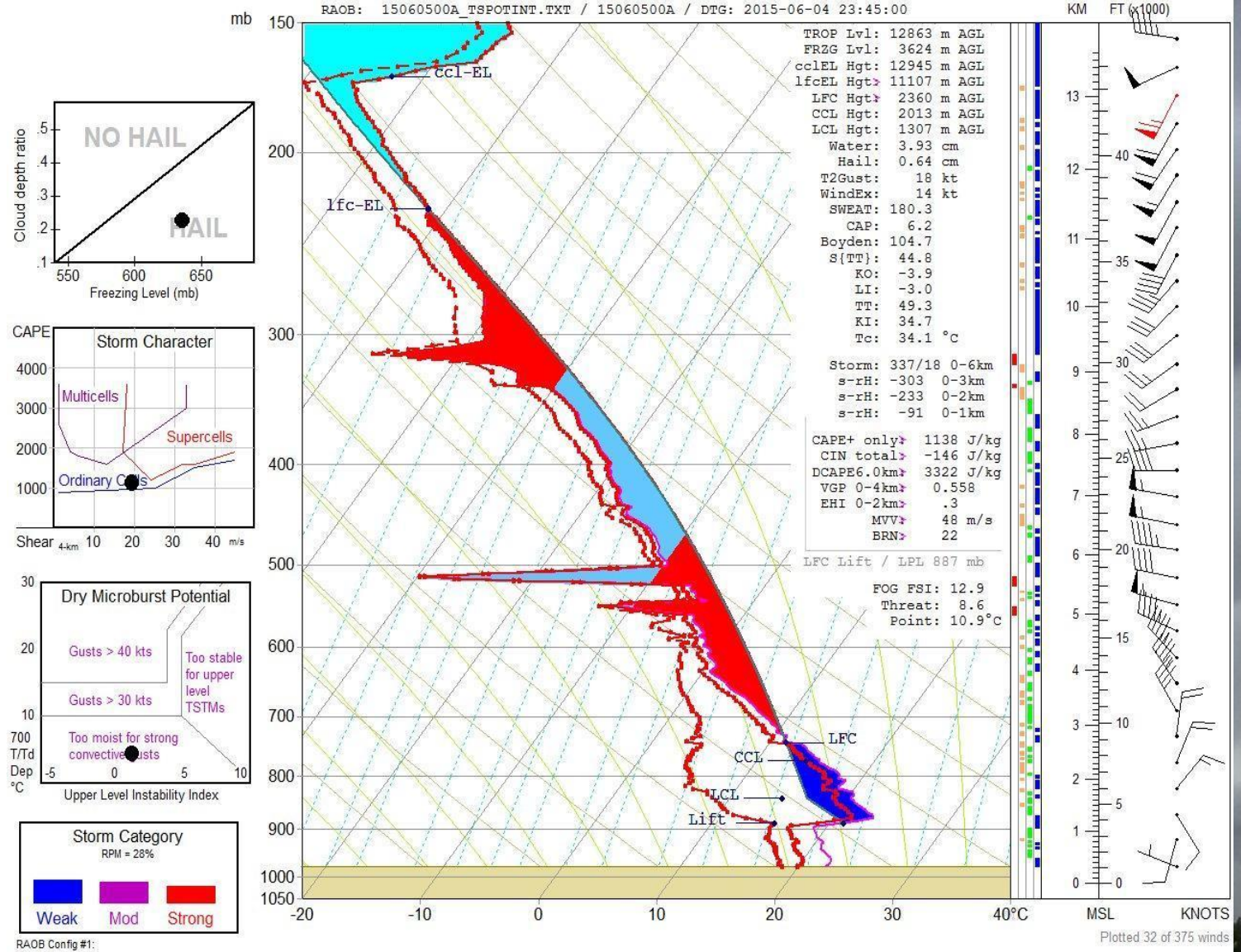

Figure 5.14. Sounding from observed from PRECIP balloon launch during IOP 5 valid 0000 UTC 05 June 2015. Launched near Nebraska City, NE.
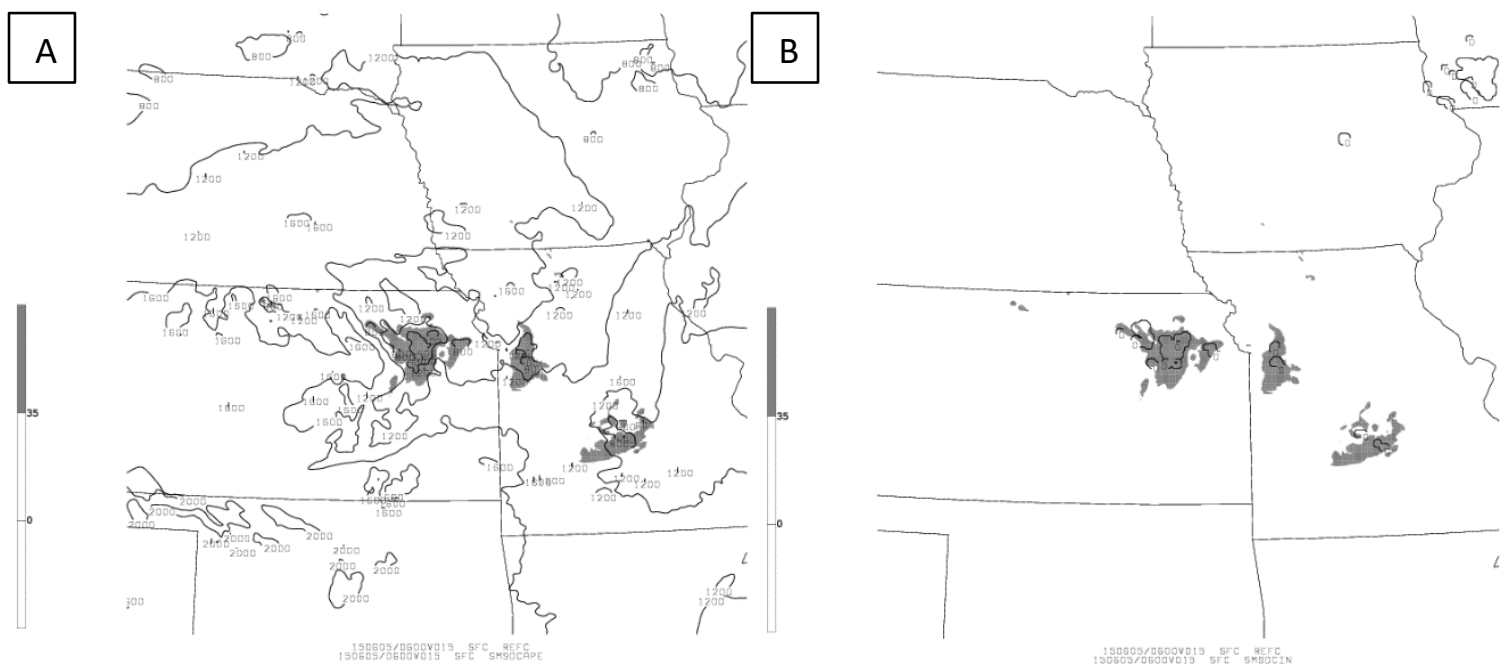

Figure 5.15. (a) DCAPE (black contours) and simulated reflectivity (gray color fill) from the WDYG model configuration. Valid 0600 UTC 05 June 2015. (b) DCIN (black contours) and simulated reflectivity (gray color fill) from the WDYG model configuration. Valid 0600 UTC 05 June 2015 


\subsubsection{IOP 8: 8 July 2015}

IOP 8 occurred 08 Jul 2015 over western and central Missouri as a cold front stalled over the Ozark Plateau and began to move northward as a weak low pressure moved northeastward from Oklahoma.. A large precipitation shield formed in the vicinity of the boundary with the most intensive cores forming along and north of the developing warm front as elevated convection.

The best performing model by CSI for IOP 8 at the one inch threshold was the MNGW configuration as seen in the performance diagram (Fig. 5.16). The performance diagram also reveals an interesting pattern in which all the parameterized convection configurations had FBIAS values near 1.25 and nearly all of the explicit convection configurations had FBIAS values near 1.00. This is likely an artifact of the parameterized convection overproducing convection and trying to create a broader MCS when in fact the elevated cells were more isolated within a stratiform rain shield. This scenario was similar to that observed in IOP 1, where cells stayed isolate and the FBIAS was handled better by explicit model configurations in that instance as well. The MODE analysis Fig. 5.17 confirms the over forecast indicated by the Roebber diagram for the MNGW model configuration.

Figure 5.18a shows the 2 meter temperature field from the MNGW at 0000 UTC 8 July 2015 and then again 12 hours later in Fig 5.18c. 1200 UTC is when elevated convection began to intensify over central Missouri. Of note is the lack of a clearly defined cold pool region in the temperature field. This is because DCIN values of less than zero were found indicating that cold pools would not be able to penetrate to the surface. Figure 5.19 shows a sounding launched by PRECIP as elevated convection was 
occurring from Columbia, MO 1200 UTC 08 July 2015 and depicts a deep inversion topping out between 875 and $850 \mathrm{mb}$ with only $\sim 200 \mathrm{Jkg}^{-1}$ of DCAPE analyzed.

Figure 5.20 show a system with negative DCIN values analyzed across northeast Oklahoma and Missouri. At 1200 UTC the highest simulated reflectivity values are found in northeast Oklahoma and southwest Missouri along and north of an axis of DCIN values $<50 \mathrm{Jkg}^{-1}$. By 1500 UTCT the convection has intensified and moved northeast 100 miles while DCIN values decreased such that much of the convection occurred in an environment with DCIN values $<100 \mathrm{Jkg}^{-1}$. Of note is that convection moved readily to the northeast during this event and, the 2 meter temperature field shows no indication of convective cold pools north of the boundary. This was an expected result as the downdrafts from convection were unable to penetrate to the surface and impact the warm front in the presence of negative DCIN values. This is similar to the pattern that was observed in IOP 1. Indeed, a deep inversion was also observed during this case, with the warm nose maximized near $850 \mathrm{mb}$. 


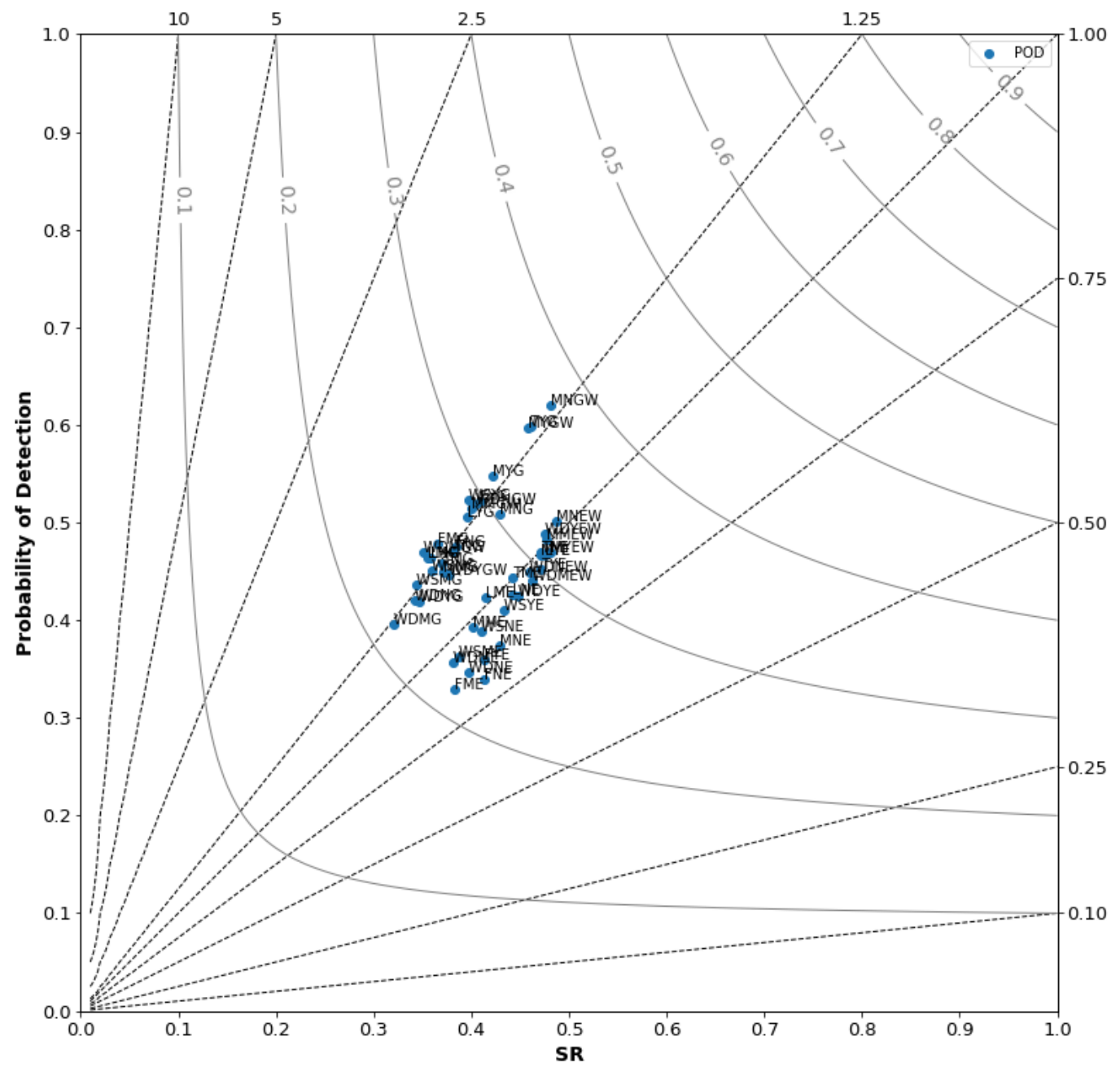

Figure 5.16. Roebber performance diagram showing each member (labeled blue dots) of the WRF-HRHPEFS for IOP 8. X -Axis shows the Success Ratio (SR), Y-Axis shows the Probability of Detection, curved lines represent Critical Success Index (CSI) values and the dashed diagonal lines represent Frequency Bias (FBIAS). A full description of each member can be found in Table 5.2. 


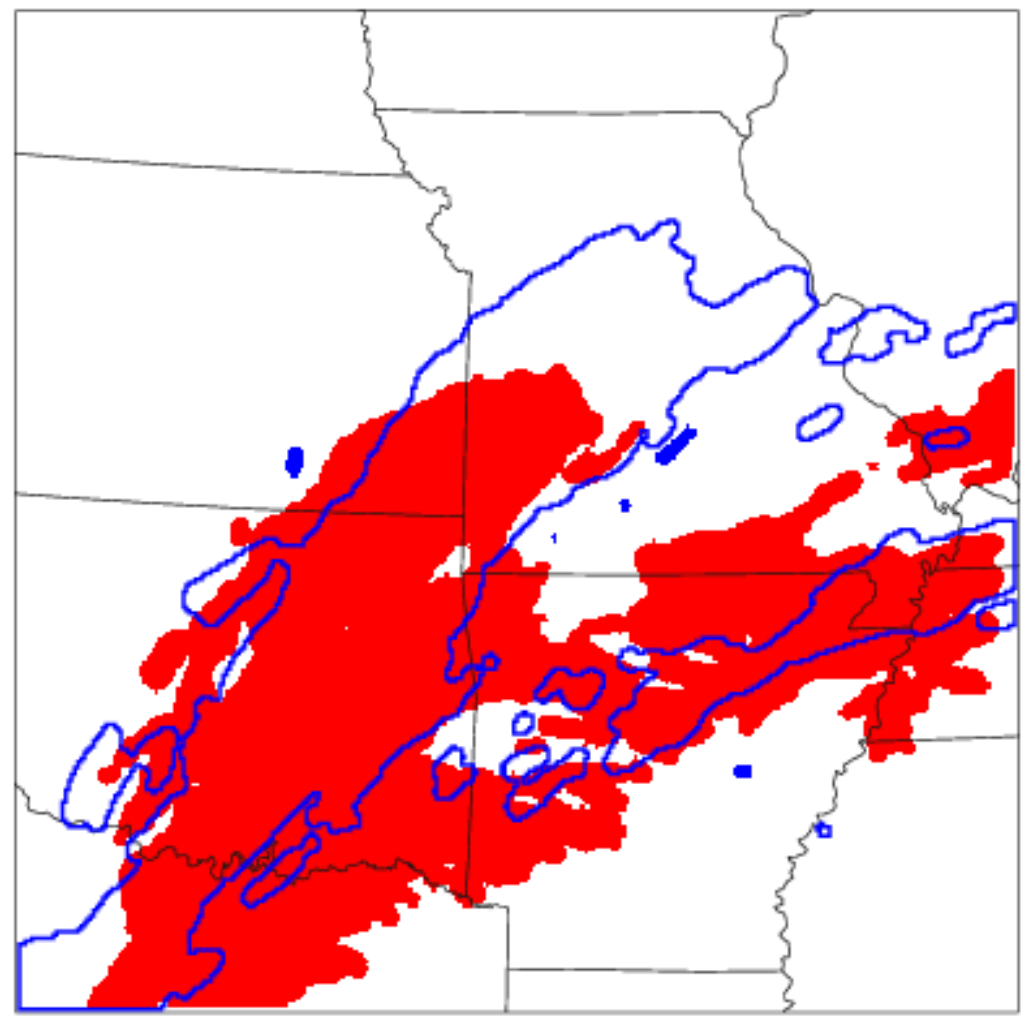

\begin{tabular}{|l|c|c|c|c|c|c|c|c|c|c|c|c|}
\hline $\begin{array}{l}\text { CLUS } \\
\text { PAIR }\end{array}$ & $\begin{array}{c}\text { CEN } \\
\text { DIST }\end{array}$ & $\begin{array}{c}\text { ANG } \\
\text { DIFF }\end{array}$ & $\begin{array}{c}\text { FCST } \\
\text { AREA }\end{array}$ & $\begin{array}{c}\text { OBS } \\
\text { AREA }\end{array}$ & $\begin{array}{c}\text { INTER } \\
\text { AREA }\end{array}$ & $\begin{array}{l}\text { UNION } \\
\text { AREA }\end{array}$ & $\begin{array}{c}\text { SYMM } \\
\text { DIFF }\end{array}$ & $\begin{array}{c}\text { FCST } \\
\text { INT 50 }\end{array}$ & $\begin{array}{c}\text { OBS } \\
\text { INT 50 }\end{array}$ & $\begin{array}{c}\text { FCST } \\
\text { INT 90 }\end{array}$ & $\begin{array}{c}\text { OBS } \\
\text { INT 90 }\end{array}$ & $\begin{array}{c}\text { TOT } \\
\text { INTR }\end{array}$ \\
\hline 1 & 25.58 & 13.94 & 29671 & 22341 & 15581 & 36431 & 20850 & 37.01 & 43.50 & 62.00 & 79.45 & 0.9884 \\
\hline
\end{tabular}

Figure 5.17. MODE output showing observed (red color filled area) QPE and forecast QPF (blue outline) from the MNGW model configuration for IOP 8. The Table at the bottom of the image describes comparison of the forecasted (blue outline) to observed object (red color filled); these values are described in the text. 

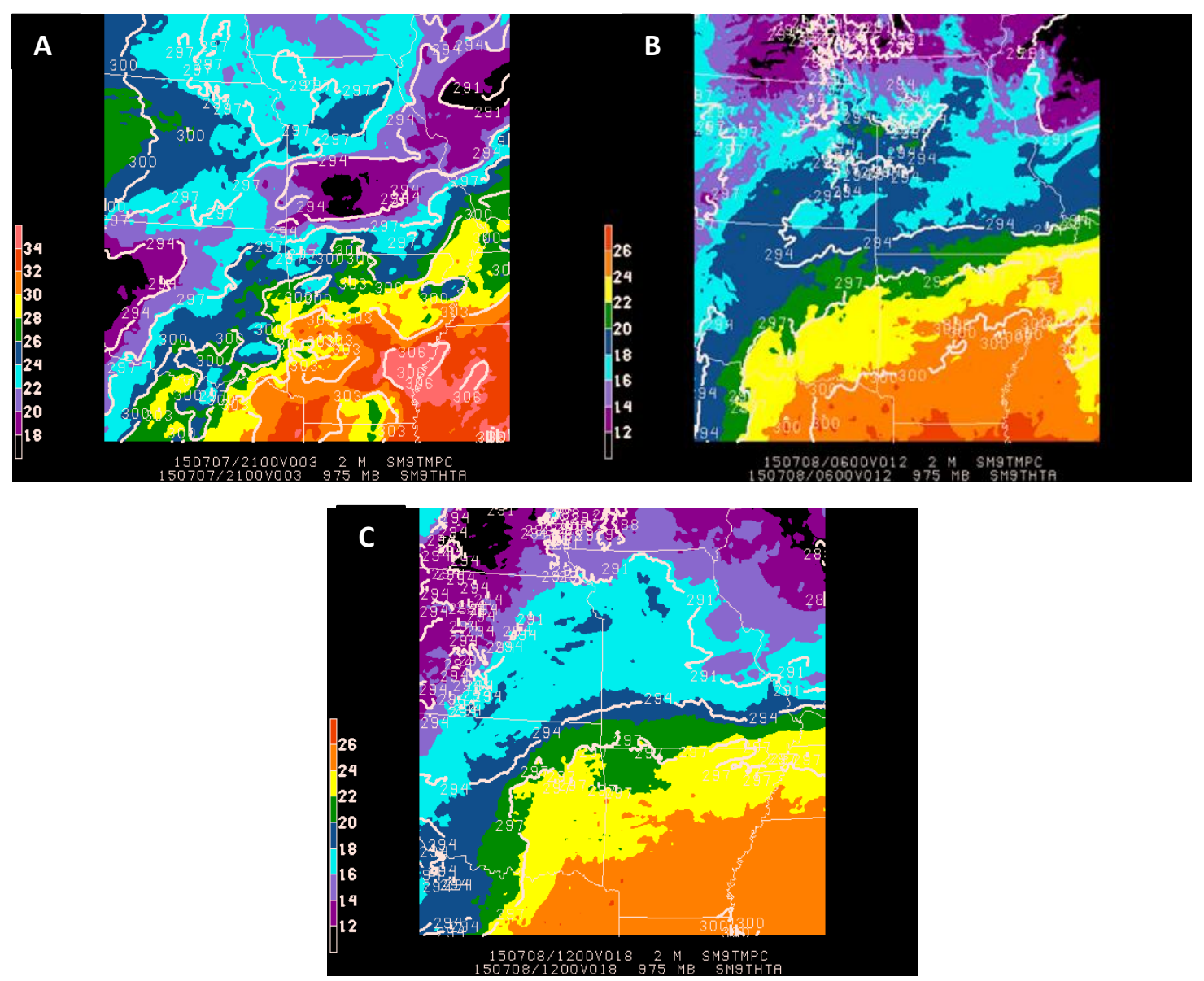

Figure 5.18. MNGW model configuration 2-meter temperature (every $2{ }^{\circ} \mathrm{C}$; color filled) and 975-mb $\theta_{e}$ (every $3 \mathrm{~K}$; white contours) during IOP 8; at a) 2100 UTC 07 June 2015, at b) 0600 UTC 08 June 2015, at c) 1200 UTC 08 June 2015. 


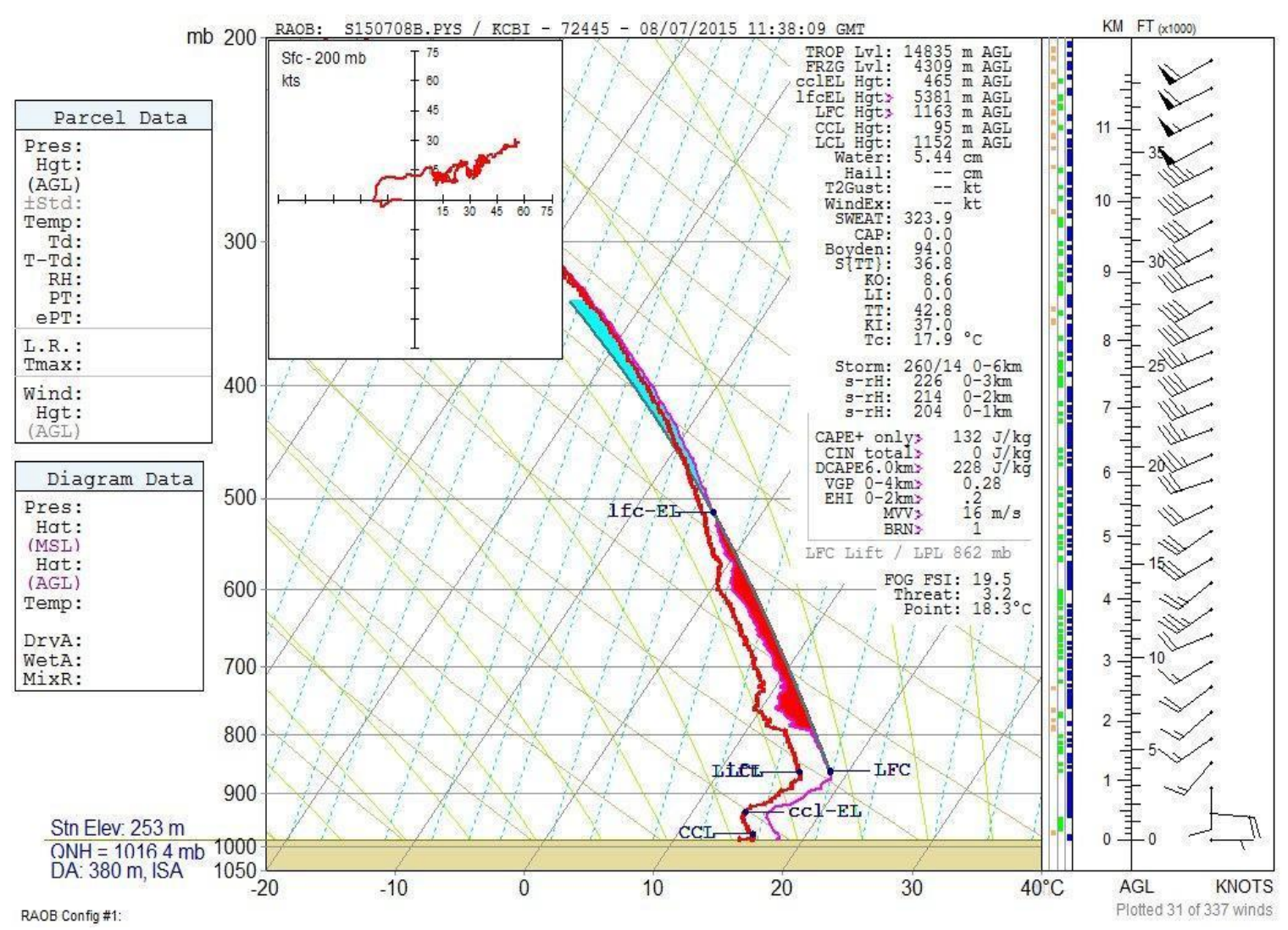

Figure 5.19. Observed sounding valid at 1200 UTC 08 June 2015, launched by PRECIP near Columbia, MO during IOP 8.
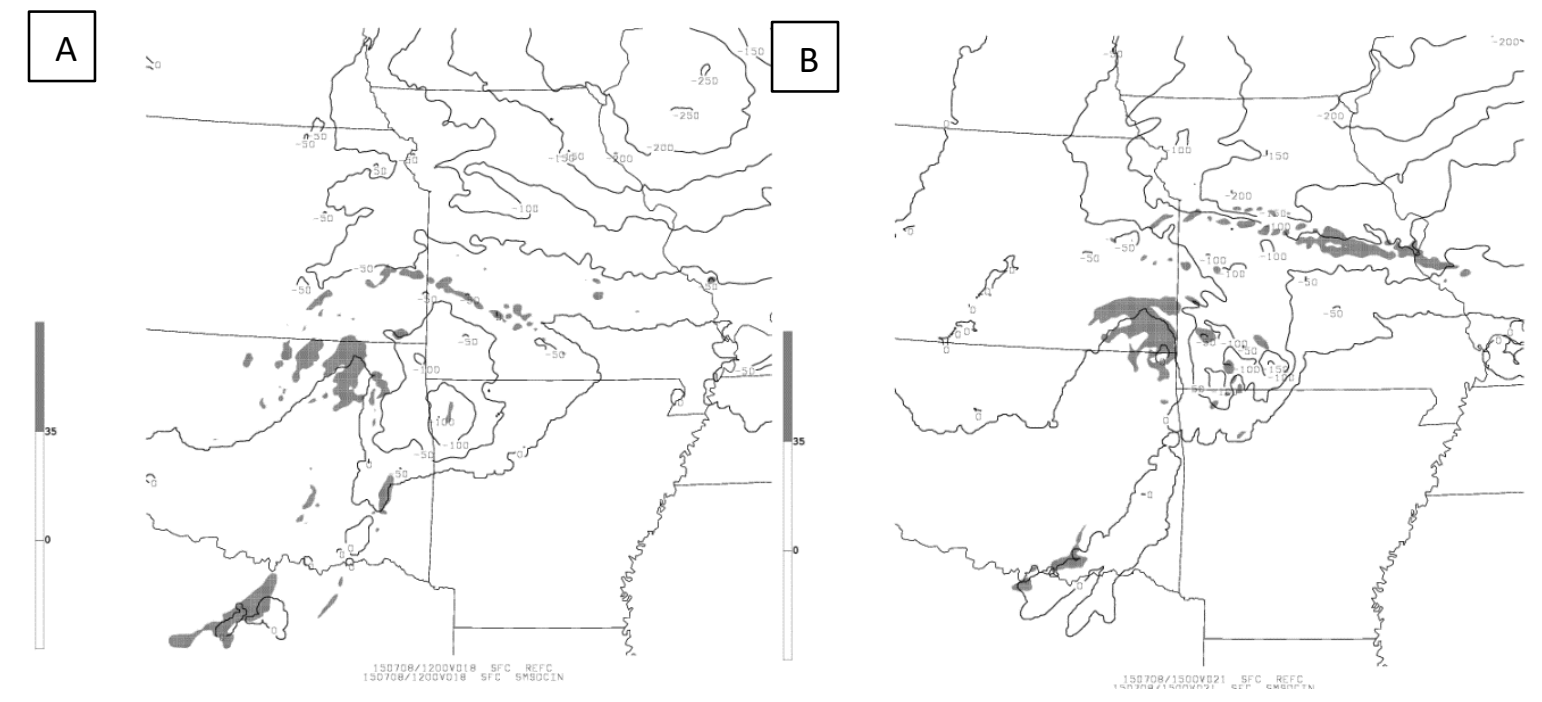

Figure 5.20. Showing DCIN values (black contours) and simulated reflectivity (gray color fill) from the MNGW model configuration.(a) Valid 1200 UTC 08 July 2015 and (b) valid 1500 UTC 08 July 2015 


\subsection{Summary and Concluding Thoughts}

During the PRECIP field campaign elevated convection was sampled by radiosondes while events were ongoing. It was observed that some episodes of elevated convection resulted in convection in an anticipated location, along and north of an advancing warm front. However, several were observed where the boundary was stalled and forced southward as convection north of a boundary laid out large cold pools that dominated surface weather. When this was observed, heavy precipitation was observed where the boundary and cold pools were interacting. Evidence was presented supporting the notion that during some events featuring convection north of a synoptic boundary significant cold pools were in juxtaposition with warm air the south of the boundary. This created a scenario in which you had cooler air north of a boundary with an embedded area of even cooler air from convective cold pools. Enhanced convection and heavy rainfall were observed where this coolest region interacted with the warm air along and south of the boundary. Cases in which this was observed occurred in environments that were favorable for elevated MCSs, consistent with what was shown by Moore et al., (2003). Convection was able to sustain itself in this optimal region of cold pools were able to push the boundary south, thus putting the cold air in contact with a fresh, undisturbed warm air environment.

Figure 5.21 shows this very scenario resulting in sustained elevated convection. Figure 5.21 (which focusing on IOP 2; see table 1 for details) shows the RAP initial fields between 1800 UTC - 0600 UTC 03-04 June 2014 and depicts the response of Petterssen Frontogenesis as convection north of the boundary acts to tighten the low level (950-mb) $\theta$ _e field as cold pools from elevated convection reach the surface. Radar 
depiction of this MCS (seen in Figs. 5.21a,c and e) is super imposed on Petterssen Frontogenesis and 950-mb $\theta_{-}$e and shows how the complex was able to sustain itself as new cold pools (seen in the 2-meter temperature field in Figs. 5.21b,d, and f) pushed into untarnished air. Figure 5.21d shows frontogenesis maximized when the 2-meter temperature field is the sharpest, as fresh outflow (thanks to the sufficient DCAPE, as seen in Fig. 5.10) from ongoing convection pushed the boundary into the warm sector air. In such cases (IOP2, IOP 5), DCIN was not found. DCIN is theorized to be able to indicate if downdrafts will be able to impact surface weather by penetrating to the surface (Market et al, 2017), or if the DCIN layer will impede momentum of descending parcels enough to not allow downdrafts to reach the surface.

In order to investigate and delineate cases that featured frontal displacement and front progression, four instances (two in which the front was forced south and two where the front continued to progress) of elevated convection that were sampled during PRECIP were investigated using a reanalysis ensemble. A mixed physics approach was used to build the model ensemble (WRF-HRHPEFS) using the Weather Research and Forecasting (WRF) model with the Advanced Research WRF (ARW) core. It contained 48 individual members which varied microphysics, cumulus parameterization, boundary layer physics and moisture advection schemes. All 48 member of the model were run for the following events listed in Table 5.1. MODE analysis was also performed on these cases, with its analysis providing traditional grid statistics information used to generate Roebber performance diagrams and information forecasted QPF objects compared to observed Stage IV QPE. 
A distinct pattern emerged from the analysis; those cases in which DCIN values less than zero are observed and those without such values. In the cases with negative DCIN (IOP 1 and IOP 8) downdrafts from elevated convection were unable to penetrate to the surface and the 2 meter temperature field is unaffected by any convective cold pools. In the model ensemble reanalysis this was handled better by model configurations with explicit convection. In these cases the surface warm front is able to progress with time. In cases without negative DCIN, DCAPE was able to overcome the thermal inversion and convective cold pools were able to unify and impact surface sensible weather. This disrupted surface weather and lead to the displacement of the surface boundary. This scenario was handled best in the model ensemble reanalysis with members configured with parametrized (Grell 3-D cumulus parameterization) convection.

The presence of unified surface cold pools north of a boundary clearly has an impact on the movement of the boundary. Boundary displacement seems to be favored when DCAPE values are large enough to overcome DCIN values found in the inversion layer.

DCIN clearly has potential to be an effective tool in heavy rainfall forecasting, as it can be used to help discern if there is enough DCAPE to generate cold pools that can influence surface weather, including boundary location. This tool also has the potential to be useful for forecasting wind events associated with convection, as suggested by Market et al. (2017). If DCIN is present in an area thought to be a wind threat (> $50 \mathrm{kt}$ ), cases where $\mid$ DCIN $\mid>$ DCAPE it would suggest thunderstorms would not be able to produce windy surface conditions. This needs to be investigated further. DCIN should also be 
investigated in a real-time environment as it has been shown to have utility in case analysis in this study and the Market et al. 2017 study.
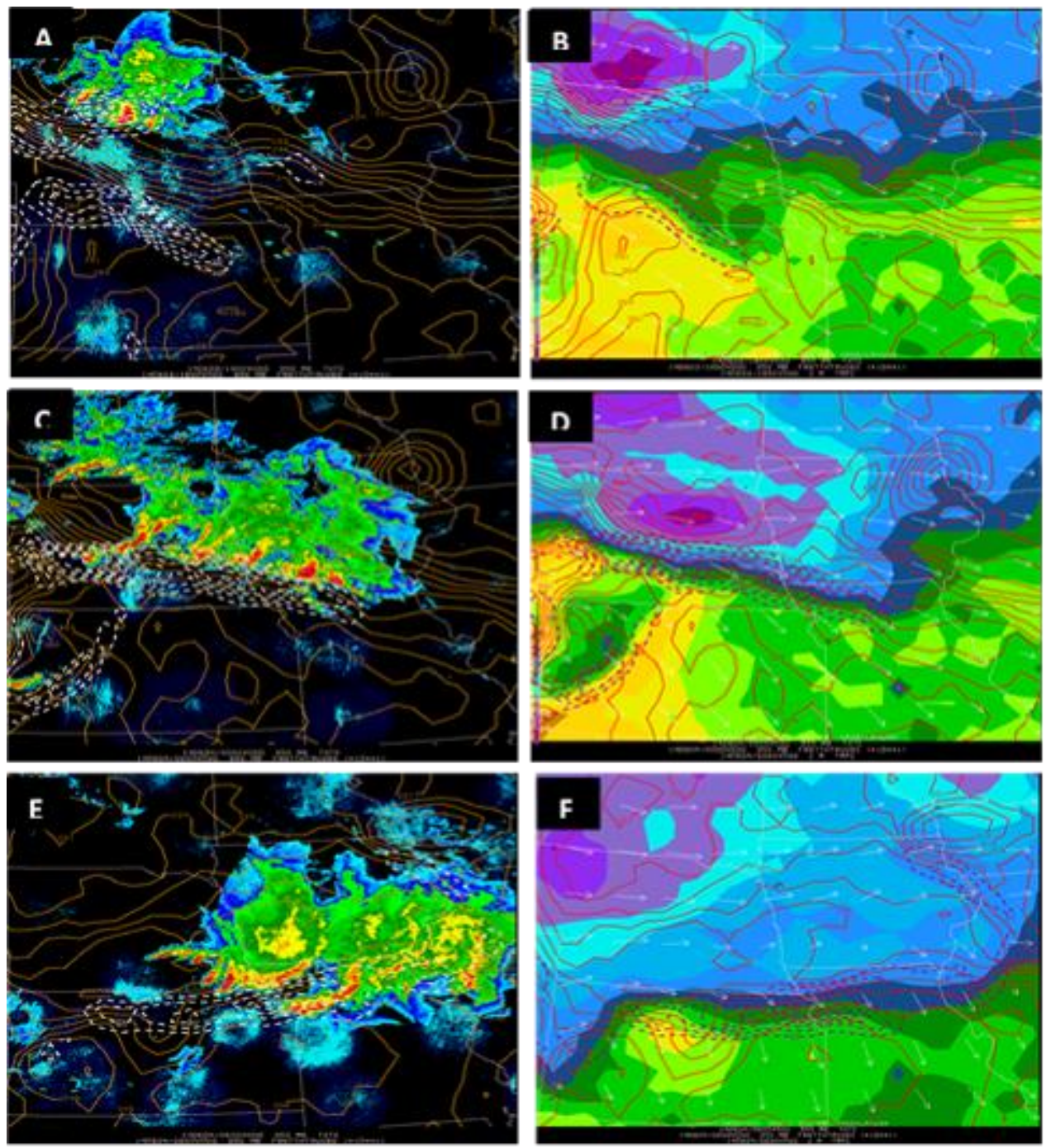

Figure 5.21. $13 \mathrm{~km}$ RAP model initial fields. 950-mb $\theta_{e}$ Every $3 \mathrm{~K}$ (brown contours). Reflectivity Every $5 \mathrm{dBZ}$ (filled colors). 950-mb Petterssen Frontogenesis every $10^{-1}$ $\mathrm{K} / 100 \mathrm{~km} / 3 \mathrm{hr}$ (white dashes) at a) 1800 UTC 03 June 2014, at c) 0000 UTC 04 June 2014, and at e) 0600 UTC 04 June 2014. Corfidi Vectors. 2-meter Temperature every 2 ${ }^{\circ} \mathrm{C}$ (filled colors). $\theta_{e}$ Every $3 \mathrm{~K}$ (red contours). 950-mb Petterssen Frontogenesis every $10^{-1} \mathrm{~K} / 100 \mathrm{~km} / 3 \mathrm{hr}$ (brown dashes) at b) 1800 UTC 03 June 2014, at d) 0000 UTC 04 June 2014, and at f) 0600 UTC 04 June 2014. 
Acknowledgments: This work is supported in part by the National Science Foundation (NSF), Award No. AGS-1258358. Any opinions, findings, conclusions or recommendations expressed herein are those of the author(s) and do not necessarily reflect the views of NSF. The authors would like to thank all members of the PRECIP who worked as forecasters and field research associates during the project. All observed soundings and raw observed data collected during the project can be found at http://weather.missouri.edu/PRECIP/data.html. 


\subsection{References}

Billings JM, Parker MD. 2012. Evolution and maintenance of the 22-23 June 2003 nocturnal convection during BAMEX. Weather and Forecasting 27: 279-300.

Clark, A. J., W. A. Gallus, M. Xue, and F. Kong, 2010: Convection-Allowing and Convection-Parameterizing Ensemble Forecasts of a Mesoscale Convective Vortex and Associated Severe Weather Environment. Weather and Forecasting, 25, 1052-1081.

Corfidi, S.F., J.H. Meritt, and J.M. Fritsch, 1996: Predicting the Movement of Mesoscale Convective Complexes. Wea. Forecasting, 11, 41-46, https://doi.org/10.1175/15200434(1996)011<0041:PTMOMC>2.0.CO;2

Corfidi, S. F., 2003: Cold Pools and MCS Propagation: Forecasting the Motion of Downwind-Developing MCSs. Weather and Forecasting, 18, 997-1017.

Corfidi, S. F., S. J. Corfidi, and D. M. Schultz, 2006: Toward a better understanding of elevated convection. Preprints 23rd Conf. on Severe Local Storms, St. Louis, Mo, Amer. Meteor. Soc., CD-ROM P1.5

Corfidi, S. F., S. J. Corfidi, and D. M. Schultz, 2008: Elevated Convection and Castellanus: Ambiguities, Significance, and Questions. Weather and Forecasting, 23, 1280-1303.

Colman, B. R., 1990a: Thunderstorms above frontal surfaces in environments without positive CAPE. Part I: A climatology. Mon. Wea. Rev., 118,1103-1122

Colman, B. R., 1990b: Thunderstorms above Frontal Surfaces in Environments without Positive CAPE. Part II: Organization and Instability Mechanisms. Mon. Wea. Rev., 118, 1123-1144.doi: http://dx.doi.org/10.1175/1520-0493(1990)118<1123:TAFSIE >2.0.CO;2

Clark, A. J., and Coauthors, 2012a: An overview of the 2010 Hazardous Weather Testbed Experimental Forecast Program spring experiment. Bull. Amer. Meteor. Soc., 93, 55-74. Link

Done, J., C. A. Davis, and M. Weisman, 2004: The next generation of NWP: explicit forecasts of convection using the weather research and forecasting (WRF) model. Atmospheric Science Letters, 5, 110-117.

Droegemeier, K. K., and R. B. Wilhelmson, 1987: Numerical Simulation of Thunderstorm Outflow Dynamics. Part I: Outflow Sensitivity Experiments and Turbulence Dynamics. Journal of the Atmospheric Sciences, 44, 1180-121

Grant, B. N., 1995: Elevated cold-sector severe thunderstorms: A preliminary study. Natl. Wea. Dig., 19 (4) 25-31.

Grell, G. A. and Freitas, S. R., 2014: A scale and aerosol aware stochastic convective parameterization for weather and air quality modeling, Atmos. Chem. Phys., 14, 52335250, doi:10.5194/acp-14-5233-2014. 
Hong, S.-Y., and J.-O. J. Lim, 2006: The WRF single-moment 6-class microphysics scheme (WSM6). J. Korean Meteor. Soc., 42, 129-151.

Hong, Song-You, Yign Noh, Jimy Dudhia, 2006: A new vertical diffusion package with an explicit treatment of entrainment processes. Mon. Wea. Rev., 134, 2318-2341.

Janjic, Zavisa I., 1994: The Step-Mountain Eta Coordinate Model: Further developments of the convection, viscous sublayer, and turbulence closure schemes. Mon. Wea. Rev., $122,927-945$.

Jeong, J.-H., D.-I. Lee, and C.-C. Wang: Impact of Cold Pool on Mesoscale Convective System Produced Extreme Rainfall over southeastern South Korea: 7 July 2009. Monthly Weather Review, 0, null.

Jirak, I. L., S. J. Weiss, and C. J. Melick, 2012: The SPC storm scale ensemble of opportunity: Overview and results from the 2012 Hazardous Weather Testbed Spring Forecasting Experiment. Preprints, 26th Conf. Severe Local Storms, Nashville, TN. Amer. Meteor. Soc., P9.137.

Kastman JS and Market PS. 2015a. The Role of Elevated Thunderstorms in the Poleward Progression of Warm Fronts. 27th Conference On Weather Analysis And Forecasting/23rd Conference On Numerical Weather Prediction. American meteorological Society: Chicago, IL.

Kastman JS, Market PS, Foscato A. 2015b. Rainfall-Lightning Ratio Calculations for Elevated Thunderstorms With Heavy Rainfall. Seventh Conference on the Meteorological Applications of Lightning Data. American Meteorological Society: Phoenix, AZ.

Kastman, Joshua S., Laurel D. Mccoy, Patrick S. Market, and Neil I. Fox. "An example of synergistic coupling of upper-and lower-level jets associated with flash flooding." Meteorological Applications 24, no. 2 (2017a): 206-210.

Kastman, Joshua S., Patrick S. Market, Neil I. Fox, Alzina L. Foscato, and Anthony R. Lupo. "Lightning and Rainfall Characteristics in Elevated vs. Surface Based Convection in the Midwest that Produce Heavy Rainfall." Atmosphere 8, no. 2 (2017b): 36.

Lim, K.-S. S., and S.-Y. Hong, 2010: Development of an effective double-moment cloud microphysics scheme with prognostic cloud condensation nuclei (CCN) for weather and climate models. Mon. Wea. Rev., 138, 1587-1612.

Lin, Yuh-Lang, Richard D. Farley, and Harold D. Orville, 1983: Bulk Parameterization of the Snow Field in a Cloud Model. J.Climate Appl. Met., 22, 1065-1092.

Mahoney, W. P., III, 1988: Gust front characteristics and the kinematics associated with interacting thunderstorm outflows. Mon. Wea. Rev., 116, 1474-1492, doi:https://doi.org/10.1175/1520-0493(1988)116<1474:GFCATK>2.0.CO;2. 
Market, P., S. Allen, R. Scofield, R. Kuligowski, and A. Gruber, 2003: Precipitation Efficiency of Warm-Season Midwestern Mesoscale Convective Systems. Weather and Forecasting, 18, 1273-1285.

Market, P. S., Scott M. Rochette, J. Shewchuk, R. Difani, Joshua S. Kastman, C. B. Henson, and N. I. Fox. "Evaluating elevated convection with the downdraft convective inhibition." Atmospheric Science Letters 18, no. 2 (2017): 76-81.

McCoy, Laurel P., Patrick S. Market, Chad M. Gravelle, Charles E. Graves, Neil I. Fox, Scott M. Rochette, Joshua Kastman, and Bohumil Svoma. "Composites of Heavy Rain Producing Elevated Thunderstorms in the Central United States." Advances in Meteorology 2017 (2017).

Moore JT, Czarnetzki AC, Market PS. 1998. Heavy precipitation associated with elevated thunderstorms formed in a convectively unstable layer aloft. Meteorological Applications 5: 373-384.

Moore, J. T., F. H. Glass, C. E. Graves, S. M. Rochette, and M. J. Singer, 2003: The Environment of Warm-Season Elevated Thunderstorms Associated with Heavy Rainfall over the Central United States. Weather and Forecasting, 18, 861-878.

Morrison, H., G. Thompson, V. Tatarskii, 2009: Impact of Cloud Microphysics on the Development of Trailing Stratiform Precipitation in a Simulated Squall Line: Comparison of One- and Two-Moment Schemes. Mon. Wea. Rev., 137, 991-1007.

Nakanishi, M., and H. Niino, 2009: Development of an improved turbulence closure model for the atmospheric boundary layer. J. Meteor. Soc. Japan, 87, 895-912.

NOAA, cited 2001: National Oceanic and Atmospheric Administration Changes to the NCEP Meso Eta Analysis and Forecast System: Increase in resolution, new cloud microphysics, modified precipitation assimilation, modified 3DVAR analysis. [Available online at http://www.emc.ncep.noaa.gov/mmb/mmbpll/eta12tpb/.]

Nowotarski CJ, Markowski PM, Richardson YP. 2011. The characteristics of numerically simulated supercell storms situated over statically stable boundary layers. Monthly Weather Review 139: 3139-3162.

Rochette, S. M., and J. T. Moore, 1996: Initiation of an Elevated Mesoscale Convective System Associated with Heavy Rainfall. Weather and Forecasting, 11, 443-457.

Roebber, P. J., 2009: Visualizing multiple measures of forecast quality. Wea. Forecasting, 24, 601-608, doi:10.1175/2008WAF2222159.1

Romine, G. S., C. S. Schwartz, J. Berner, K. R. Fossell, C. Snyder, J. L. Anderson, and M. L. Weisman, 2014: Representing Forecast Error in a Convection-Permitting Ensemble System. Monthly Weather Review, 142, 4519-4541. 
Schumacher, R.S., 2009: Mechanisms for Quasi-Stationary Behavior in Simulated Heavy-Rain-Producing Convective Systems. J. Atmos. Sci., 66, 1543-1568, https://doi.org/10.1175/2008JAS2856.1

Schumacher RS. 2015. Sensitivity of precipitation accumulation in elevated convective systems to small changes in low-level moisture. Journal of the Atmospheric Sciences 72: $2507-2524$.

Schumacher, R. S., and A. J. Clark, 2014: Evaluation of Ensemble Configurations for the Analysis and Prediction of Heavy-Rain-Producing Mesoscale Convective Systems*. Monthly Weather Review, 142, 4108-4138.

Schumacher, R. S., A. J. Clark, M. Xue, and F. Kong, 2013: Factors Influencing the Development and Maintenance of Nocturnal Heavy-Rain-Producing Convective Systems in a Storm-Scale Ensemble. Monthly Weather Review, 141, 2778-2801.

Smull, B. F., and J. A. Augustine, 1993: Multiscale Analysis of a Mature Mesoscale Convective Complex. Monthly Weather Review, 121, 103-132.

Schwartz, C. S., and Coauthors, 2010: Toward Improved Convection-Allowing Ensembles: Model Physics Sensitivities and Optimizing Probabilistic Guidance with Small Ensemble Membership. Weather and Forecasting, 25, 263-280.

Skamarock, B, 2015: Dynamics Overview and Best Practices. Retrieved from http://www2.mmm.ucar.edu/wrf/users/workshops/WS2015/ppts/dynamics_skamarock.pd $\mathrm{f}$

Thompson, Gregory, Paul R. Field, Roy M. Rasmussen, William D. Hall, 2008: Explicit Forecasts of Winter Precipitation Using an Improved Bulk Microphysics Scheme. Part II: Implementation of a New Snow Parameterization. Mon. Wea. Rev., 136, 5095-5115.

Tapiador, F. J., and Coauthors, 2012: A Comparison of Perturbed Initial Conditions and Multiphysics Ensembles in a Severe Weather Episode in Spain. Journal of Applied Meteorology and Climatology, 51, 489-504. 


\section{Chapter 6. Discussion and Conclusions}

\subsection{Discussion of Questions and Key Findings}

Recall that the first hypothesis stated: The presence of convective complexes north of a synoptic/mesoscale boundary alters poleward progression and/or causes an equatorward retreat of the synoptic/mesoscale boundary as a result of convectively generated cold pools (and associated gust fronts). When unified cold pools form they lower-tropospheric advections, prevent precipitation from advancing poleward, and result in a more intense, rainfall (often in the shape of a narrow horizontal band) than instances when convective cold pools are not present at the surface (relatively more equally distributed area of rainfall). A second hypothesis stated: DCIN can be used as an indicator if there is a potential for elevated parcels to reach the surface unabated or if they will be impacted by a DCIN layer. Chapter 5 was dedicated to testing these hypotheses' with supporting and ground work done in Chapters 2 - 4.

It was shown that during PRECIP there were primarily two types of scenarios that unfolded, either convective cells remained in a state in which the convective mode was single cellular (or clusters of cells embedded within a stratiform rain shield (Fig 6.1)) or a mesoscale convective system organized along and north of the boundary (Fig. 6.2). Note the difference in small isolated appearance of the cells in Fig 6.1 compared to the larger, unified behavior of the cells in 6.2 


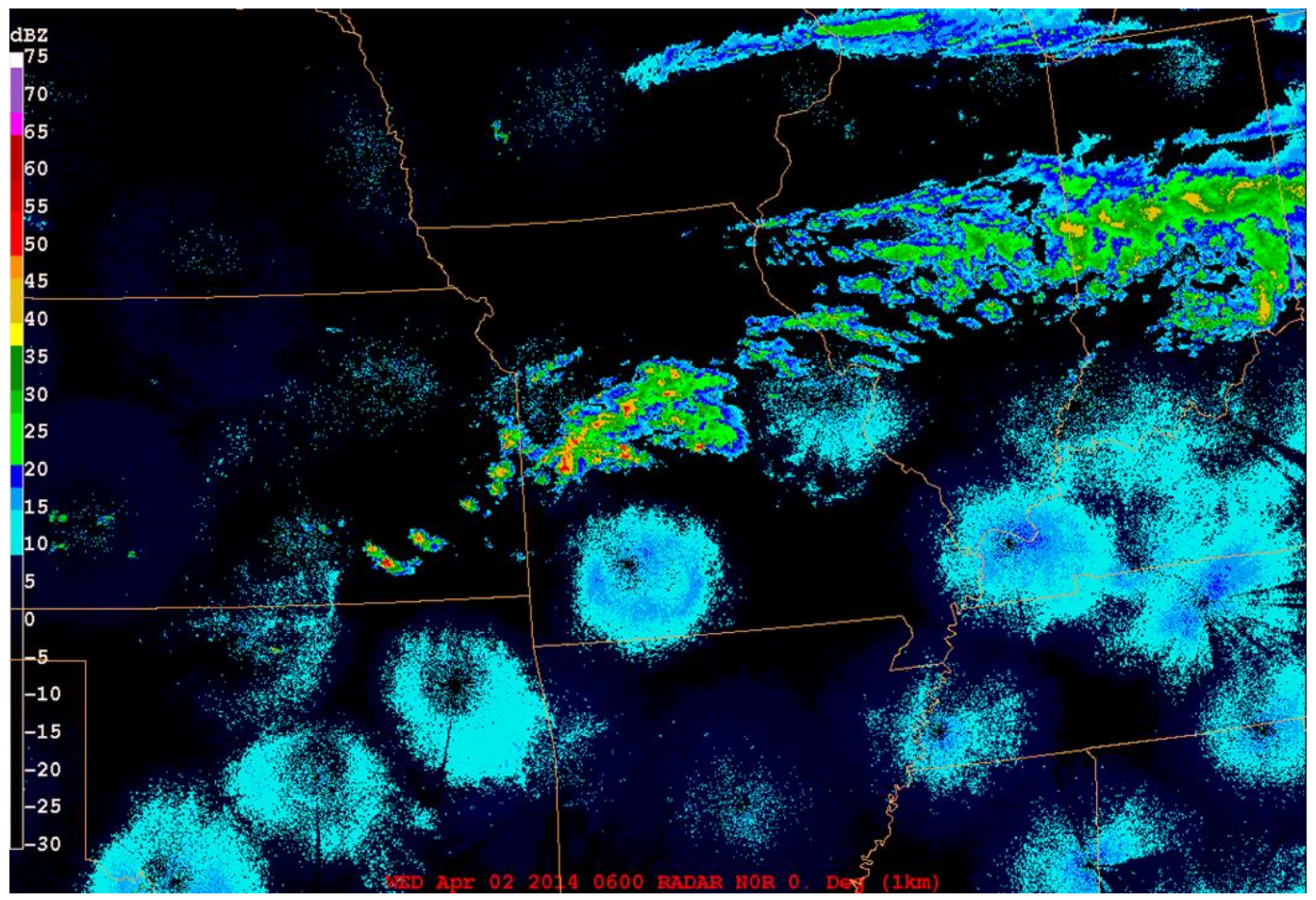

Figure 6.1. 1 km Radar Composite Valid 06002 April 2014 (IOP 1). Showing reflectivity colorfill) every $5 \mathrm{dBZ}$ from $10-75 \mathrm{dBZ}$.

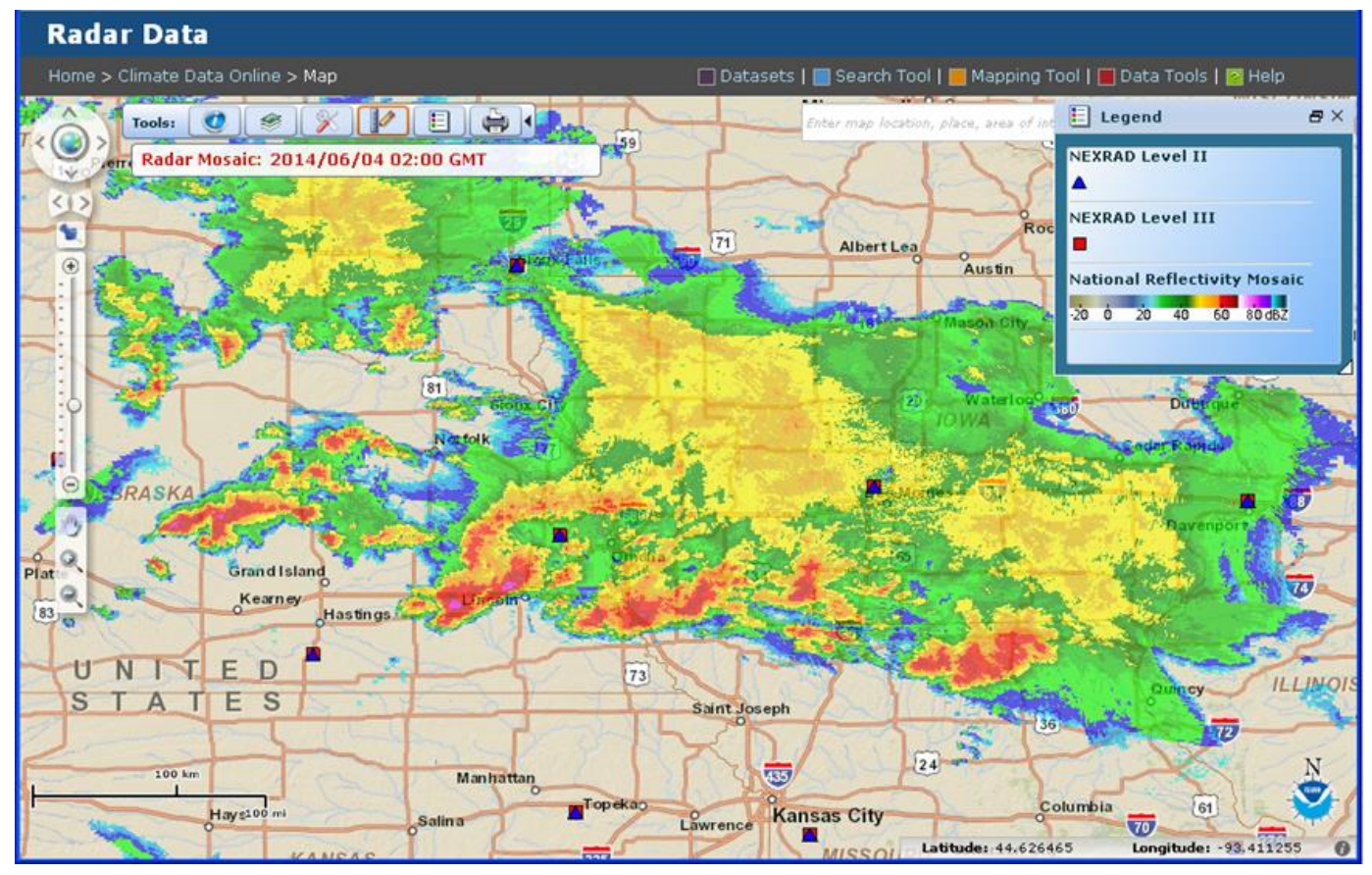

Figure 6.2. 1 km Radar Composite Valid 02004 June 2014 (IOP 2). Showing reflectivity colorfill) every $5 \mathrm{dBZ}$ from $10-80 \mathrm{dBZ}$. 
When cells remained embedded within a synoptic rain shield (or as an isolated cell) it was observed that boundaries and convection continued in a poleward progression. Precipitation in this scenario was typically more spread out with a larger coverage area. This was found to be the case in IOP 1,3,8. Note the widespread coverage with isolated higher amounts found in both IOP 1 (Fig 6.3) and in IOP 3 (Fig 6.4). It was shown in IOP 1 and 8 that DCIN was present, indicating that downdrafts were impacted by the DCIN layer. It was also shown (Chapter 5) that during this type of isolated/embedded convection that surface cold pools did not unify, but rather remained very localized or nonexistent. Unified cold pools did not form because downdrafts were not reaching the surface and spreading out. The presence of DCIN was an indicator of an environment conducive to downdrafts being impacted by the subinversion layer for IOPs 1 and 8. It was shown in Chapter 5 that explicit convection model configurations performed the best at forecasting rainfall amounts and system propagation. No one model configuration was shown to be superior to others, but systems with localized boundary layer mixing and explicit convection performed the strongest. Further testing is certainly needed before specific conclusions are drawn, that being said, this work certainly indicates promise and it needs to be further explored. 


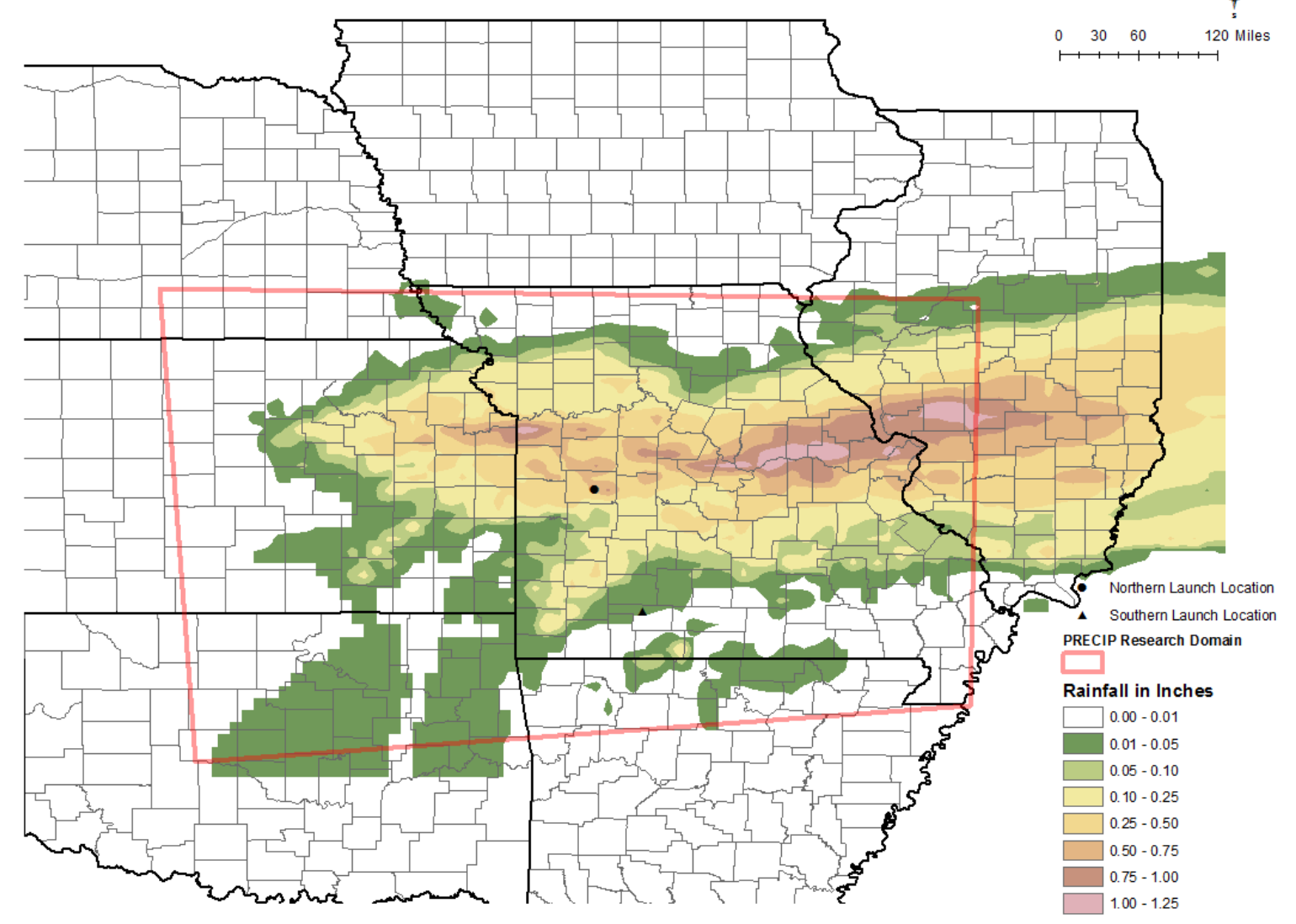

Figure 6.3. 24 Hour Observed Rainfall (inches, color fill from 0.01 in to 1.25 in) Valid 1200 UTC 2 April 2014. Black dot indictes data collection point for northern PRECIP deployed team. Black triangle indicates data collection point for southern PRECIP team. 


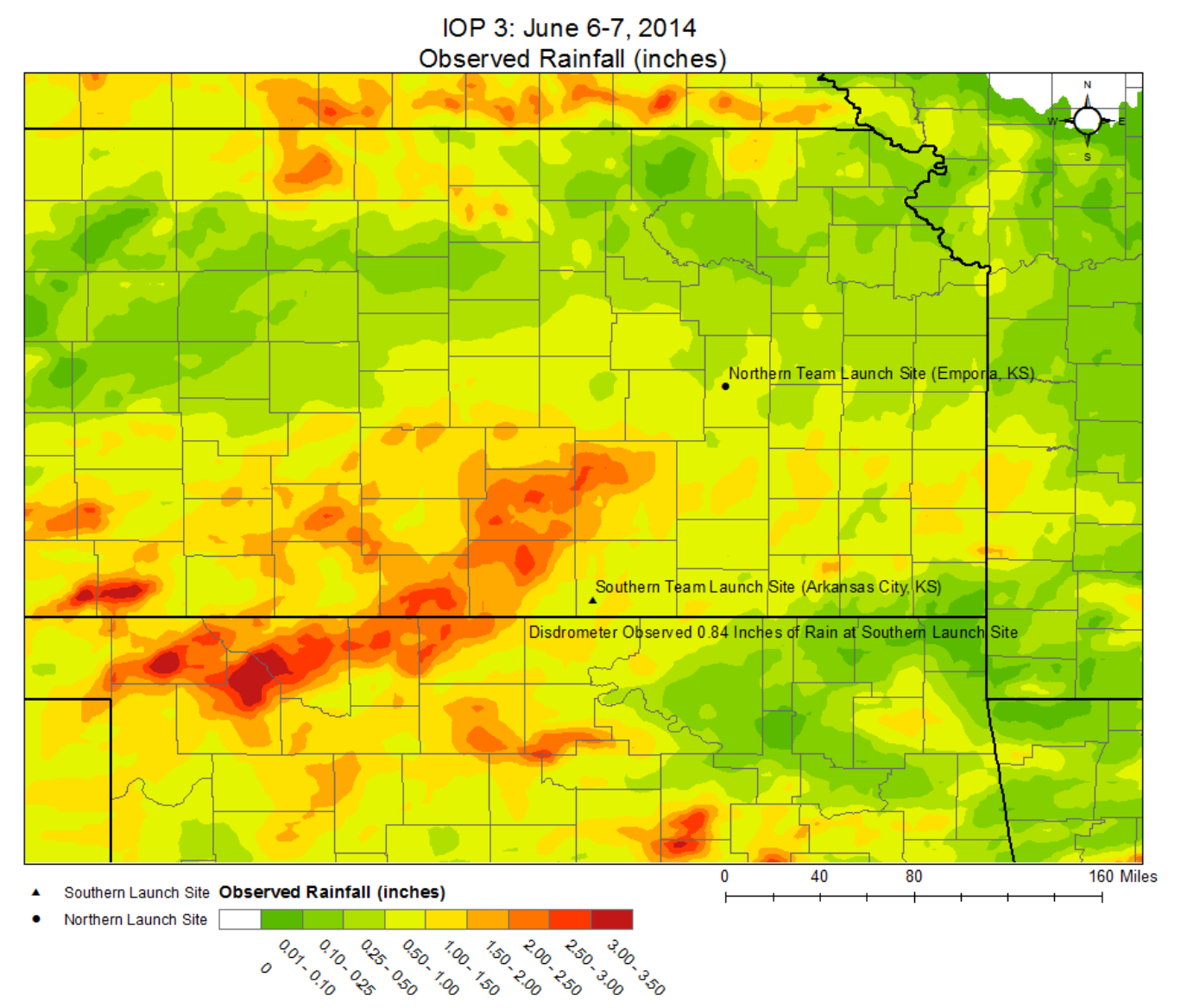

Figure 6.4. 24 Hour Observed Rainfall (inches, color fill from 0.01 in to 3.50 in) Valid 1200 UTC 7 June 2014. Black dot indicates data collection point for northern PRECIP deployed team. Black triangle indicates data collection point for southern PRECIP team.

It was shown that when cells became organized into a MCS, cold pools were able to unify and impact surface boundaries which resulted in stalling or retrogression. Precipitation typically took the form of a very heavy band along and north of the original boundary, pushing southward with time. IOP 2, 5 and 7 took on this formation. Figure 6.5 shows an example of the observed precipitation from IOP 2, highlighting the heavy banded appearance. Figure 6.6 shows a similar pattern that was observed during IOP 5 . As discussed in Chapter 5, the primary reason for the intense banding is the colocation of warm air south of the boundary being impended upon by cold pool air from the MCS (which is already forming on the cool side of the boundary). This embedded cool air mass 
on the cool side of the boundary in juxtaposition acts to tighten the thermal gradient. As a result low-level frontogenesis responds, which in turn generates increasing upward vertical motion along and on the warm side of the boundary - MCS interface. This encourages new convection to form, which in turn strengthens the cold pool and aides to continue to drive the system. The net effect is to disrupt the synoptic boundary motion and create a region of very intense rainfall. An example of this can be seen in Fig. 5.21 and in Appendix A. It was found that model configurations which featured parameterized convection performed the best at forecasting this scenario. It was shown in Chapter 5 that environments rich in DCAPE were necessary for this scenario to unfold. Indeed, |DCIN| was not analyzed in IOP 2 or 5 (IOP 7 not shown). Downdrafts reaching the surface is a key factor to the development of surface based cold pools (seen in Chapter 5) necessary to disrupt the frontal motion. 
IOP 2: June 3-4, 2014

Observed Rainfall Amounts (inches)

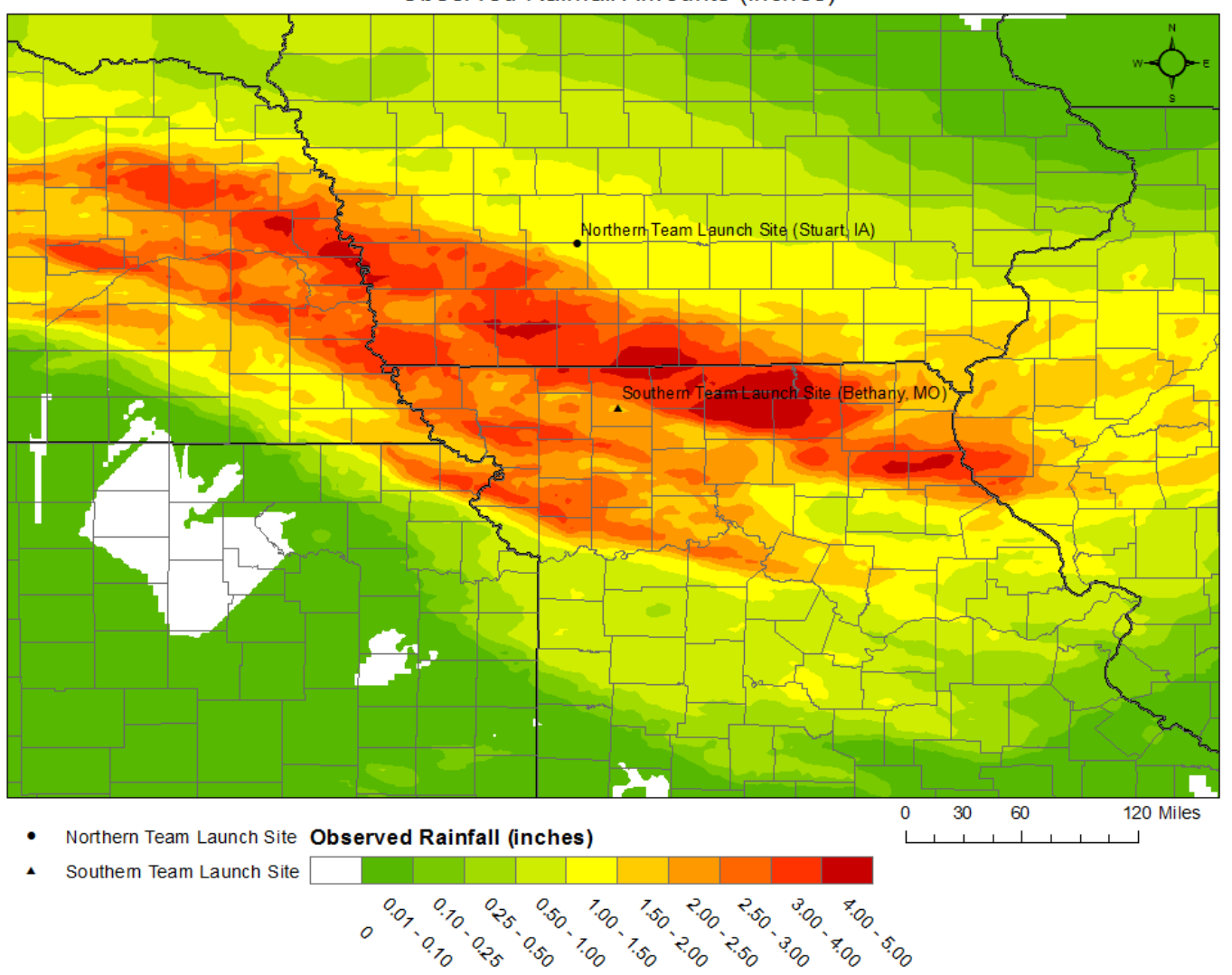

Figure 6.5 24 Hour Observed Rainfall (inches, color fill from 0.01in to 5.00 in) Valid 1200 UTC 4 June 2014. Black dot indicates data collection point for northern PRECIP deployed team. Black triangle indicates data collection point for southern PRECIP team. 


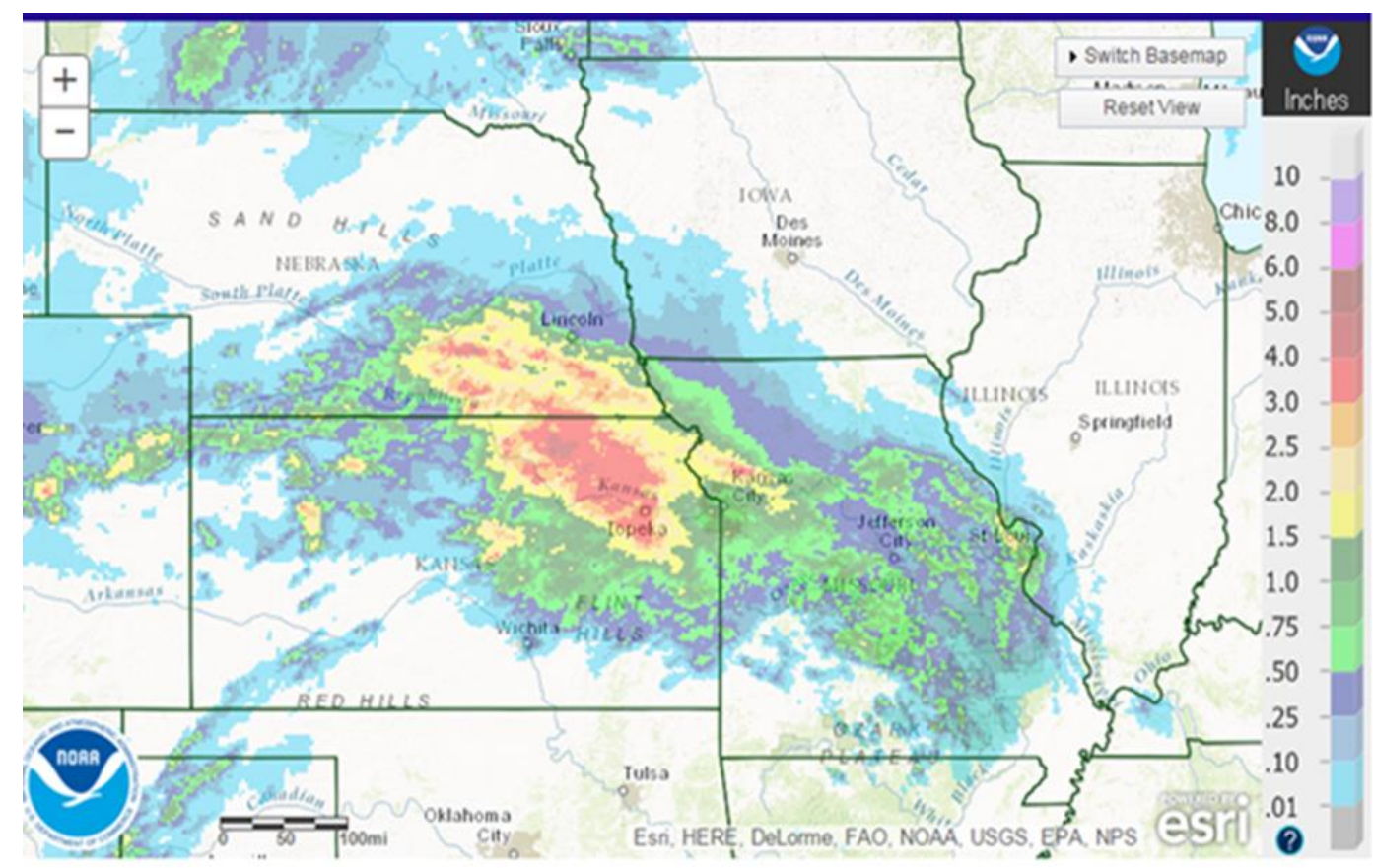

Figure 6.6. 24 Hour Observed Rainfall (inches, color fill from 0.01 in to 3.50 in) Valid 1200 UTC 5 June 2015

\subsection{Other Findings}

\subsubsection{IOP 4}

IOP 4 was a unique event to this study. It had both surface based and elevated convection in close proximity early during the event. It did force a boundary to stall and retrograde causing heavy rainfall (Fig. 6.7) in the banded pattern also shown in Figs 6.5 and 6.6. However a complex thermal pattern in concert with an old boundary sparked a secondary round of elevated convection much further north of the boundary. A radar snapshot of the ongoing event is seen in Figure 6.8. Note the western and southern regions of higher reflectivity are associated with the tightening thermal gradient while the secondary region over central Oklahoma is associated with an old elevated boundary, with isolated cells forming, efficiently raining and decaying. Those cells did not regenerate in the same fashion as the cells near the boundary did. This case was not 
investigated for evidence of DCIN but is certainly an interesting candidate for future work as it highlights the complexities of a chaotic atmosphere featuring multiple forcing mechanisms, though in such an environment even very high resolution reanalysis simulations have a very hard time recreating environmental conditions accurately.

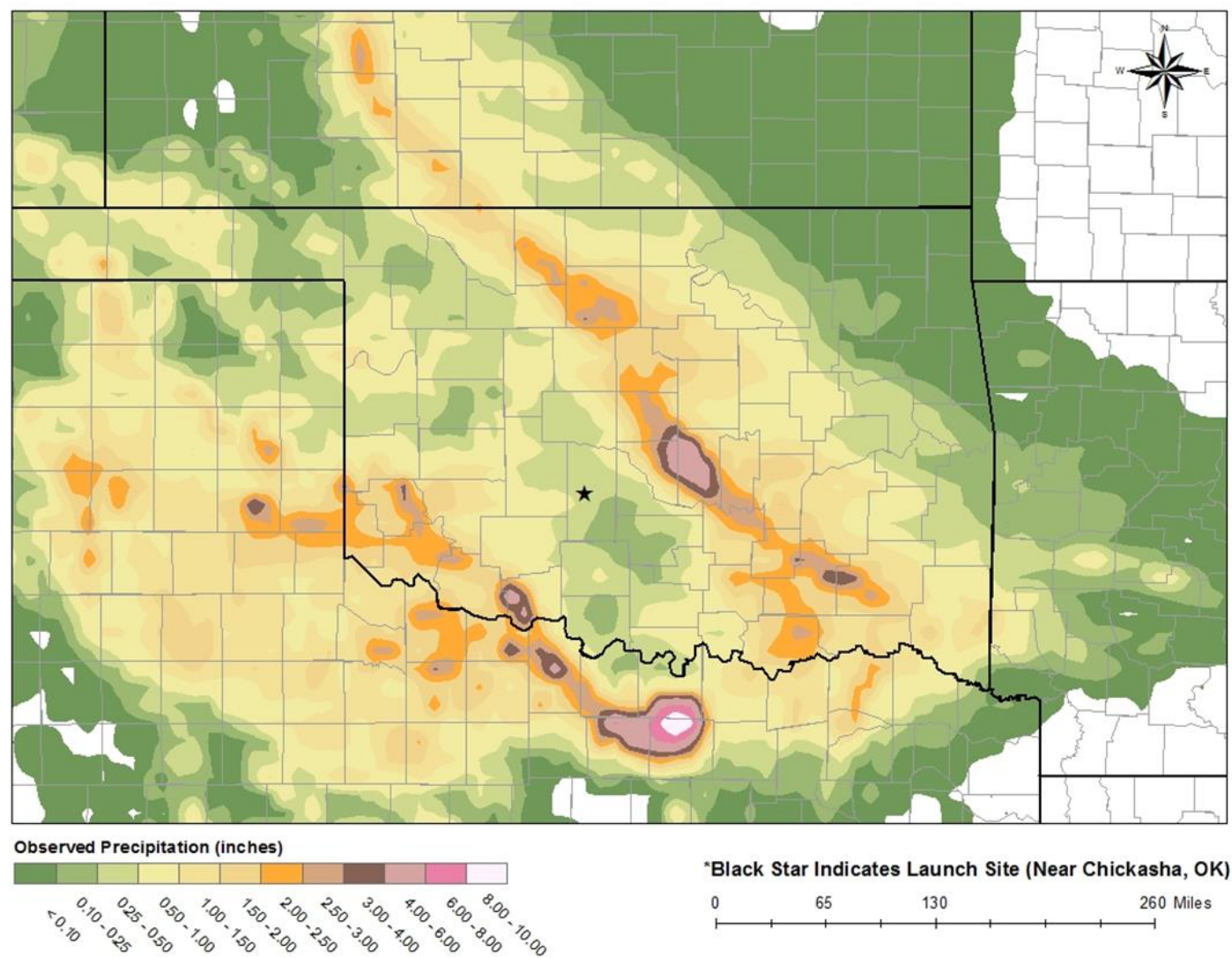

Figure 6.7. 24-Hour observed rainfall (inches, color fill from 0.10 in to 10.00 in) Valid 1200 UTC 17 July 2014. Black star indicates data collection point for northern PRECIP deployed team. 


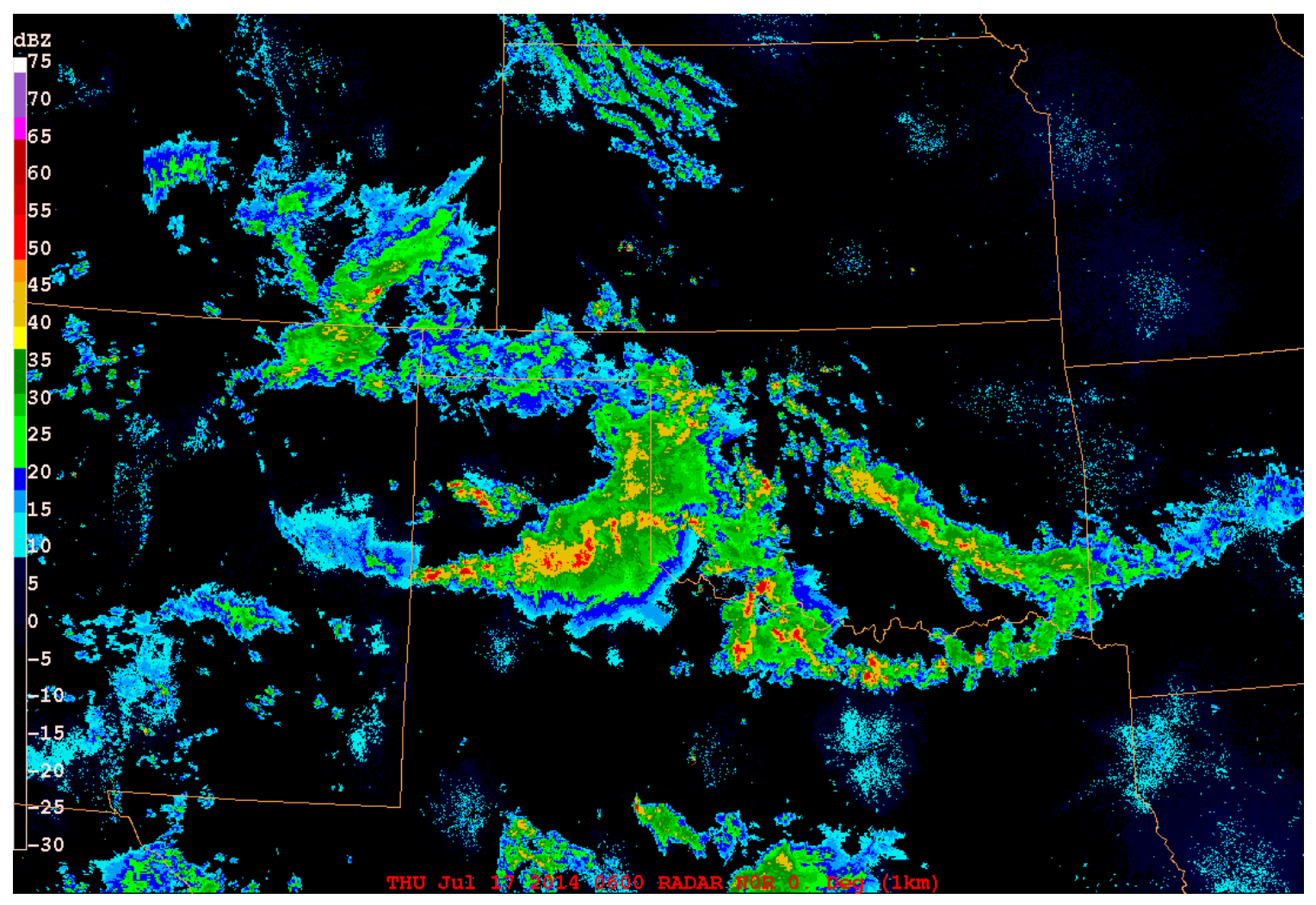

Figure 6.8. $1 \mathrm{~km}$ radar composite valid 060017 July 2014 (IOP 4), showing reflectivity (colorfill) every $5 \mathrm{dBZ}$ from $10-75 \mathrm{dBZ}$.

\subsubsection{Elevated Convection Environments}

Chapter 2 discusses environmental comparisons between surface based and elevated convection. Composites (see Chapter two for a listing of composite cases) showed elevated convection environments that featured a stronger, more southerly 850mb jet, higher precipitable water values, and strong upward velocity than surface based environments.

A more thorough discussion of the environment for elevated convection was presented by McCoy et al. 2017 (referenced in Chapter 5). Her work showed that $68 \%$ of the cases she looked at had flash flooding reported, reinforcing the danger these storms can bring. Her study also found environments that featured the $250-\mathrm{hPa}$ jet streak to the 
northeast of the region, with divergence values over the event site of $>3 \times 10^{-5} \mathrm{~s}^{-1}$ and so favorable for elevated convection. This paired with an $850-\mathrm{hPa}$ advection maximum (and convergence maximum), often in the form of a low-level jet from the south-southwest created an even more favorable environment. The coupling of upper level jet streaks and the low-level jet is discussed further in Chapter 3 of this dissertation. Other indicators of an environment favorable for elevated convection was $\mathrm{K}$-index, with values $>32$, and precipitable water with values $>40 \mathrm{~mm}$ ( 1.6 in.).

\subsubsection{Surface Based Convection Compared to Elevated Convection}

One of the additional goals of this study was to explore environmental and surface weather impact differences between surface based and elevated convection. Environmental differences are discussed in the previous subsection.

It was shown in chapter 2 that for the cases investigated, elevated convection featured, on average, larger rainfall amounts and larger areal coverage. It was also found that elevated convection feature higher RLR values, an indicator of heavy rainfall, and elevated convection had a higher number of positive CG flashes than surface based convection.

\subsection{Conclusions and Future Work}

Is elevated convection responsible for boundary displacement? The answer is: Yes, Under the right environmental conditions. What seems most important is that elevated environments rich in moisture with high DCAPE are necessary for otherwise poleward progressing boundaries to be forced to stall and retrograde. However, not all elevated convective environments have these key ingredients. When sufficiently strong 
DCIN is present downdrafts are clearly impacted and may not be able to impact surface boundaries.

Future work into DCIN is necessary and upcoming. More cases are necessary to corroborate the findings shown here. In addition to helping forecast boundary displacement and potential heavy rain areas, DCIN could also help severe weather forecasters discern environments in which wind events are more or less likely. It is expected that severe wind events, which can happen in some elevated convection environments, are not likely when DCIN is present.

Additional work should also be undertaken evaluating the utility of high resolution parameterized convection schemes in the forecasting of elevated convection. Many operational schemes currently do not employ convective parameterization in high resolution forecasts. It has been shown here that elevated mesoscale convective systems were better forecasted when utilizing parameterized convection.

By reading this dissertation one should be able to forecast for environments capable of producing elevated convection and understand the dangers that elevated convection can pose including; heavy rainfall, flash flooding, frequent CG lightning flashes and numerous positive CG flashes. A reader will also understand that downward moving parcels will have an increasingly difficult time reaching the surface in soundings where DCIN is increasingly larger than DCAPE, also recognizing that when DCAPE is increasing larger than DCIN that surface impacts are increasingly likely. A reader will also be armed with the knowledge that when DCAPE is increasingly larger than DCIN that cold pools north of an associated boundary are likely to reach the surface and will likely alter any poleward progression with the associated boundary. When this happens 
heavy, prolonged rainfall is possible. Finally, a reader will understand when DCIN is increasingly more dominant than DCAPE the boundary should progress poleward without impact as the downdraft will be increasingly less likely to reach the surface and create boundary stalling cold pools. 


\section{APPENDIX A}

Sample Namelist from the WRF-HRHPEFS

\begin{tabular}{|c|c|}
\hline $\begin{array}{l}\text { ¿time_control } \\
\text { run_days }\end{array}$ & $=0$, \\
\hline run_hours & $=0$, \\
\hline run_minutes & $=0$, \\
\hline run_seconds & $=0$ \\
\hline start_year & $=2014,2014,2014$, \\
\hline start_month & $=06,06,06$ \\
\hline start_day & $=03,03,03$, \\
\hline start_hour & $=18,21, \quad 18$ \\
\hline start_minute & $=00, \quad 00, \quad 00$ \\
\hline start_second & $=00, \quad 00, \quad 00$ \\
\hline end_year & $=2014,2014,2014$ \\
\hline end_month & $=06,06,06$ \\
\hline end_day & $=04, \quad 04,04$ \\
\hline end_hour & $=12, \quad 12, \quad 12$ \\
\hline end_minute & $=00, \quad 00, \quad 00$ \\
\hline end_second & $=00, \quad 00, \quad 00$ \\
\hline interval_seconds & $=3600$ \\
\hline input_from_file & $=$.true.,.true.,.true., \\
\hline history_interval & $=60,15,60$ \\
\hline history_outname & $=$ "wrfout_d $<$ domain $>$ _ date $>$ " \\
\hline frames_per_outfile & $=1,1,1$, \\
\hline estart & $=$.false. \\
\hline restart_interval & $=5000$ \\
\hline o_form_history & $=2$ \\
\hline io_form_restart & $=2$ \\
\hline o_form_input & $=2$ \\
\hline io_form_boundary & $=2$ \\
\hline auxhist1_outname & $=$ "auxhist1_d<domain>_<date>" \\
\hline auxhist1_interval & $=0,0,0$ \\
\hline frames_per_auxhist1 & $=1,1,1$ \\
\hline io_form_auxhist1 & $=2$ \\
\hline io_form_auxinput2 & $=2$ \\
\hline auxhist2_outname & $=$ "auxhist2_d<domain $>$ $<$ date $>$ " \\
\hline auxhist2_interval & $=0,0,0$ \\
\hline output_diagnostics & $=0$ \\
\hline auxhist3_outname & $=$ "wrfxtrm_d $<$ domain $>$ < date $>$ " \\
\hline auxhist3_interval & $=0,0,0$ \\
\hline frames_per_auxhist2 & $=1,1,1$ \\
\hline form_auxhist2 & $=2$ \\
\hline input4_inname & $=$ "wrflowinp_d $<$ domain $>$ " \\
\hline xinput4_interval & $=360,360,360$ \\
\hline
\end{tabular}




\begin{tabular}{|c|c|}
\hline io_form_auxinput4 & $=2$ \\
\hline fine_input_stream & $=0,2,2$ \\
\hline adjust_output_times & $=\mathrm{T}$ \\
\hline reset_simulation_start & $=\mathrm{F}$ \\
\hline cycling & $=\mathrm{F}$ \\
\hline diag_print & $=0$ \\
\hline $\begin{array}{l}\text { debug_level } \\
\text { / }\end{array}$ & $=0$ \\
\hline \&domains & \\
\hline time_step & $=21$, \\
\hline time_step_fract_num & $=0$ \\
\hline time_step_fract_den & $=1$, \\
\hline max_dom & $=2$ \\
\hline e_we & $=200,361, \quad 601$ \\
\hline e_sn & $=200,361, \quad 526$ \\
\hline e_vert & $=51, \quad 51, \quad 30$ \\
\hline p_top_requested & $\begin{array}{l}=5000 \\
=51\end{array}$ \\
\hline $\begin{array}{l}\text { num_metgrid_levels } \\
\text { num_metgrid_soil_levels }\end{array}$ & $\begin{array}{l}=51 \\
=3\end{array}$ \\
\hline & $=9000,3000,1000$, \\
\hline & $=9000,3000,1000$, \\
\hline grid_id & $=1, \quad 2, \quad 3$ \\
\hline parent_id & $=1, \quad 1, \quad 2$ \\
\hline i_parent_start & $=1, \quad 30, \quad 75$ \\
\hline j_parent_start & $=1, \quad 50, \quad 85$ \\
\hline parent_grid_ratio & $=1, \quad 3, \quad 3$ \\
\hline parent_time_step_ratio & $=1, \quad 3, \quad 3$, \\
\hline feedback & $=1$, \\
\hline smooth_option & $=1$ \\
\hline grid_allowed & $=\mathrm{T}, \mathrm{T}, \mathrm{T}$ \\
\hline max_dz & $=1000$ \\
\hline numtiles & $=1$ \\
\hline nproc_x & $=-1$ \\
\hline nproc_y & $=-1$ \\
\hline interp_type & $=2$ \\
\hline extrap_type & $=2$ \\
\hline t_extrap_type & $=2$ \\
\hline use_levels_below_ground & $=\mathrm{T}$ \\
\hline use_surface & $=\mathrm{T}$ \\
\hline lagrange_order & $=1$ \\
\hline zap_close_levels & $=500$ \\
\hline lowest_lev_from_sfc & $=\mathrm{F}$ \\
\hline force_sff__in_vinterp & \\
\hline sfcp_to_sfcp & \\
\hline smooth_cg_topo & \\
\hline
\end{tabular}




$$
\begin{array}{ll}
\text { use_tavg_for_tsk } & =\mathrm{F} \\
\text { aggregate_lu } & =\mathrm{F} \\
\text { rh2qv_wrt_liquid } & =\mathrm{T} \\
\text { rh2qv_method } & =1 \\
\text { vert_refine_fact } & =1 \\
\text { use_adaptive_time_step } & =\mathrm{F} \\
\text { / } &
\end{array}
$$

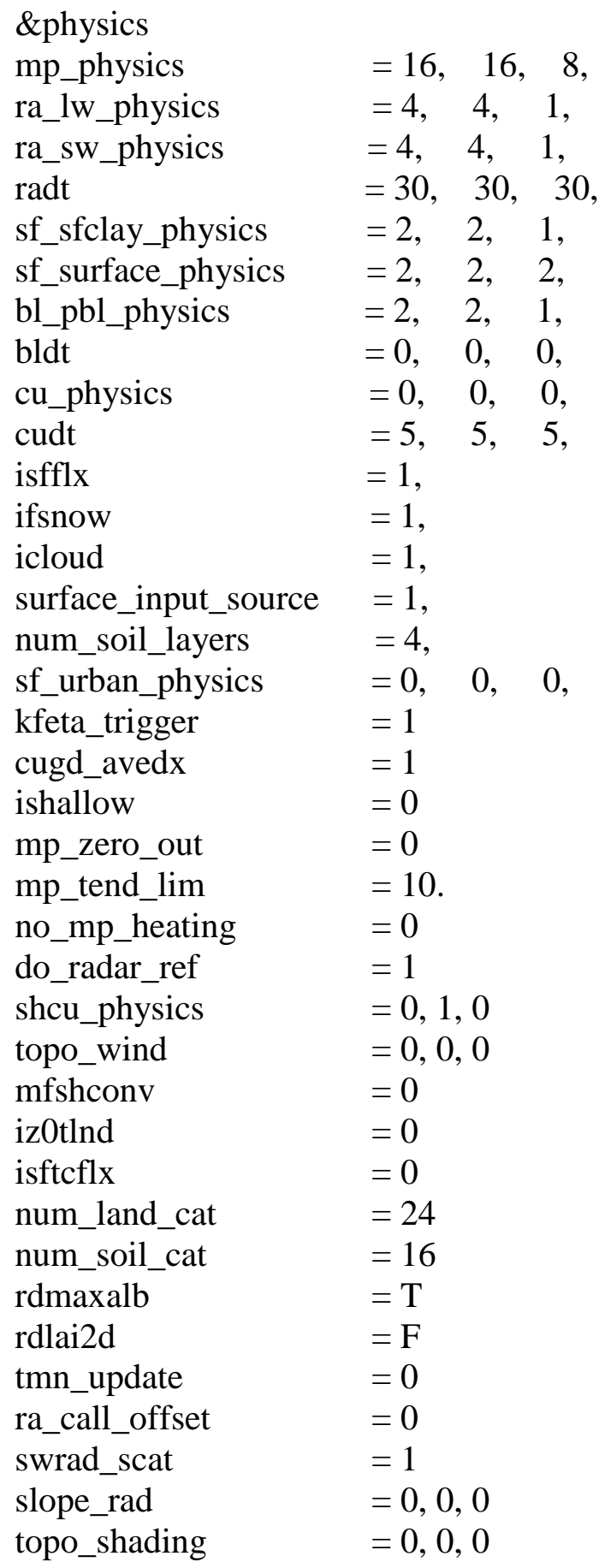




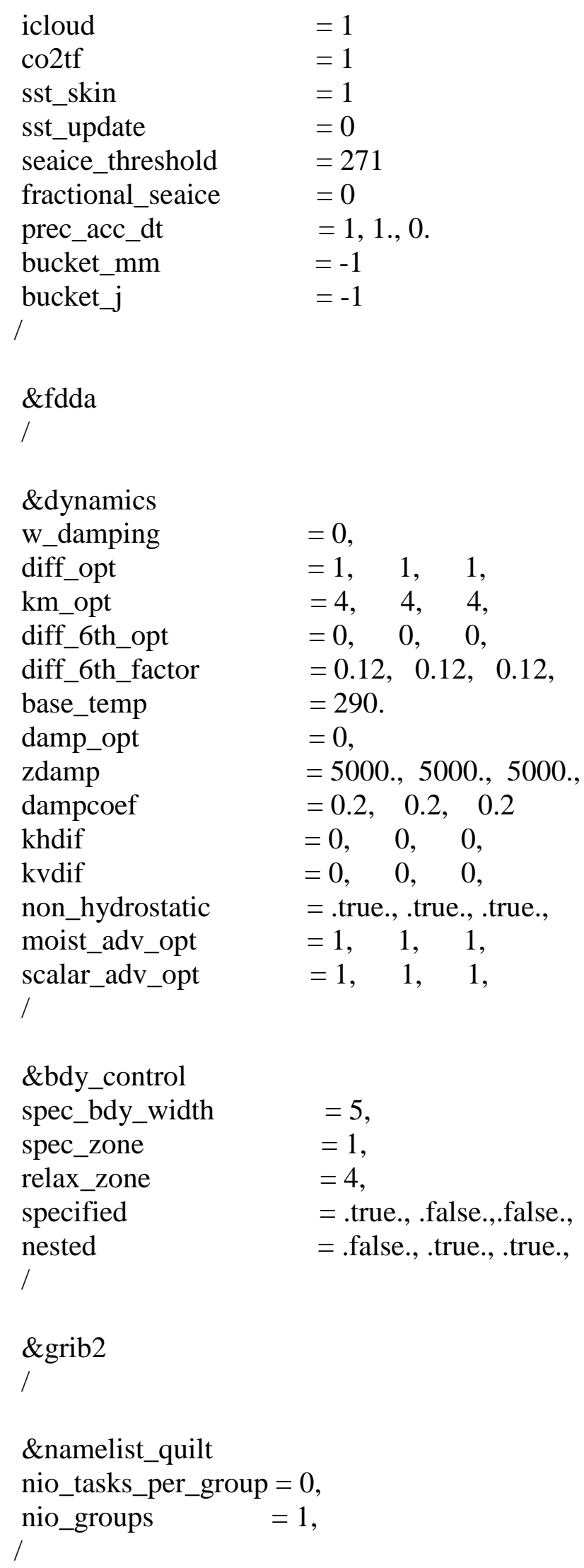




\section{APPENDIX B}

\section{American Meteorological Society Conference Poster}
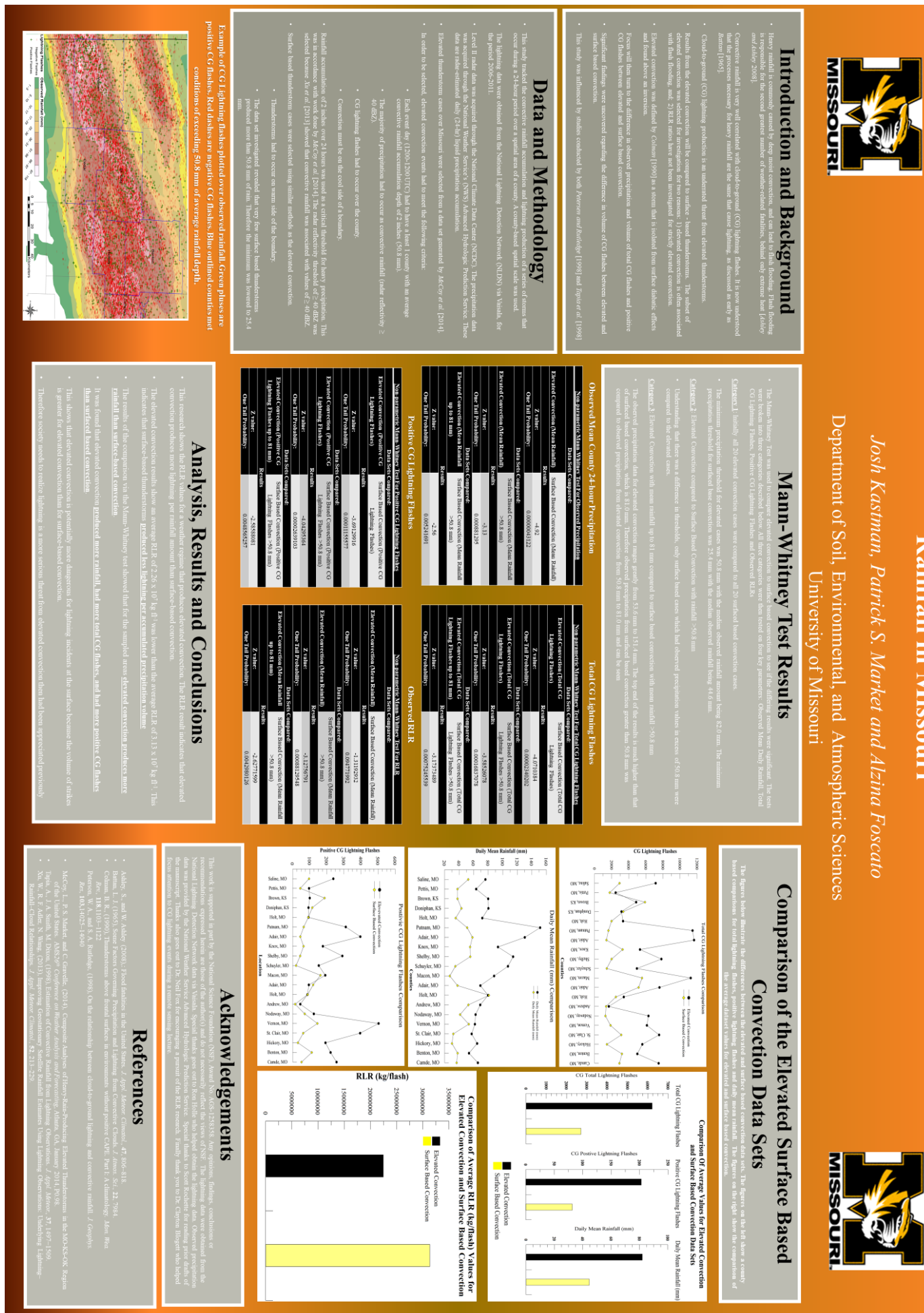


\section{APPENDIX C}

\section{National Weather Association Conference Poster}

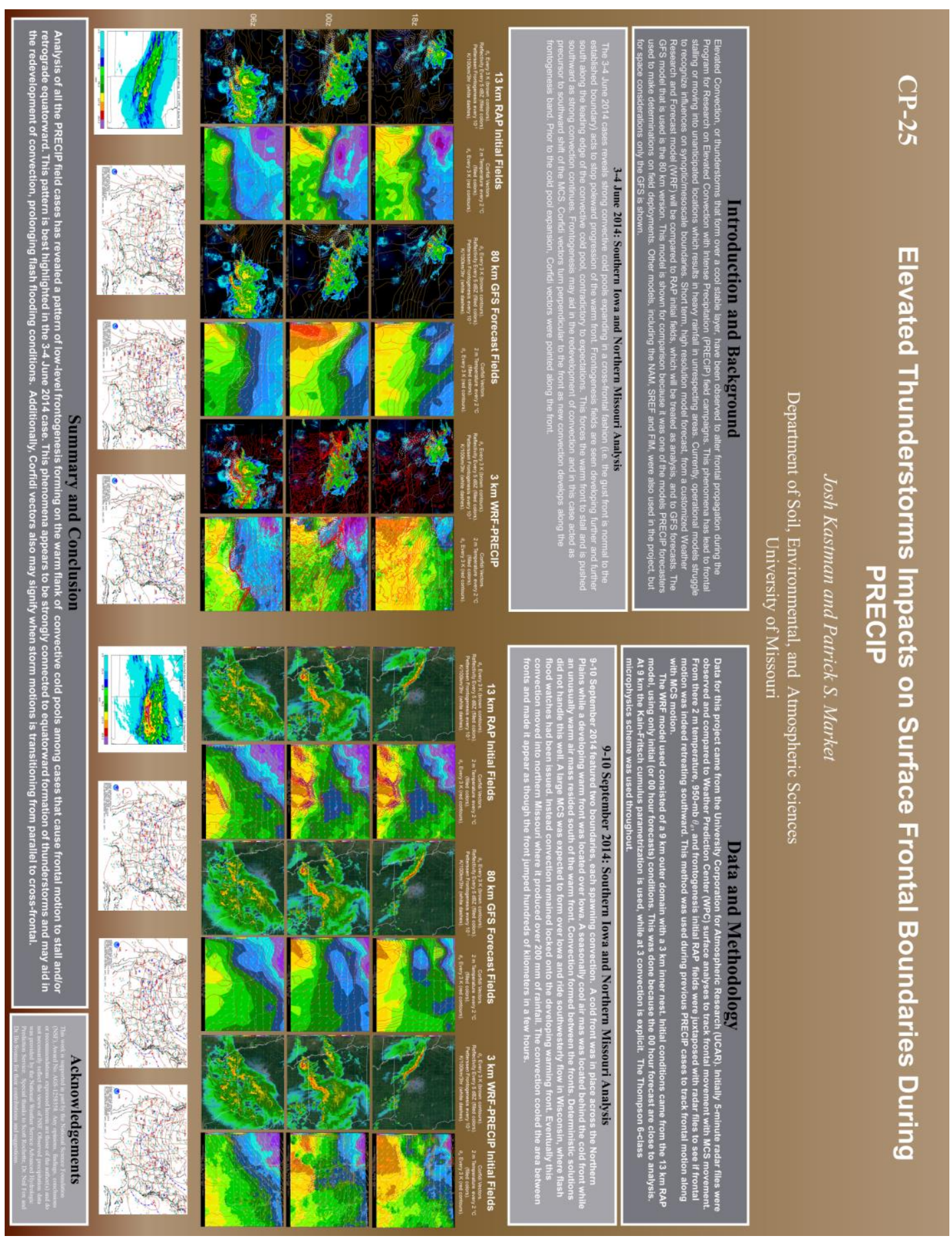




\section{VITA}

Joshua Scott Kastman was born on April 14, 1989 in Beloit Wisconsin, to Scott and Lisa Kastman. The author has one sister, Samantha Kastman. The family lived throughout the central United States during the author's childhood, including stops in Beloit, Wisconsin; Paris, Texas; Kansas City, Missouri and Springfield, Missouri. The author moved to Columbia, Missouri in 2007 to start his time at the University of Missouri.

Weather started as something the author feared as child as the movie Twister caused great anxiety for him. However, wanting to overcome this fear, much time and effort was spent learning what caused the weather to behave as it does. The atmosphere piqued the author's curiosity and eventually developed into a passion at an early age. The author pursued this passion and began studying at the University of Missouri to pursue a Bachelor's of Science in Atmospheric Science, which was completed in 2011. After graduating with the author stayed at the University of Missouri to pursue a Master's of Science in Atmospheric Science. This was completed in 2013. As the author's Master degree was being completed his advisor offered him a position as a Doctoral student. This degree was completed in the fall of 2017. During his time at the University of Missouri the author got to experience engaging with partners all over the county, traveling for conferences, field research (launching weather balloons in fields), designing a weather model, publishing papers, teaching and so man more terrific experiences.

While studying he met and fell in love with an enchanting young women named Anna. The two courted throughout college, getting married on August 4, 2012. They shared adventures throughout their time together at the University. The pair moved to 
Rockville, MD in January 2017 where the author is excited to pursue research and operational opportunities as a professional. 